\title{
MODELING THE BOND STRESS AT STEEL-CONCRETE INTERFACE FOR UNCORRODED AND CORRODED REINFORCING STEEL
}

\author{
by \\ Alaka Ghosh \\ B.Sc. Engg. (Civil), BUET, Bangladesh, 2000
}

\author{
A thesis exhibition \\ presented to Ryerson University \\ in partial fulfillment of the \\ requirements for the degree of \\ Master of Applied Science \\ in the Program of Civil Engineering
}

Toronto, Ontario, Canada, 2004

(C) Alaka Ghosh, 2004 
UMI Number: EC53460

\section{INFORMATION TO USERS}

The quality of this reproduction is dependent upon the quality of the copy submitted. Broken or indistinct print, colored or poor quality illustrations and photographs, print bleed-through, substandard margins, and improper alignment can adversely affect reproduction.

In the unlikely event that the author did not send a complete manuscript and there are missing pages, these will be noted. Also, if unauthorized copyright material had to be removed, a note will indicate the deletion.

\section{$\mathrm{UMI}^{\circ}$}

UMI Microform EC53460

Copyright 2009 by ProQuest LLC

All rights reserved. This microform edition is protected against unauthorized copying under Title 17, United States Code.

ProQuest LLC

789 East Eisenhower Parkway

P.O. Box 1346

Ann Arbor, MI 48106-1346 


\section{Author's Declaration}

I hereby declare that I am the sole author of this thesis.

I authorize Ryerson University to lend this thesis to other institutions or individuals for the purpose of scholarly research.

Alaka Ghosh

I further authorize Ryerson University to reproduce this thesis by photocopying or by other means, in total or in part, at the request of their institutions or individuals for the purpose of scholarly research.

Alaka Ghosh 


\section{Borrowers Page}

Ryerson University requires the signatures of all persons using or photocopying this thesis. Please sign below and give address and date.

\begin{tabular}{|c|c|c|c|}
\hline Name & Address & Signature & Date \\
\hline & & & \\
\hline & & & \\
\hline & & & \\
\hline & & & \\
\hline & & & \\
\hline & & & \\
\hline & & & \\
\hline & & & \\
\hline & & & \\
\hline & & & \\
\hline & & & \\
\hline & & & \\
\hline & & & \\
\hline & & & \\
\hline & & & \\
\hline & & & \\
\hline & & & \\
\hline & & & \\
\hline & & & \\
\hline
\end{tabular}




\title{
MODELING THE BOND STRESS AT STEEL-CONCRETE INTERFACE FOR UNCORRODED AND CORRODED REINFORCING STEEL
}

\author{
Alaka Ghosh \\ MASc., Department of Civil Engineering, Ryerson University, 2004
}

\begin{abstract}
Corrosion of reinforcing steel causes cracking and spalling of concrete structures, reduces the effective cross-sectional area of the reinforcing steel and the concrete and simultaneously decreases the bond strength at the steel-concrete interface. The detrimental effect of corrosion on the service life of reinforced concrete structures highlights the need for modeling of bond strength between the corroded steel and the concrete.
\end{abstract}

This research presents a nonlinear finite element model for the bond stress at the steelconcrete interface for both uncorroded and corroded reinforcing steel. The nonlinear finite element program ABAQUS is used for this purpose. The expanded volume of corroded product of reinforcing steel produces radial and hoop stresses which cause longitudinal cracks in the concrete. The increased longitudinal crack width, the loss of effective cross-sectional area of the steel and the concrete and the deterioration of rib height reduces the contact pressure which acts normal to the steel-concrete interface. The frictional force between the reinforcing steel and the concrete is also reduced due to the lubricating effect of flaky corroded layer. This research models the loss of contact pressure and the decrease of friction coefficient with the mass loss of the reinforcing steel. The model analyzes the pullout tests of Amleh (2000) and a good agreement is noted between the analytical and the experimental results. Both in FE analysis and experimental results, the loss of bond capacity is almost linear with mass loss of rebar. $\mathrm{FE}$ analysis and experimental results show that, up to $5 \%$ mass loss, the bond capacity loss is moderate, at 10 to $15 \%$ mass loss, significant amount of bond capacity is lost and at about $20 \%$ mass almost all bond capacity is lost. The model is also validated by analyzing the pullout tests performed by Cabrera and Ghoddoussis (1992) and those by Al-Sulaimani et al. (1990). 


\section{Acknowledgements}

The author would like to express her deepest gratitude to her supervisor, Dr. Lamya Amleh, for her invaluable advice, guidance, suggestion, patience and encouragement throughout the execution of this research program. Her encouragement always prompted the author to overcome the difficulties in completing this research.

The author would like to sincerely thank the Natural Sciences and Engineering Research Council of Canada (NSERC) and Canada Foundation for Innovation (CFI) for providing the fund for this research.

Finally, the author is grateful to her parents and her husband, because without their unconditional love, encouragement and understanding, the completion of this work would not have been possible. 


\section{Table of Contents}

Author's Declaration............................................................

Borrowers Page...................................................................

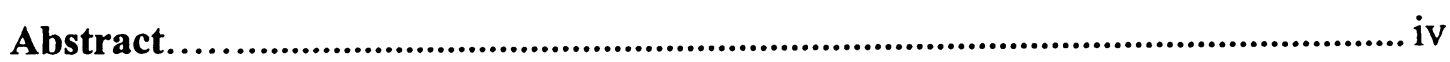

Acknowledgements …...............................................................................................

Table of Contents ................................................................................................ vi

List of Figures........................................................................................................ $\mathrm{x}$

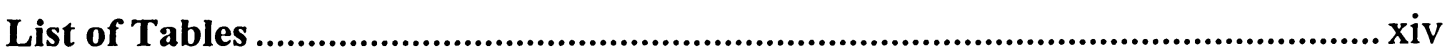

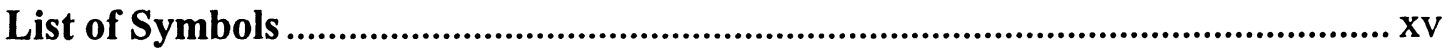

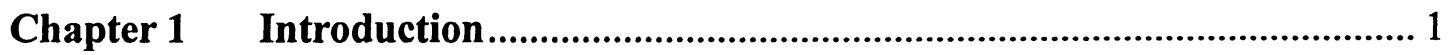

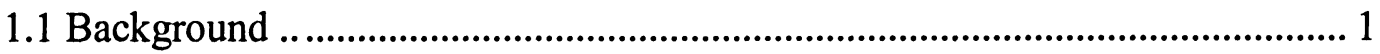

1.2 Scope and Objective ........................................................................................ 2

1.3 Thesis Layout...............................................................................................

Chapter 2 Fundamentals of Bond between Steel and Concrete................4

2.1 Introduction .................................................................................................

2.2 Definition of Bond stress.....................................................

2.3 Bond Mechanisms........................................................

2.4 Failure Modes of Bond..................................................

2.5 Factors Affecting Bond Strength.........................................11

2.5.1 Influence of Concrete Strength.....................................11

2.5.2 Effect of Concrete Cover Thickness..................................12

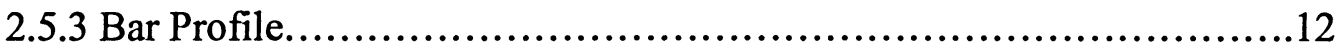

2.5.4 Effect of Corrosion ...............................................13

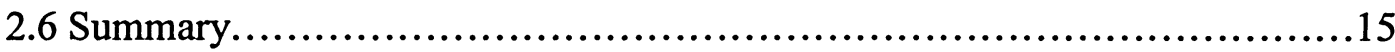

Chapter 3 Review of Bond Model............................................

3.1 Constitutive Equation of Bond-Slip Relationship $\quad$.........................16

3.2 Review of Models for Bond in Uncorroded Bar................................20 
3.2.1 Mirza-Houde Model (1978).......................................20

3.2.2 The Comité Euro-International du Béton (CEB) Code Model (1990)......20

3.2.3 Marti's Model (1999)...............................................22

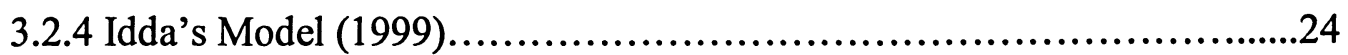

3.2.5 Lundgren and Gylltofs' Bond Model (2000).........................25

3.2.6 Russo and Paulettas' Model (2002)...................................28

3.3 Review of Bond Models in Corroded Bars.....................................31

3.3.1 Coronelli's Model for Bond Strength of Corroded Rebar (2002)............31

3.3.1.1 Bar-Concrete pressure ...................................... 31

3.3.1.2 Bond Capacity of Anchored Bar.................................34

3.3.2 Lundgren's Model for Bond Between Corroded Reinforcement and Concrete (2002) ....................................................

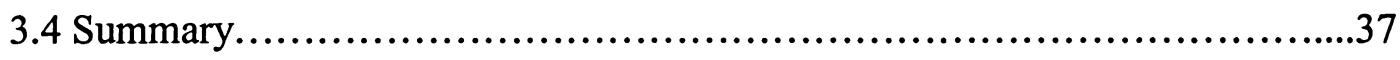

\section{Chapter 4 Finite Element Modeling of Bond Strength for Uncorroded and}

Corroded Reinforcing Steel.....................................38

4.1 Modeling the Bond at Steel-Concrete Interface.............................38

4.2 Details of Pullout Specimen................................................39

4.3 Material Properties of Concrete .........................................40

4.3.1 Elastic Properties .............................................40

4.3.2 Plastic Properties....................................................................................... 41

4.3.2.1 Compressive Behaviour .......................................................... 41

4.3.2.2 Concrete Smeared Cracking Model............................45

4.3.2.2.1 Tension Stiffening.................................45

4.3.2.2.2 Stress Ratios and Strain Ratio to Define Failure

Surface............................................49

4.4 Material Properties of Reinforcing Steel ........................................................51

4.5 Modeling Contact Interface between Reinforcing Steel and Concrete..........51

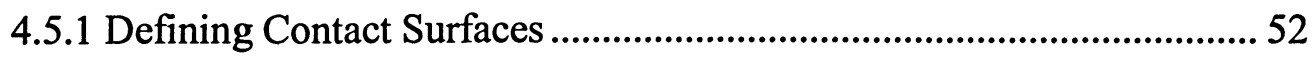

4.5.2 Modeling Contact Pressure and Friction ..............................54

4.5.2.1 Modeling the Contact Pressure.................................54 
4.5.2.1.1 Modeling Contact Pressure at Uncorroded Steel-

Concrete Interface.

4.5.2.1.2 Modeling Contact Pressure at Corroded Steel-

Concrete Interface. 58

4.5.2.2 Modeling Friction at Steel-Concrete Interface 62

4.5.2.2.1 Modeling the Friction Coefficient at Uncorroded

Steel-Concrete Interface 63

4.5.2.2.2 Modeling the Friction Coefficient at Corroded

Steel-Concrete Interface. 66

4.6 Boundary Conditions of the Pull-out Test. .69

4.7 Developing the Mesh ......................................................................................

4.8 Input File ...........................................................................................................71

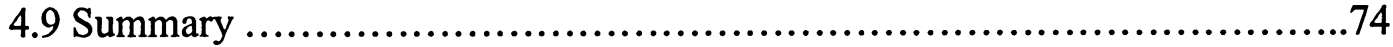

Chapter 5 Analysis of Results of Finite Element Analysis...................75

5.1 Analysis of Results for Uncorroded Specimens ...........................................75

5.1.1 Relationship of Bond Stress and Slip ....................................................75

5.1.2 Bond Stress and Slip using Very Fine Mesh..........................79

5.1.3 Effect of Concrete Cover Thickness on Bond Strength..................80

5.1.4 Effect of Compressive Strength on Bond Strength ................................ .83

5.1.5 Comparison of Finite Element Analysis with Experimental Results.....85

5.2 Analysis of Results for Corroded Specimens ................................................... 86

5.2.1 Bond Stress-Slip Relation for Corroded Specimens ................................ 86

5.2.2 Effect of Corrosion on Bond Strength.............................93

5.2.3 Effect of Concrete Cover Thickness on the Bond strength at Corroded Steel-Concrete Interface......................................................................... 98

5.2.4 Effect of Compressive Strength of Concrete on the Bond strength at

Corroded Steel-Concrete Interface .......................................................... 100

5.3 Validation of the Bond Model ...........................................103

- 5.3.1 Cabrera and Ghoddoussis' (1992) Pullout Test........................103

$\Rightarrow$ 5.3.2 Pullout Tests of Al-Sulaimani et al. (1990)...........................105 
Chapter 6 Conclusions and Future Recommendations......................109

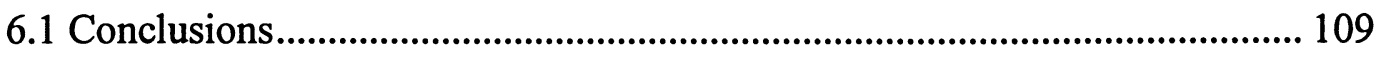

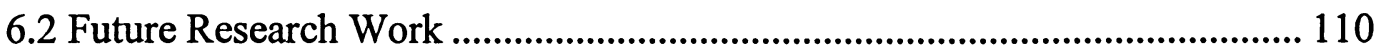

References.................................................................... 


\section{List of Figures}

Figure 2.1: The stresses between two ribs of a deformed bar (Park and Paulay, 1975)..........5

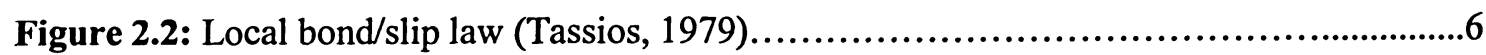

Figure 2.3: Transverse cracks according to (Giuriani, 1981).............................6

Figure 2.4: Longitudinal tensile stresses at the tip of the rib (Gambarova and Karakoc, 1982)...7

Figure 2.5: Separation between reinforcing bar and concrete near a primary crack

(Lutz and Gergely, 1967)...............................................

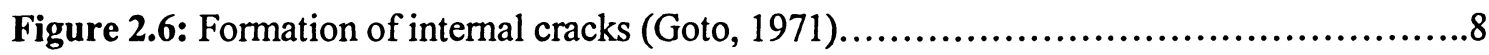

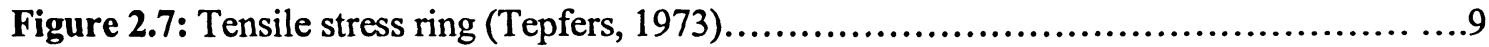

Figure 2.8: Failure mechanisms at the ribs of deformed bars (Rehm, 1968)..................11

Figure 2.9: Effects of corrosion in residual strength (CEB-FIP 2000)....................15

Figure 3.1: Stresses in an element.................................................... 16

Figure 3.2: CEB bond model (The Comité Euro-International du Béton, 1990)................21

Figure 3.3: Bilinear constitutive relationship for the reinforcement..........................23

Figure 3.4: Assumed bond stress distribution (Marti, 1999)..............................23

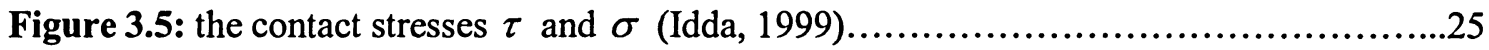

Figure 3.6: Physical interpretation of the variables $t_{n}, t_{t}, u_{n}$ and $u_{t}$

(Lundgren and Gylltoft, 2000)..............................................26

Figure 3.7: The stress in the inclined compressive struts determines the upper limit

(Lundgren and Gylltoft, 2000).......................................................................26

Figure 3.8: The yield lines (Lundgren and Gylltoft, 2000)................................27

Figure 3.9: Typical slip and strain for pull-out of a bar embedded in tensioned concrete (Russo

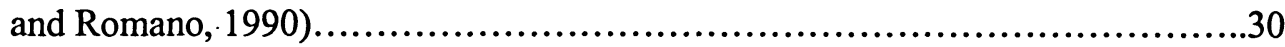

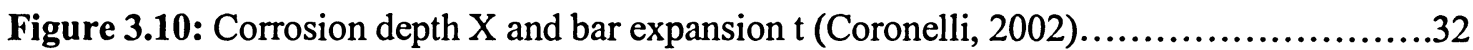

Figure 3.11: Corrosion-crack patterns: (a) corrosion cracks smaller cover; and (b) corrosion cracks both sides (Coronelli, 2002).......................................32

Figure 3.12: Beam model for concrete cover (Coronelli, 2002)............................33

Figure 3.13: Physical interpretation of the variables in the corrosion model

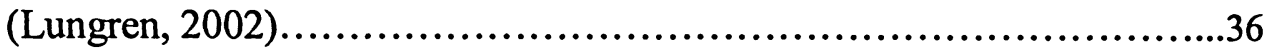

Figure 4.1: Forces acting at steel-concrete interface.....................................38

Figure 4.2: Typical pullout specimen tested by Amleh (2000)..........................39 
Figure 4.3: Variation of compressive stress with strain for $60 \mathrm{MPa}$ concrete..................42

Figure 4.4: Variation of compressive stress with strain for $50 \mathrm{MPa}$ concrete.................43

Figure 4.5: Variation of compressive stress with plastic strain for $60 \mathrm{MPa}$ concrete.............44

Figure 4.6: Variation of compressive stress with plastic strain for $50 \mathrm{MPa}$ concrete............44

Figure 4.7: Tensile stiffening: Tensile stress verses tensile strain...........................46

Figure 4.8: Tension Stiffening model using post failure stress-strain characteristics (Abaqus/Standard Manual, Volume 2).....................................47

Figure 4.9: Variation of the ratio of tensile stress to cracking tensile strength with the difference between direct strain and the cracking strain...................................48

Figure 4.10: Failure surfaces in plane stress (Abaqus/Standard Manual, Volume 2) ...........50

Figure 4.11: Master surface and slave surface (Abaqus/Standard User's Manual volume 3)....52

Figure 4.12: The master and slave surface used in the analysis...........................53

Figure 4.13: Master and slave surface in three dimensions................................54

Figure 4.14: "Softened" pressure-overclosure relationship

(Abaqus/Standard User Manual, Volume 3)......................................56

Figure 4.15: Variation of contact pressure at the uncorroded steel-concrete interface with concrete cover thickness..........................................58

Figure 4.16: Loss of contact pressure at different level of corrosion for $60 \mathrm{MPa}$ concrete mixture. 60

Figure 4.17: Loss of contact pressure at different level of corrosion for $50 \mathrm{MPa}$ concrete mixture.

Figure 4.18: The coefficient of friction as a function of the slip evaluated from tests of Tepfers and Olsson (1992) together with the chosen function of Lundgren and Gylltoft (2000).....................................................64

Figure 4.19: Friction model for different decay coefficients.............................65

Figure 4.20: Exponential decay friction model used at uncorroded steel-concrete interface....66

Figure 4.21: Variation of static friction coefficient with mass loss........................67

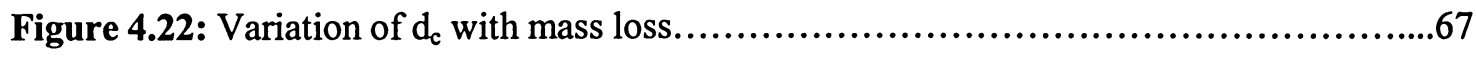

Figure 4.23: Variation of friction coefficient with slip at different mass losses................69

Figure 4.24: Specimen with top surface fixed.......................................70

Figure 4.25: Specimen with load at top of the reinforcement..............................................70

Figure 4.26: Specimen with finite element mesh (a) specimen in three dimension

(b) Top view.......................................................................

Figure 5.1: Variation of average bond stress with slip for $25 \mathrm{~mm}$ concrete cover thickness for $60 \mathrm{MPa}$ concrete mixture...............................................76 
Figure 5.2: Variation of average bond stress with slip for $50 \mathrm{~mm}$ concrete cover thickness for $60 \mathrm{MPa}$ concrete mixture.

Figure 5.3: Variation of average bond stress with slip for $75 \mathrm{~mm}$ concrete cover thickness for $60 \mathrm{MPa}$ concrete mixture.

Figure 5.4: Variation of average bond stress with slip for $25 \mathrm{~mm}$ concrete cover thickness for $50 \mathrm{MPa}$ concrete mixture.

Figure 5.5: Variation of average bond stress with slip for $50 \mathrm{~mm}$ concrete cover thickness for $50 \mathrm{MPa}$ concrete mixture. .78

Figure 5.6: Variation of average bond stress with slip for $75 \mathrm{~mm}$ concrete cover thickness for $50 \mathrm{MPa}$ concrete mixture. .79

Figure 5.7: Variation of average bond stress with slip for $25 \mathrm{~mm}$ concrete cover thickness for $60 \mathrm{MPa}$ concrete mixture using very fine mesh.

Figure 5.8: Variation of average bond stress with slip for different cover thickness for $60 \mathrm{MPa}$ concrete mixtures.

Figure 5.9: Variation of average bond stress with slip for different cover thickness for $50 \mathrm{MPa}$ concrete mixtures.

Figure 5.10: Variation of average bond strength with concrete cover thickness for $60 \mathrm{MPa}$ concrete mixtures.

Figure 5.11: Variation of average bond strength with concrete cover thickness for $50 \mathrm{MPa}$ concrete mixtures.

Figure 5.12: Variation of average bond strength with concrete cover thickness for different concrete mixtures.

Figure 5.13: Variation of $\mathrm{u} / \mathrm{f}_{\mathrm{t}}^{\prime}$ with concrete cover thickness for different concrete mixtures.....84

Figure 5.14: Variation of average bond stress with slip at different level of corrosion for $25 \mathrm{~mm}$ cover thickness for $60 \mathrm{MPa}$ concrete mixture.

Figure 5.15: Variation of average bond stress with slip at different level of corrosion for $50 \mathrm{~mm}$ cover thickness for $60 \mathrm{Mpa}$ concrete mixture.

Figure 5.16: Variation of average bond stress with slip at different level of corrosion for $75 \mathrm{~mm}$ cover thickness of $60 \mathrm{MPa}$ concrete mixture.

Figure 5.17: Variation of average bond stress with slip at different level of corrosion for $25 \mathrm{~mm}$ cover thickness for $50 \mathrm{MPa}$ concrete mixture. 
Figure 5.18: Variation of average bond stress with slip at different level of corrosion for $50 \mathrm{~mm}$ cover thickness for $50 \mathrm{MPa}$ concrete mixture.

Figure 5.19: Variation of average bond stress with slip at different level of corrosion for $75 \mathrm{~mm}$ cover thickness for $50 \mathrm{MPa}$ concrete mixture.

Figure 5.20: Effect of corrosion on bond strength for different cover thicknesses for $60 \mathrm{MPa}$ concrete.

Figure 5.21: Effect of corrosion on bond strength for different cover thicknesses for $50 \mathrm{MPa}$ concrete.

Figure 5.22: Loss of bond strength at different level of corrosion for $60 \mathrm{MPa}$ concrete mixture.

Figure 5.23: Loss of bond strength at different level of corrosion for $50 \mathrm{MPa}$ concrete mixture.

Figure 5.24: Loss of average bond strength for different cover thicknesses at $5 \%$ mass loss for $60 \mathrm{MPa}$ concrete mixture. . .98

Figure 5.25: Loss of average bond strength for different cover thicknesses at $10 \%$ mass loss for $60 \mathrm{MPa}$ concrete mixtures. 99

Figure 5.26: Loss of average bond strength for different cover thicknesses at $5 \%$ mass loss for $50 \mathrm{MPa}$ concrete mixture. .99

Figure 5.27: Loss of average bond strength for different cover thicknesses at $10 \%$ mass loss for $50 \mathrm{MPa}$ concrete mixture.

Figure 5.28: Effect of corrosion on average bond strength for $25 \mathrm{~mm}$ concrete cover thickness for different concrete mixtures .101

Figure 5.29: Effect of corrosion on average bond strength for $50 \mathrm{~mm}$ concrete cover thickness for different concrete mixtures. .101

Figure 5.30: Effect of corrosion on average bond strength for $75 \mathrm{~mm}$ concrete cover thickness for different concrete mixtures. 102

Figure 5.31: Effect of corrosion on average bond strength for $100 \mathrm{~mm}$ concrete cover thickness for different concrete mixtures. 102

Figure 5.32: Variation of average bond stress with slip at different level of corrosion.........104

Figure 5.33: Average bond strength at different level of corrosion..........................104

Figure 5.34: Loss of average bond strength at different level of corrosion.....................105

Figure 5.35: Variation of average bond stress with slip at different level of corrosion.........106

Figure 5.36: Average bond strength at different level of corrosion.........................107

Figure 5.37: Loss of average bond strength at different level of corrosion...................107 


\section{List of Tables}

Table 3.1: Parameters for defining the mean bond stress-slip relationship..................22

Table 4.1: Properties of concrete obtained from experimental data.......................40

Table 4.2: Input data for tension stiffening ........................................48

Table 4.3: Data input of stress ratios and strain ratio....................................51

Table 5.1: Comparison of average bond strength for finite element analysis with those of experimental results for uncorroded specimens of $60 \mathrm{MPa}$ concrete mixtures.....85

Table 5.2: Comparison of average bond strengths for finite element analysis results with those of experimental results for uncorroded specimens of $50 \mathrm{MPa}$ concrete mixtures..86

Table 5.3: Data for loss of average bond strength (\%) at different levels of corrosion for both finite element analysis and experimental results for $60 \mathrm{MPa}$ concrete. .96

Table 5.4: Data for loss of average bond strength (\%) at different levels of corrosion for both finite element analysis and experimental results for $50 \mathrm{MPa}$ concrete. .97 


\section{List of Symbols}

\begin{tabular}{|c|c|}
\hline$f_{b}$ & $=$ bearing stress \\
\hline$f_{c}^{\prime}, f_{c k}$ & $=$ concrete compressive strength \\
\hline$f_{t}, f_{c t}$ & $=$ concrete tensile strength \\
\hline$v_{a}$ & $=$ the shear stress due to adhesion of concrete and steel \\
\hline$v_{c}$ & $=$ shear stress, in the tangential \\
\hline$\tau$ & $=$ average bond stress \\
\hline$C$ & $=$ concrete cover thickness \\
\hline$d_{b}$ & $=$ diameter of the reinforcing steel \\
\hline$A_{c}$ & $=$ cross-sectional area of the concrete section \\
\hline$A_{s}$ & $=$ cross-sectional area of the reinforcing steel \\
\hline$E_{c}$ & $=$ elastic modulus of concrete \\
\hline$E_{s}$ & $=$ elastic modulus of reinforcing steel \\
\hline$\sigma_{1}, \sigma_{2}$ & $=$ principle stresses of concrete \\
\hline$w$ & $=$ crack width \\
\hline$t$ & $=$ thickness of corrosion product \\
\hline$V_{r s}$ & $=$ ratio between the volumes of corroded and virgin stee \\
\hline$n$ & $=$ number of transverse ribs at section \\
\hline$A_{r}$ & $=$ rib area in the plane at right angles to bar axis \\
\hline$X_{c r}$ & $=$ depth of corrosion at cracking \\
\hline$\varepsilon_{c}^{\prime}$ & $=$ concrete strain when $f_{c}$ reaches $f_{c}^{\prime}$ \\
\hline$k$ & $\begin{aligned}= & \text { a factor to control the slope of the descending branch } \\
& \text { of the compressive stress-strain curve of concrete }\end{aligned}$ \\
\hline$\varepsilon_{t}$ & $=$ total strain of concrete \\
\hline$\varepsilon_{e l}$ & $=$ elastic strain of concrete \\
\hline$\varepsilon_{p l}$ & $=$ plastic strain of concrete \\
\hline
\end{tabular}




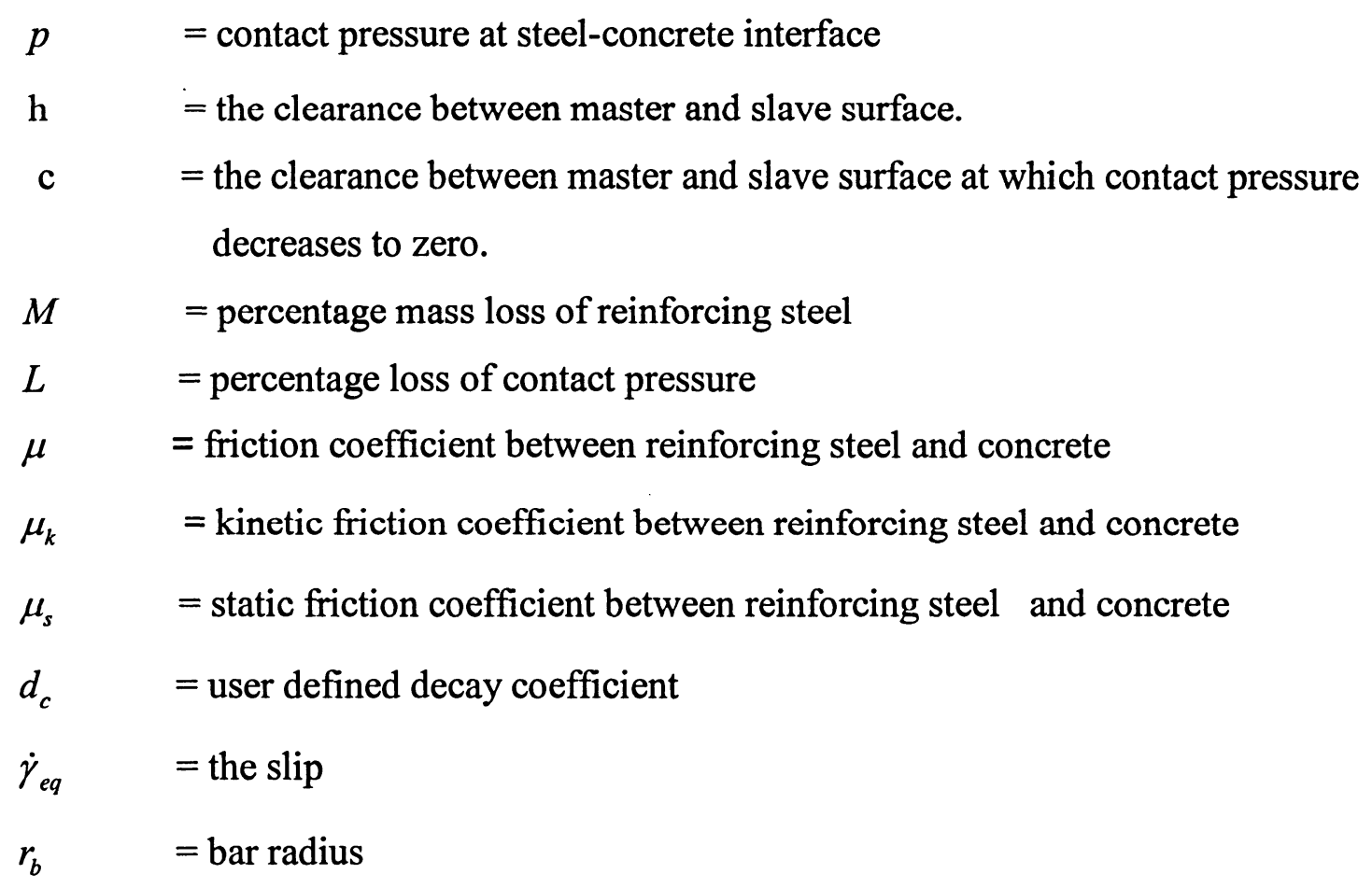




\section{Chapter 1}

\section{Introduction}

\subsection{Background}

The durability of reinforced concrete structures depends largely on the resistance of concrete against the chemical and physical factors and its ability to protect its embedded reinforcing steel against corrosion. Chloride-induced corrosion of reinforcing steel in concrete bridge decks, parking garage slabs and marine structures is considered as the primary cause of deterioration of reinforced concrete structures. Corrosion of the reinforcement leads to cracking, delamination and spalling of concrete cover, reduction in the cross-sectional area of the reinforcing steel and the concrete and thus deteriorating the bond at the steel-concrete interface.

The reinforcing steel is protected in concrete against corrosion due to the high alkalinity of concrete. The steel is protected from corrosion by the oxide film that chiefly consists of $\mathrm{Fe}_{2} \mathrm{O}_{3}$. The penetration of carbonation or chloride ions causes the depassivation of the oxide film and corrosion of reinforcing steel commences. The expanded volume of corrosion products on the steel bar surface produces radial and hoop stresses at the steelconcrete interface which causes high tensile forces in the concrete specimen. As concrete is weak in tension, longitudinal cracks are formed in concrete specimens. The cracks allow oxygen and moisture to travel directly to the reinforcing steel at a faster rate, which in turn increases the rate of corrosion. With the increase of corrosion, the width of longitudinal cracks is increased, which reduces the holding capacity and confinement of concrete. Therefore the normal contact pressure at steel concrete interface is reduced which is an important parameter for the bond characteristics at steel-concrete interface. In addition, the corrosion of steel deteriorates the rib height, thus reducing the bearing force of ribs and the mechanical interlocking between the steel and the concrete, which significantly deteriorates the contact pressure. The flaky corroded layer acts as a lubricant, which reduces the frictional force at the steel-concrete interface. This reduction 
of contact pressure and frictional force causes considerable amount of deterioration of bond between the reinforcing steel and the concrete.

Bond stress is an important phenomenon for reinforcing steel embedded in concrete as it is responsible for transferring the load between the steel and the concrete. Therefore, it is very important to study the effect of corrosion on bond specially to model the bond stress at the corroded steel-concrete interface. To study this phenomenon some experimental works have been carried out in the past. Although these experimental studies showed many interesting features, several limitations still exist, such as determining the residual

bond strength due to corrosion which is very important in predicting the service life of structures. Modeling the bond stress at the corroded steel-concrete interface is the first step in determining the residual bond strength.

Some researches have attempted to model the bond-slip behaviour at the steel-concrete interface by finite element analysis. No research is carried out to model the reduction of contact pressure and friction at the steel-concrete interface due to corrosion. The purpose of this research is to model the contact pressure and frictional force and thus model the bond stress at the uncorroded and the corroded steel-concrete interfaces.

\subsection{Scope and Objective}

The purpose of the study is to model the bond stress at both uncorroded and corrodedsteel concrete interface. The nonlinear finite element software ABAQUS is used for this purpose. There are two major objectives of this research:

1. Modeling the material properties of steel and concrete:

The elastic and plastic behaviour of steel and concrete are defined to express the nonlinearity of the response. The smeared cracking model is used to express the postcracking behaviour of the concrete. Tension stiffening is defined to express the tension carrying capacity of concrete after cracking. 
2. Modeling the contact pressure and friction at steel-concrete interface and modeling the effect of corrosion on them:

Two important phenomena associated with the bond stress such as contact pressure and friction are modeled. Moreover the effect of corrosion on them is also modeled.

The experimental data of the pullout test of Amleh (2000) are used to calibrate the model. Then the model is validated using the data of pullout tests of Cabrera and Ghoddoussis (1992) and that by Al-Sulaimani et al. (1990).

\subsection{Thesis Layout}

This thesis comprises seven chapters. This chapter (chapter one) addresses the background and scope of the research. Chapter two presents the background of the bond between the reinforcing steel and the concrete. This chapter includes the mechanisms of bond, the factors affecting the bond behaviour and the modes of failure of bond. The effect of corrosion on bond mechanism is also included. Chapter three reviews some models of bond behaviour for both uncorroded and corroded reinforcing steel. Chapter four presents the finite element model used in this research. Chapter five discusses the results obtained from the finite element analysis. It also reports the comparison of finite element results with the experimental results. Chapter six presents the validation of the model, which is done by using some experimental results. Finally, the conclusions and recommendations for further research are presented in Chapter seven. 


\section{Chapter 2}

\section{Fundamentals of Bond between Steel and Concrete}

\subsection{Introduction}

The behaviour of reinforced concrete structure largely depends on the bond at the steelconcrete interface. This chapter presents some basic information of bond behaviour such as mechanisms of bond, bond failure mode, and the factors affecting the bond. It also presents how corrosion affects the bond behaviour at the steel-concrete interface.

\subsection{Definition of Bond stress}

"Bond stress is the name assigned to the shear stress at the bar-concrete interface which, by transferring load between the bar and the surrounding concrete, modifies the steel stress." (ACI Committee 408, 1966) This bond, when efficiently developed, enables the two materials to form a composite structure. The attainment of satisfactory performance in bond is the most important aim of the detailing of reinforcement in structural components. Bond stresses in reinforced concrete members arise from two distinct situations: from the anchorage of bars, and from the change of bar force along its length due to change in bending moment along the member.

\subsection{Bond Mechanisms}

According to Lutz and Gergely (1967), the bond mechanisms, that is transfer of the force from reinforcement to concrete and vice versa, depends on mechanical interlocking, adhesion and friction between the reinforcing steel and the concrete. 
According to Park and Paulay (1975), the bond strength developed between the two ribs on the reinforcing bar is associated with the following stresses (Fig 2.1):

1. Shear stresses $v_{\mathrm{a}}$, developed through adhesion along the surface of the bar.

2. Bearing stresses $f_{\mathrm{b}}$, against the face of the rib.

3. Shear stresses $v_{c}$, acting on the cylindrical concrete surface between the adjacent ribs.

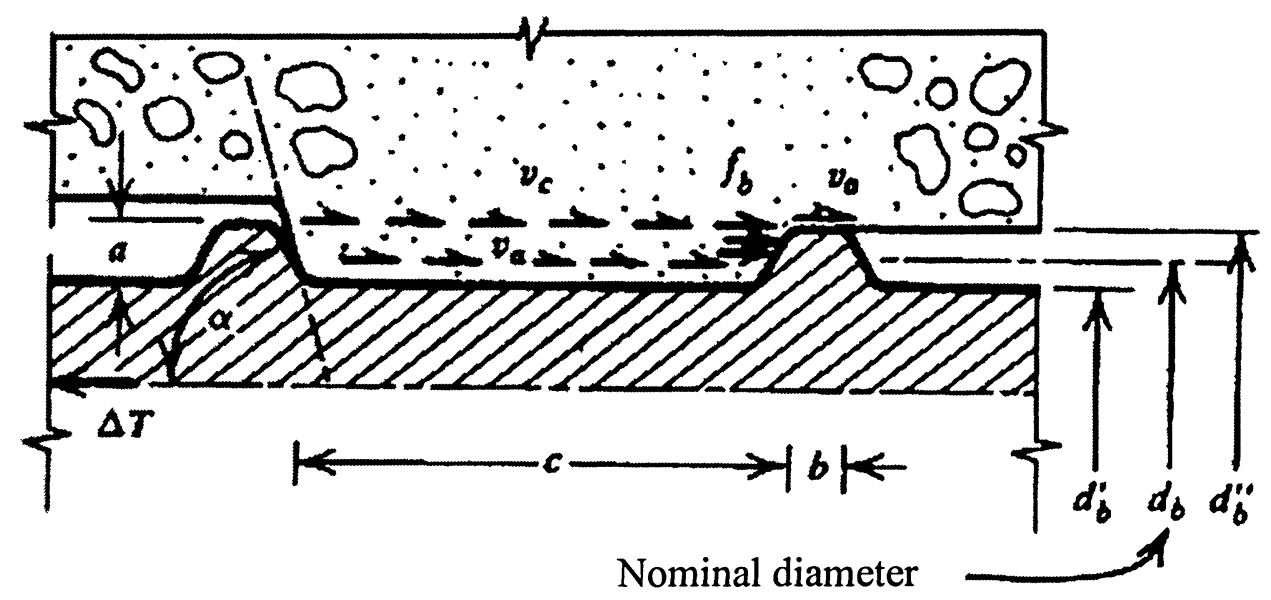

Figure 2.1: The stresses between two ribs of a deformed bar

(Park and Paulay, 1975)

For very small values of the average bond stress $\tau$, the only resisting mechanism is the chemical adhesion, which enables concrete to follow steel deformations with no relative slip, or with negligible slip (Figure 2.2, $\tau \leq \tau_{0}$ ).

At increasing values of the average bond stress, the chemical adhesion is destroyed as a consequence of the wedging action of the ribs, which pushes the concrete away and separates the concrete from the steel. As soon as transverse cracking occurs, the concrete 
keys get deformed (Figure 2.3) in such a way that they tend to move away from the bar surface, between the ribs.

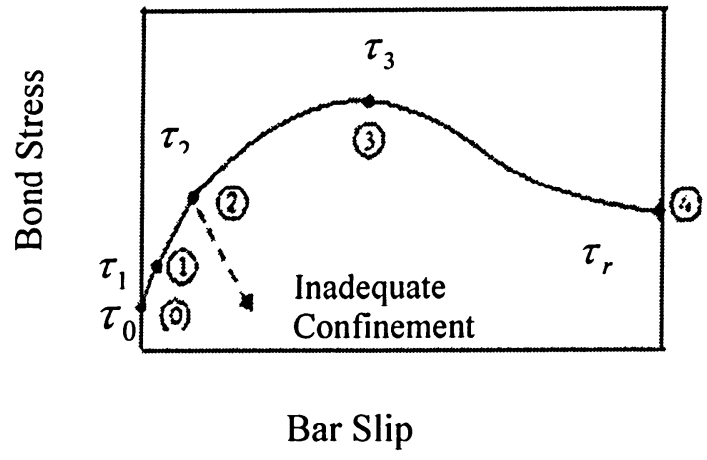

Figure 2.2: Local bond/slip law

(Tassios, 1979)

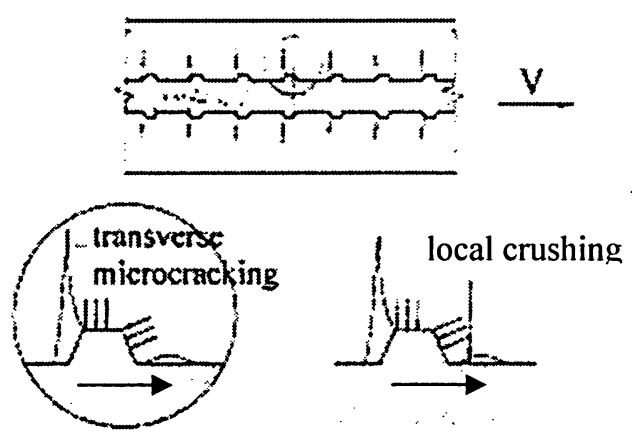

Figure 2.3: Transverse cracks

(Giuriani, 1981)

After the break down of the chemical adhesion, the next mechanism is due to the interaction between the ribs and the concrete. This interaction induces large bearing stresses under the ribs, and highly localized tensile stresses in the concrete at the tip of the ribs (Figure 2.4). 


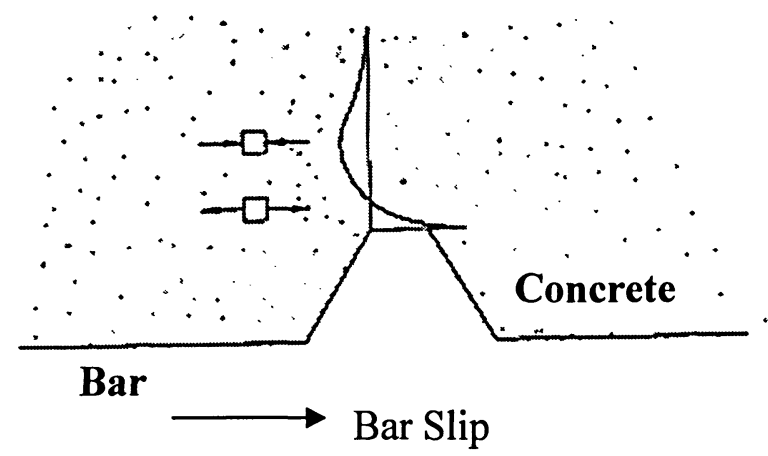

Figure 2.4: Longitudinal tensile stresses at the tip of the rib (Gambarova and Karakoc, 1982)

First internal crack develops as soon as the bond stress reaches a value $\tau_{1}$ (Figure 2.2) which is strongly dependent on the state of stress in the solid concrete close to the bar. The deformations of the concrete resulting from the stresses so generated tend to pull the concrete away from the steel in the vicinity of a major crack as shown in Figure 2.5. The tensile strength of the adhesive bond between the steel and the concrete is then reached, and the surrounding concrete separates from the steel. Different internal secondary cracks also form which may not propagate to the external surface of the concrete. In plain bars the bond stresses can be expected to disappear completely when separation between steel and concrete occurred. With deformed bars, bond forces are transmitted by rib bearing which is shown in Figure 2.5. By injecting ink between the reinforcing bar and the surrounding concrete, Goto found the sloping secondary cracks radiating from each rib as shown in Figure 2.6. 


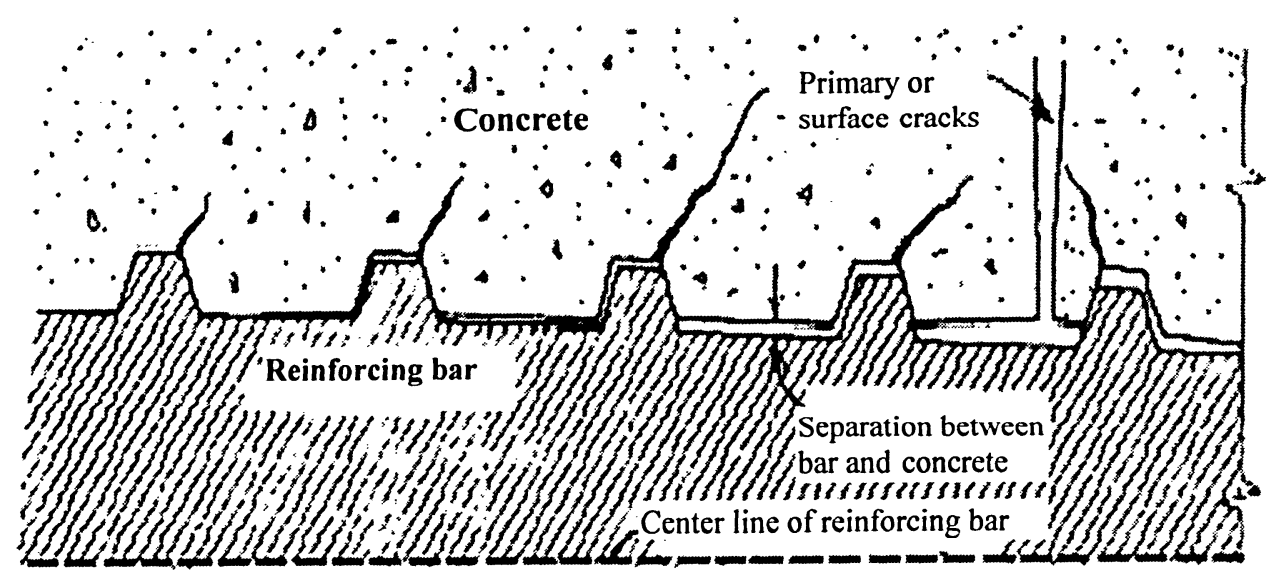

Figure 2.5: Separation between reinforcing bar and concrete near a primary crack (Lutz and Gergely, 1967)

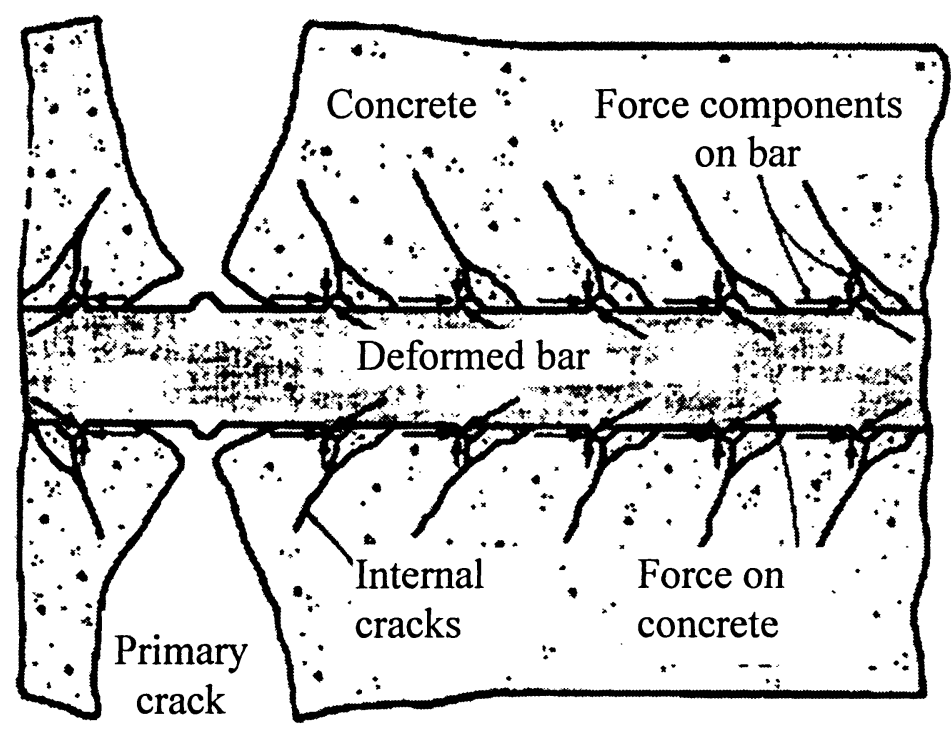

Figure 2.6: Formation of internal cracks (Goto, 1971) 
When the concrete separates itself from the reinforcing bar at a primary crack, the circumference of the concrete surface, previously in contact with the bar, increases; hence, circumferential tensile stresses are induced. These stresses can lead to the longitudinal splitting cracks.

When the ultimate capacity in bond transfer is being approached, there would be some crushed concrete in front of the ribs. The compacted concrete powder, extending in front of the rib at a distance of up to three times the rib height, forms a flat wedge and this tends to push the concrete further away from the bar. Hence additional circumferential tensile stresses are generated which may cause a splitting failure.

Tepfers (1973) studied the circumferential stress distribution over the thickness of the concrete cylinder, confining the reinforcing bars. These circumferential tensile stresses are the effect of the outward radial stresses which is caused from the action of the deformed bars on the concrete cylinder as shown in Figure 2.7. He assumed three stages in the bond response of the concrete cylinder: the uncracked stage, partially cracked stage and the plastic stage. In the plastic stage, a uniform tensile stress distribution was assumed over the thickness of the concrete cylinder.

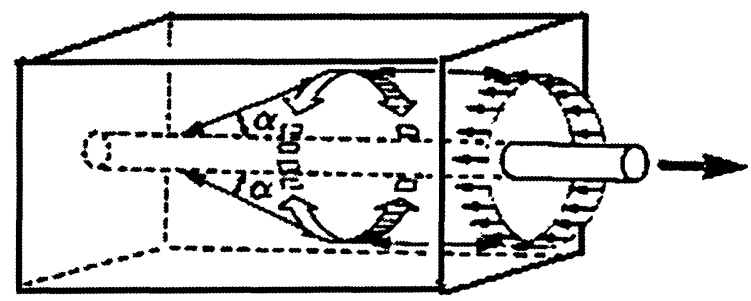

Figure 2.7: Tensile stress ring (Tepfers, 1973)

Assuming short anchorage lengths, Tepfers (1979) derived equations for the three stages and found good agreement between the measured values of the short anchorage tests and 
the partially cracked theory. According to the cracked elastic behaviour, the bond strength, $u_{c}$, at the cracking of the concrete cover is given by equation 2.1 .

$$
u_{c}=0.6\left(0.5+c / d_{b}\right) f_{t}
$$

For larger concrete cover thickness, the assumption of a plastic behaviour at the steelconcrete interface gives:

$$
u_{c}=2\left(c / d_{b}\right) f_{t}
$$

where,

$$
\begin{aligned}
& u_{c}=\text { bond strength when the concrete cracks } \\
& c=\text { minimum concrete cover thickness } \\
& \mathrm{d}_{\mathrm{b}}=\text { diameter of the steel reinforcing bar } \\
& f_{t}=\text { concrete tensile strength }
\end{aligned}
$$

\subsection{Failure Modes of Bond}

According to Rehm (1968) and Lutz and Gergely (1967), failure of bond between deformed bars and concrete can occur due to following reasons:

1) Crushing of the concrete in front of the ribs.

2) Splitting of the concrete by wedging action.

Rehm (1968) succeeded in relating the mode of failure of the bond with the geometric parameter $\mathrm{a} / \mathrm{c}$ (the ratio of the rib height to the rib spacing). When the ribs are high and spaced too closely, the shear stress $v_{c}$ will govern the behaviour and the bar will pull out. When the rib spacing is larger than approximately 10 times the rib's height, the partially 
crushed concrete may form a wedge in front of the rib, and failure is normally due to the splitting of the surrounding concrete. The two types of failure mechanisms associated with the rib are shown in Figure 2.8.

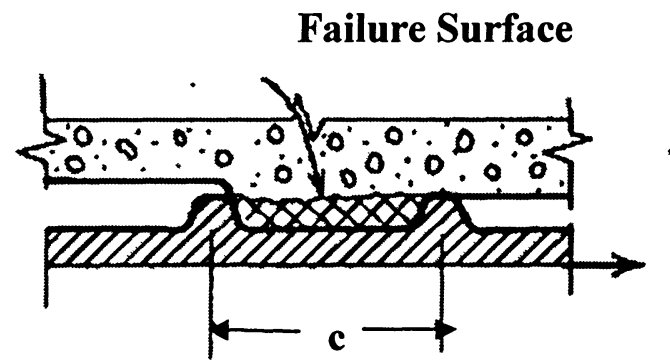

(a)

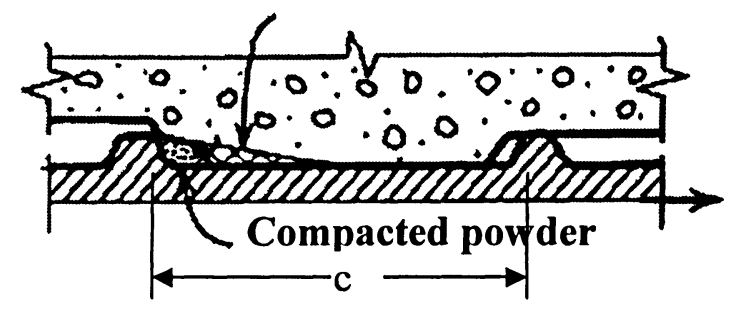

(b)

$a / c>0.15$

$a / c<0.15$

Figure 2.8: Failure mechanisms at the ribs of deformed bars

(Rehm, 1968)

\subsection{Factors Affecting the Bond Strength}

The bond strength between the steel and the concrete depends on many factors such as concrete strength, steel strength, concrete cover thickness, embedment length of steel, rib geometry of bar, spacing of bars, stirrups, temperature, corrosion etc. A brief discussion of different factors that affect the bond at the steel-concrete interface is presented in the following sections.

\subsubsection{Influence of Concrete Strength}

Compressive strength is considered to be a significant parameter because the force between steel and concrete is transferred mainly by bearing and bond failure may occur by splitting and shearing of the concrete (Orangun, et al. 1977). Tepfers (1973) showed 
that with higher concrete strength, the slope of the bond str ess distribution varies considerably over the splice length compared to that with lower concrete strength.

The tensile and compressive stresses contribute to the development of bond stress. For example, transverse micro cracks depend on the tensile stress of concrete while bearing stress induces high compressive stress in front of the ribs. The tensile strength of concrete has a strong relationship with compressive strength of concrete.

Based on pullout test, Martin (1982) observed that for a slip range of 0.1 to $1 \mathrm{~mm}$, the bond stress is proportional to the compressive strength when concrete strength varies from 16 to $50 \mathrm{MPa}$. He also found that for a very small slip, less than $0.01 \mathrm{~mm}$, and for a high slip, larger than $1 \mathrm{~mm}$, the influence of concrete compressive strength is less important and proportional to the $2 / 3$ power of the concrete compressive strength.

\subsubsection{Effect of Concrete Cover Thickness}

Concrete cover gives the protection against transverse cracking which has a great effect on bond strength. Hence, bond strength increases with the increase of concrete cover thickness. Tepfers (1973) and Orangun et al., (1977) observed that the concrete cover and the reinforcement spacing significantly influence the type of bond failure. Splitting tensile failure occurs with small concrete covers and bond capacity in pullout will be higher for the larger cover thickness.

\subsubsection{Bar Profile}

The geometry of the bar ribs have great influence on bond strength. Rehm (1968) succeeded in relating aspects of bond problem to the geometric parameter a/c (rib height/rib spacing). He found the most satisfactory performance of a bar embedded in concrete over the short length $\mathrm{c}$ when $\mathrm{a} / \mathrm{c}$ was in the vicinity of 0.065 . Figure 2.8 shows 
the two types of failure mechanisms, associated with the geometric shape and size of the ribs. The deformation requirements of ASTM A 615-72 (1972), give the following range of values for $\mathrm{a} / \mathrm{c}$ :

$$
0.057<a / c<0.072
$$

Rehm (1957) and Lutz (1966) showed that for bars with steep rib face angle $\alpha$ (larger than 40 degrees with the bar axis) slip occurs only by the compression of the concrete in front of the bar rib, while in bars with flat ribs, i.e., the angle $\alpha$ is small, slip occurs with the ribs sliding relative to the concrete as the rib tends to push the concrete away from the bar.

Darwin and Graham (1993), found that the bond force-slip response is a function of the relative rib area (projected rib area normal to the bar axis/ (nominal bar perimeter xcentre-to centre rib spacing)) of the bars. They concluded that under conditions of low confinement, bond strength is independent of the deformation pattern. Under conditions in which additional bar confinement is provided by transverse reinforcement or higher covers, the bond strength increases with an increase in the relative rib area.

\subsubsection{Effect of Corrosion}

Reinforcing steel corrosion is a major cause of the deterioration of reinforced concrete structures. At the initial stage of corrosion, the expansion of corrosion product leads to increase of bond strength. However, with progressive increase in corrosion, the expanded volume of corrosion product increases the radial stresses at the steel-concrete interface which causes longitudinal cracks of concrete. The increase of longitudinal cracks reduces the contact pressure at the steel-concrete interface which decreases the bond strength. At higher level of corrosion, the deterioration of the rib height also decreases the bearing area of the ribs. Al-Sulaimani et al., (1990) state that the development of corrosion products along the bar surface causes significant loss of bond between the concrete and the reinforcement due to the following two reasons: firstly, due to a reduction of 
confinement pressure by the opening of longitudinal cracks along the reinforcement and secondly, due to significant changes at the steel-concrete interface caused by changes in the surface conditions of the steel. The changes in the surface conditions due to corrosion are characterized initially by changes in the roughness of the surface, then by the development of a less firmly adhering interstitial layer of corrosion products between the concrete and the steel and eventually, by local damage in terms of heavy pitting and degradation in the profile of the bar ribs.

Cabrera and Ghoddossi (1992) found that the bond strength in pullout specimen is significantly decreased due to corrosion of the reinforcing steel. Amleh and Mirza (1999) stated that corrosion especially when severely localized, causes a significant reduction of interlocking forces between the ribs and concrete keys due to the deterioration of the reinforcing bar ribs. Hence, the bond strength decreases significantly. Yoon et. al (2000) stated that corrosion reduces the cross-sectional area of the reinforcing steel and it may cause stress concentrations in the reinforcing steel, decreasing ductility of the structures, especially when pitting corrosion occurs.

The effect of corrosion on bond strength is explained in CEP-FIP 2000. Figure 2.9 shows the effect of corrosion on the residual strength of reinforced concrete structures. 


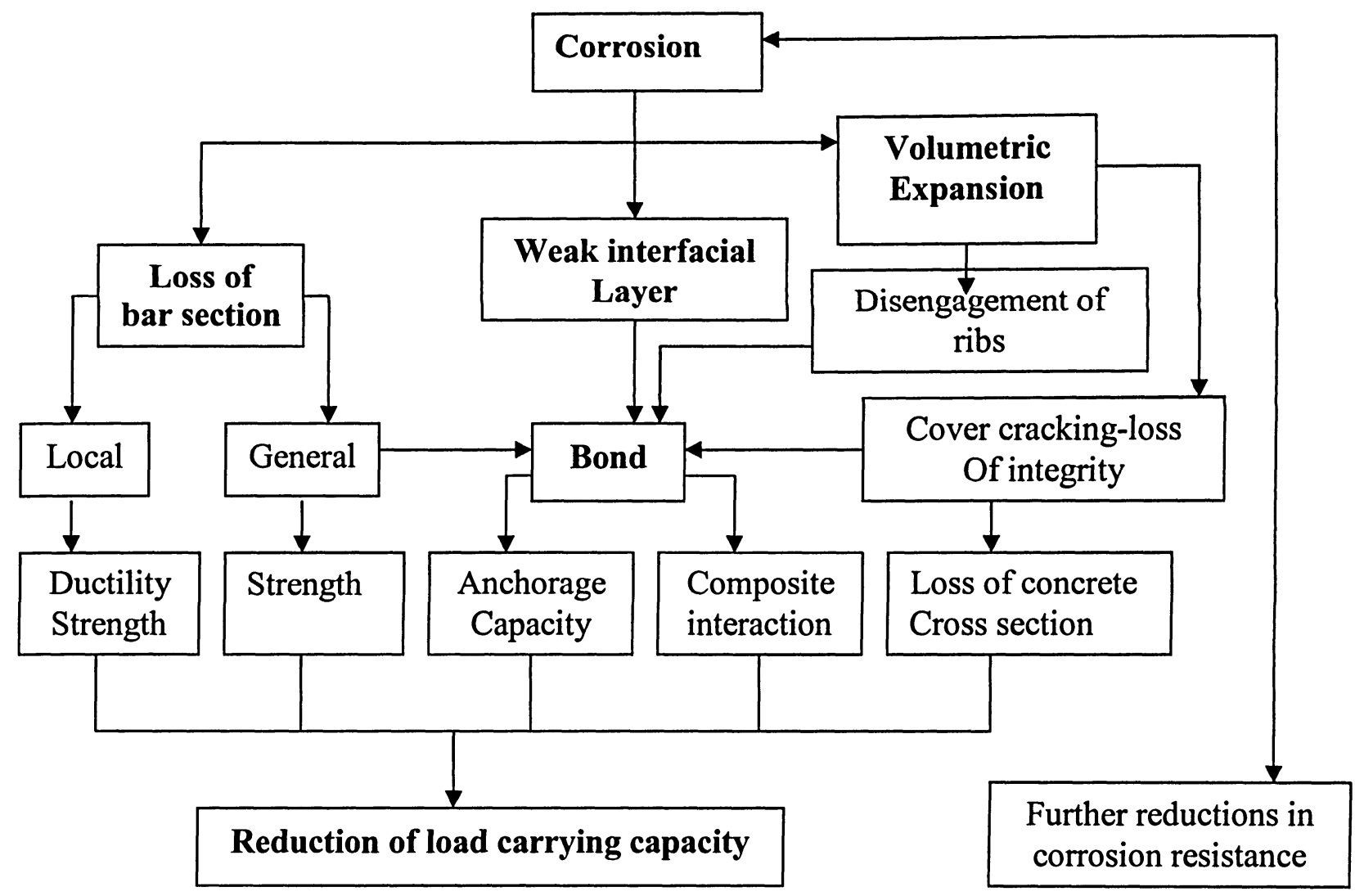

Figure 2.9: Effects of corrosion in residual strength (CEB-FIP, 2000)

\subsection{Summary}

Bond mechanisms at the steel-concrete interface largely depend on mechanical interlocking, friction and adhesion. The mode of failure of bond depends on rib geometry of the bar. Corrosion of the steel in concrete is considered a fundamental problem in all concrete structures as the bond behaviour is seriously affected by corrosion of the reinforcing steel. 


\section{Chapter 3}

\section{Review of Bond Model}

This chapter discusses some available research on analytical models for bond in uncorroded and corroded steel bars. The models of Lundgren (2000) and Coronelli (2002), describing the effect of corrosion on bond strength, are particularly reviewed.

\subsection{Constitutive Equation of Bond-Slip Relationship}

Bond-slip relationship is developed considering equilibrium of the section as shown in Figure 3.1.

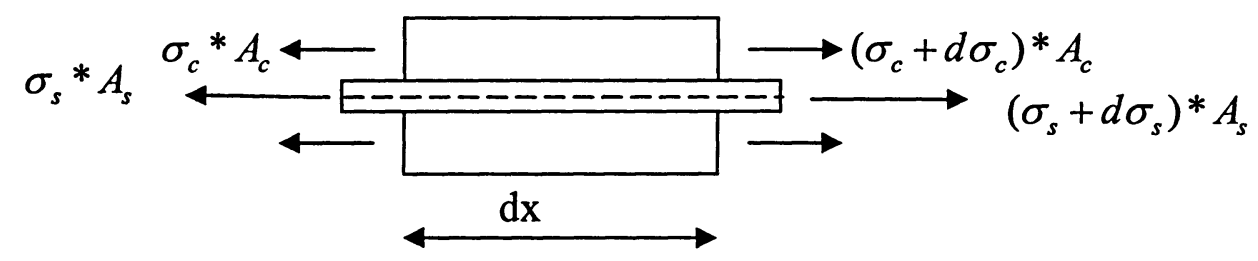

(a) Element length $d x$ with steel and concrete stresses

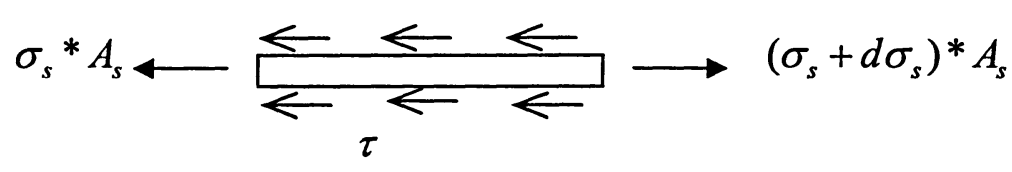

(b) Free-body diagram of the steel bar of length $d x$

Figure 3.1 Stresses in an element 


$$
\begin{aligned}
& d \sigma_{c} \cdot A_{c}+d \sigma_{s} \cdot A_{s}=0 \\
& \text { So } d \sigma_{s}=\frac{-d \sigma_{c} \cdot A_{c}}{A_{s}} \\
& \text { or } \quad d \sigma_{c}=\frac{-d \sigma_{s} \cdot A_{s}}{A_{c}} \\
& \tau=\frac{A_{s} \cdot d \sigma_{s}}{d_{b} \cdot \pi \cdot d x} \\
& \frac{d \sigma_{s}}{d x}=\frac{4 \tau}{d_{b}}
\end{aligned}
$$

where,

$d_{b}$ is the reinforcing bar's diameter

$A_{c}$ and $A_{s}$ are the area of the concrete and steel bar

$\sigma_{c}$ and $\sigma_{s}$ are the stresses in the concrete and steel respectively

$d \sigma_{c}$ and $d \sigma_{s}$ are the change in the concrete and steel stresses respectively

The increment of the local slip, $S_{x}$ within an infinitesimal bar length $d x$ at the location $x$ can be defined as the difference between the extension of the bar, $S_{s}$ and the concrete extension, $S_{c}$ at $x$.

In addition, since the change in length with respect to the original length is equal to strain, it follows that the difference between the bar strain, $\varepsilon_{s}$ and the concrete strain, $\varepsilon_{c}$ is

$$
\begin{aligned}
& S_{x}=S_{s}-S_{c} \\
& \frac{d S_{x}}{d x}=\varepsilon_{s}-\varepsilon_{c}
\end{aligned}
$$


The value of strain can be related to stress by assuming that concrete and steel behave elastically. Therefore, Hook's law can be used and the stress is a linear function of the strain.

$$
\sigma_{s}=E_{s} \cdot \varepsilon_{s} \quad \text { and } \quad \sigma_{c}=E_{c} \cdot \varepsilon_{c}
$$

where,

$E_{c}$ and $E_{s}$ are the elastic modulus of the concrete and the steel respectively.

Substituting equation 3.6 into equation 3.5 ,

$$
\frac{d S_{x}}{d x}=\frac{\sigma_{s}}{E_{s}}-\frac{\sigma_{c}}{E_{c}}
$$

The differentiation of equation 3.7 with respect to $\mathrm{x}$ gives:

$$
\frac{d^{2} S_{x}}{d x^{2}}=\frac{d \sigma_{s}}{E_{s} \cdot d x}-\frac{d \sigma_{c}}{E_{c} \cdot d x}=\frac{d \sigma_{s}}{E_{s} \cdot d x}\left(1+\frac{A_{s} \cdot E_{s}}{A_{c} \cdot E_{c}}\right)
$$

Substituting for $\frac{d \sigma_{s}}{d x}=\frac{4 \tau}{d_{b}}$, results in

$$
\begin{aligned}
& \frac{d^{2} S_{x}}{d x^{2}}=\frac{1}{E_{s}} \cdot \frac{4 \tau}{d_{b}}\left(1+\frac{A_{s} \cdot E_{s}}{A_{c} \cdot E_{c}}\right) \\
& \text { Let } k=\frac{4}{E_{s} \cdot d_{b}}\left(1+\frac{A_{s} \cdot E_{s}}{A_{c} \cdot E_{c}}\right), \text { then } \\
& \frac{d^{2} S_{x}}{d x^{2}}=k \cdot \tau
\end{aligned}
$$

The bond stress is calculated by $\tau=\frac{A_{s} \cdot d \sigma_{s}}{d_{b} \cdot \pi \cdot d x}$, this means that it varies with the change of axial stress and the axial stress resulting from the steel strain. In this case, the bond stress includes two zones, one is the elastic zone and the other is the non-elastic zone. 
If we consider a constant stress along the total bar length, $\tau=b_{1}$, where $b_{1}$ is constant, then

$$
\frac{d^{2} S_{x}}{d x^{2}}=k \cdot b_{1}
$$

Alternatively, $\tau$ is directly proportional to the slip $S_{x}$ i.e. $\tau=b_{2} \cdot S_{x}$

$$
\frac{d^{2} S_{x}}{d x^{2}}=k \cdot b_{2} \cdot S_{x}
$$

in general

$$
\begin{aligned}
& \frac{d^{2} S_{x}}{d x^{2}}=k \cdot b_{2} \cdot S_{x}^{N} \\
& \tau=b_{3} \cdot S_{x}^{N}, \text { which means that } \tau \text { is found to be as a nonlinear function. } \\
& \frac{d^{2} S_{x}}{d x^{2}}=k \cdot b_{1}, \text { and by integrating it, we have, } \\
& \frac{d S_{x}}{d x}-A_{1} x+A_{2}=0 \\
& S_{x}=\frac{A_{1} x^{2}}{2}+A_{2} x+A_{3}
\end{aligned}
$$

$A_{1}, A_{2}$ and $A_{3}$ can be found by defining the boundary conditions.

The above formulation is a trial for a combination between the slip and the bond stress at any $x$.

Many other studies have been made in order to get a best-fit curve for bond-slip phenomena, but all those were based in one way or another on initial assumptions between the bond stress and the slip. 


\subsection{Review of Models for Bond in Uncorroded Bar}

Some models which described the bond stress at steel-concrete interface are reviewed in this section.

\subsubsection{Mirza-Houde Model (1978)}

Mirza and Houde tested 62 concentric tension specimens and measured the end slips, elongation of the embedded bar. Following bond stress-slip relationship was derived using the experimental data.

$$
\tau=539.8 \cdot s-256.1 \cdot 10^{2} \cdot s^{2}+592.2 \cdot 10^{3} \cdot s^{3}-557.4 \cdot 10^{4} \cdot s^{4}
$$

where,

$$
\begin{aligned}
& \tau=\text { bond stress } \\
& s=\operatorname{slip}
\end{aligned}
$$

\subsubsection{The Comité Euro-International du Béton (CEB) Code Model (1990)}

This model was proposed by Ciampi et al. (1981). The following equations were developed to describe the ascending and descending branches of the model which is shown in Figure 3.2.

$$
\begin{array}{ll}
\tau=\tau_{\max } \cdot\left(\frac{S}{S_{1}}\right)^{\alpha} & \text { for } 0 \leq S \leq S_{1} \\
\tau=\tau_{\max } & \text { for } S_{1} \leq S \leq S_{2} \\
\tau=\tau_{\max }-\left(\tau_{\max }-\tau_{f}\right) \cdot\left(\frac{S-S_{2}}{S_{3}-S_{2}}\right) & \text { for } S_{2} \leq S \leq S_{3}
\end{array}
$$




$$
\tau=\tau_{f} \quad \text { for } S<S_{3}
$$

Where $\alpha$ is an empirical constant $(0 \leq \alpha \leq 1)$ that describes the shape of the bond stressslip curve.

The CEB Model Code states that the ascending branch refers to the stage where the ribs on the reinforcement penetrate into the mortar matrix, characterized by the local crushing and micro-cracking. Hence, in the ascending branch, the bond stress increases nonlinearly up to a point where the slip $S$ is equal to $S_{1}$ (equation 3.17). The horizontal level between $S_{1}$ and $S_{2}$ occurs only for confined concrete, referring to advanced crushing and shearing off the concrete between the ribs (equation 3.18). During this stage, the bond stress is a constant maximum. The descending branch refers to the reduction of bond stress due to the splitting cracks along the bars (equation 3.19). The last horizontal part represents a residual bond capacity, which is maintained by minimum transverse reinforcement, keeping a certain degree of integrity intact (equation 3.20).

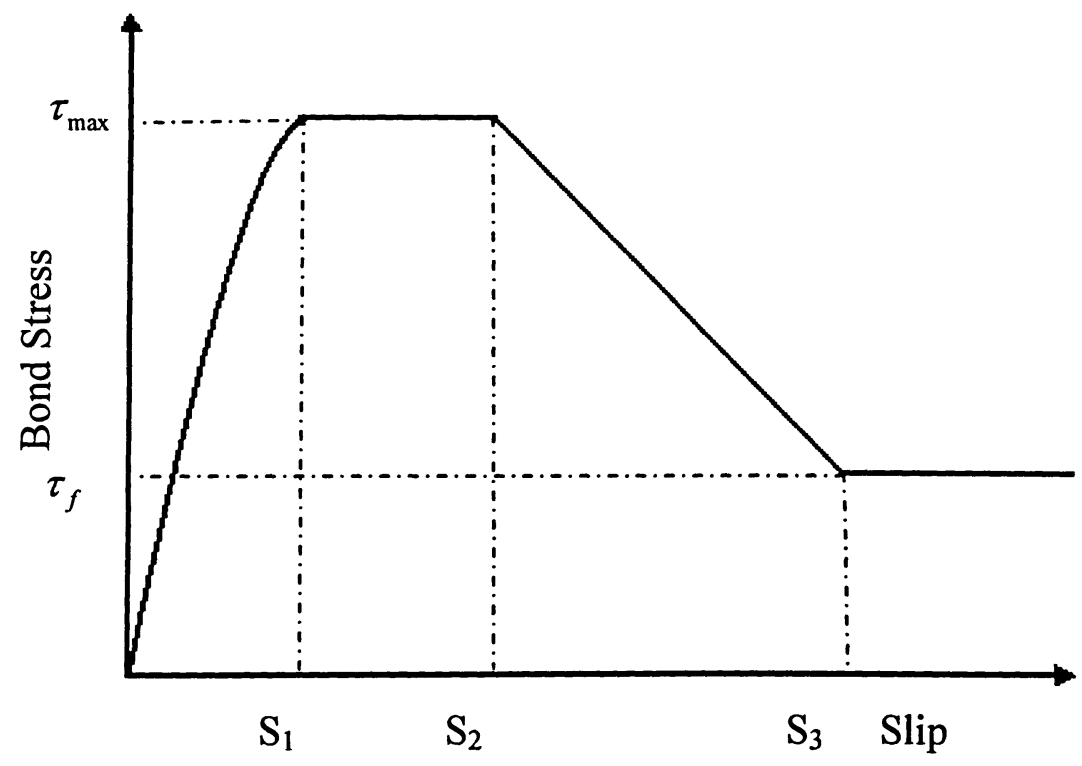

Figure 3.2: CEB bond model (The Comité Euro-International du Béton, 1990) 
According to CEB Model Code MC90, the parameters in Equations 3.17 to 3.20 are given in Table 3.1.

Table 3.1: Parameters for defining the mean bond stress-slip relationship

\begin{tabular}{|c|c|c|c|c|}
\hline \multirow{2}{*}{ Parameters } & \multicolumn{2}{|c|}{ Unconfined Concrete } & \multicolumn{2}{c|}{ Confined Concrete } \\
\cline { 2 - 5 } & $\begin{array}{c}\text { Good bond } \\
\text { condition }\end{array}$ & $\begin{array}{c}\text { All other bond } \\
\text { condition }\end{array}$ & $\begin{array}{c}\text { Good bond } \\
\text { condition }\end{array}$ & $\begin{array}{c}\text { All other bond } \\
\text { condition }\end{array}$ \\
\hline $\mathrm{S}_{1}$ & $0.6 \mathrm{~mm}$ & $0.6 \mathrm{~mm}$ & $1.0 \mathrm{~mm}$ & $1.0 \mathrm{~mm}$ \\
\hline $\mathrm{S}_{2}$ & $0.6 \mathrm{~mm}$ & $0.6 \mathrm{~mm}$ & $3.0 \mathrm{~mm}$ & $3.0 \mathrm{~mm}$ \\
\hline $\mathrm{S}_{3}$ & $1.0 \mathrm{~mm}$ & $2.5 \mathrm{~mm}$ & Clear rib spacing & Clear rib spacing \\
\hline$\alpha$ & 0.4 & 0.4 & 0.4 & 0.4 \\
\hline$\tau_{\max }$ & $2.0 \sqrt{f_{c k}}$ & $1.0 \sqrt{f_{c k}}$ & $2.5 \sqrt{f_{c k}}$ & $1.25 \sqrt{f_{c k}}$ \\
\hline$\tau_{f}$ & $0.15 \tau_{\max }$ & $0.15 \tau_{\max }$ & $0.4 \tau_{\max }$ & $0.4 \tau_{\max }$ \\
\hline
\end{tabular}

\subsubsection{Marti’s Model (1999)}

Marti's approach is based on one main simplified assumption. His rigid-plastic assumption is that the bond stress is constant with respect to the variation of slip. Since the Young modulus of steel varies between the elastic and the non-elastic region (Figure 3.3), Marti's assumption was on the change of the Young modulus of steel, and he concluded that the bond stress would have two constant values, one before yielding and one after it. Figure 3.4 shows the rigid plastic assumption that has been made; in order to develop a bond-slip relationship before yielding and after yielding.

According to Marti, Bond stress before yielding is:

$$
\tau_{b 0}=2.0 f_{c t}
$$

The bond stress after Yielding is:

$$
\tau_{b 1}=f_{c t}
$$




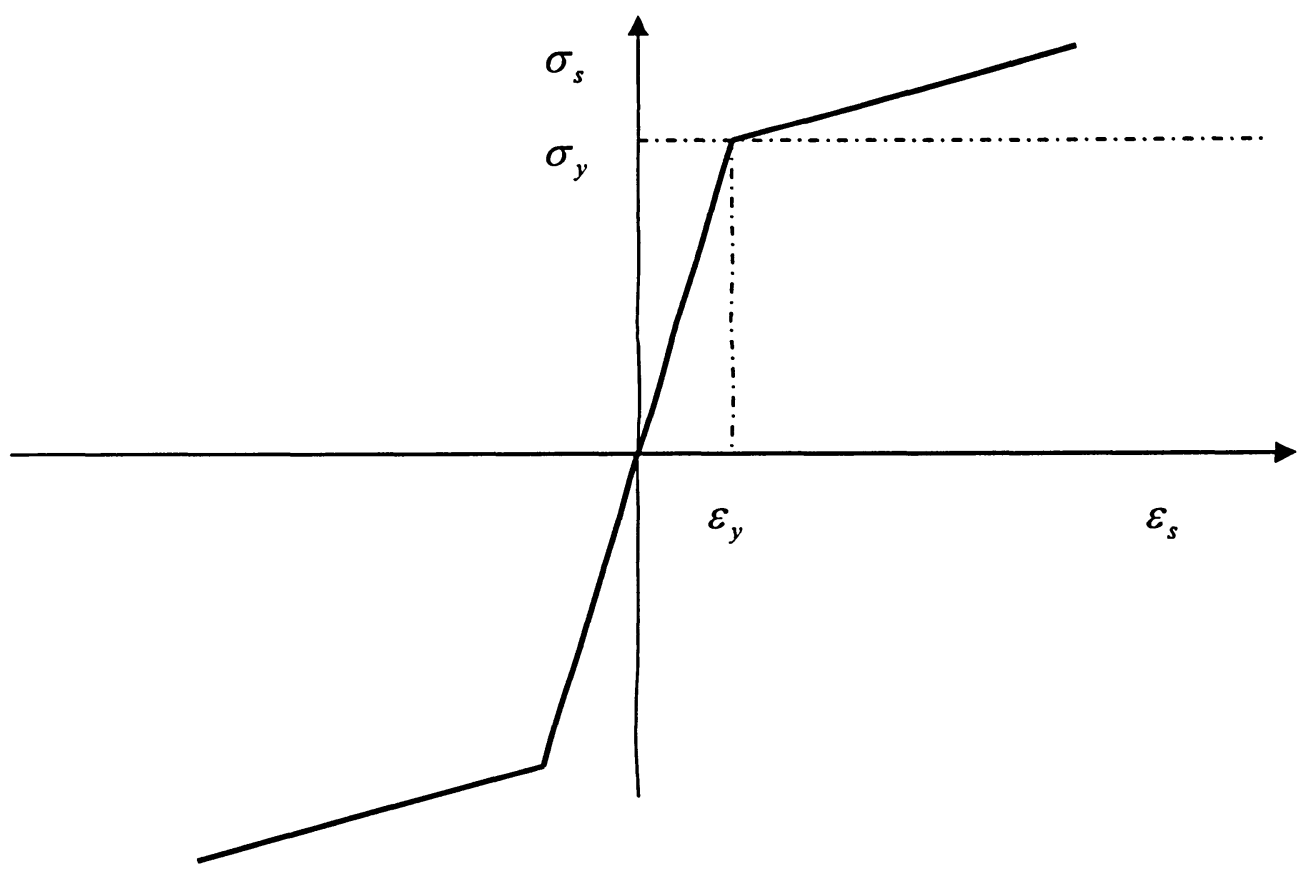

Figure3.3: Bilinear constitutive relationship for the reinforcement

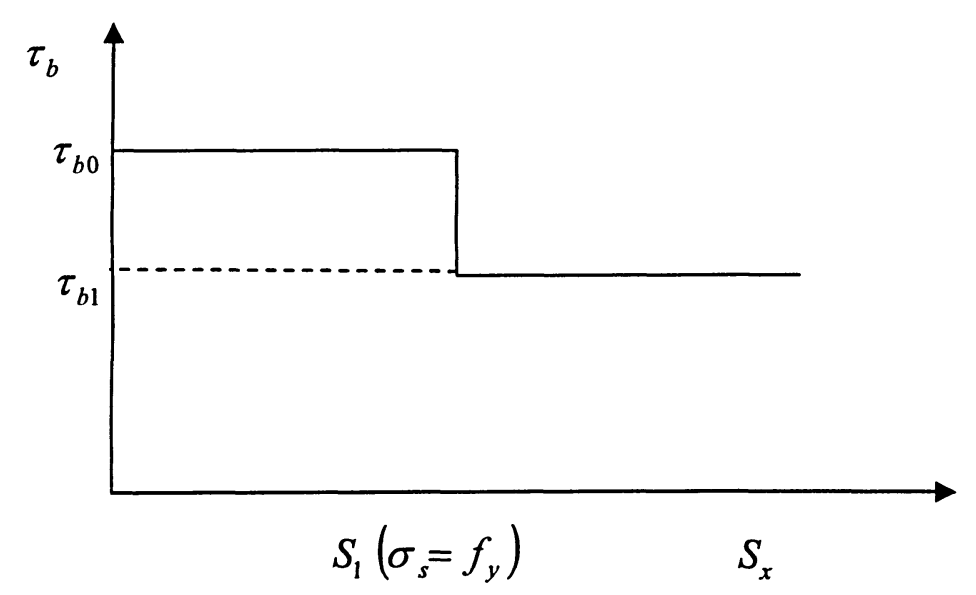

Figure3.4 Assumed bond stress distribution (Marti, 1999) 


\subsubsection{Idda's Model (1999)}

Idda (1999) developed a model to calculate the contact stress's $\tau$ and $\sigma$ which are given by equations 3.23 and 3.24 and shown in Figure 3.5.

$$
\begin{gathered}
\tau=\left[a_{0} \cdot\left(\frac{\delta}{c_{s}}\right)^{b_{0}} \cdot e^{\left(c_{0} \cdot \frac{\delta}{c_{s}}+d_{0} \sqrt{\frac{w}{h_{s}}}\right)}\right] \cdot f_{c} \\
\sigma=\left[a_{1} \cdot \frac{\delta^{h_{1}}}{c_{s}} \cdot e^{\left(c_{1} \frac{\delta}{c_{s}}+d_{1} \cdot \sqrt{\frac{w}{h_{s}}}\right)}\right] \cdot f_{c}
\end{gathered}
$$

Where $\mathrm{w}, \delta, \tau$ and $\sigma$ is greater than zero.

Eight values have been determined from experimental results:

$$
\begin{aligned}
& \mathrm{a}_{0}=+1.9 \\
& \mathrm{~b}_{0}=+0.5 \\
& \mathrm{c}_{0}=-2.3 \\
& \mathrm{~d}_{0}=-1.4 \\
& \mathrm{a}_{1}=-2.3 \\
& \mathrm{~b}_{1}=+0.5 \\
& \mathrm{c}_{1}=-1.3 \\
& \mathrm{~d}_{1}=-1.4
\end{aligned}
$$

where,

$\tau=$ shear stress at the steel-concrete interface

$\sigma=$ normal stress at the steel-concrete interface

$\mathrm{w}=$ crack width

$h_{s}=$ height of the ribs

$c_{s}=$ center to center distance between two ribs 


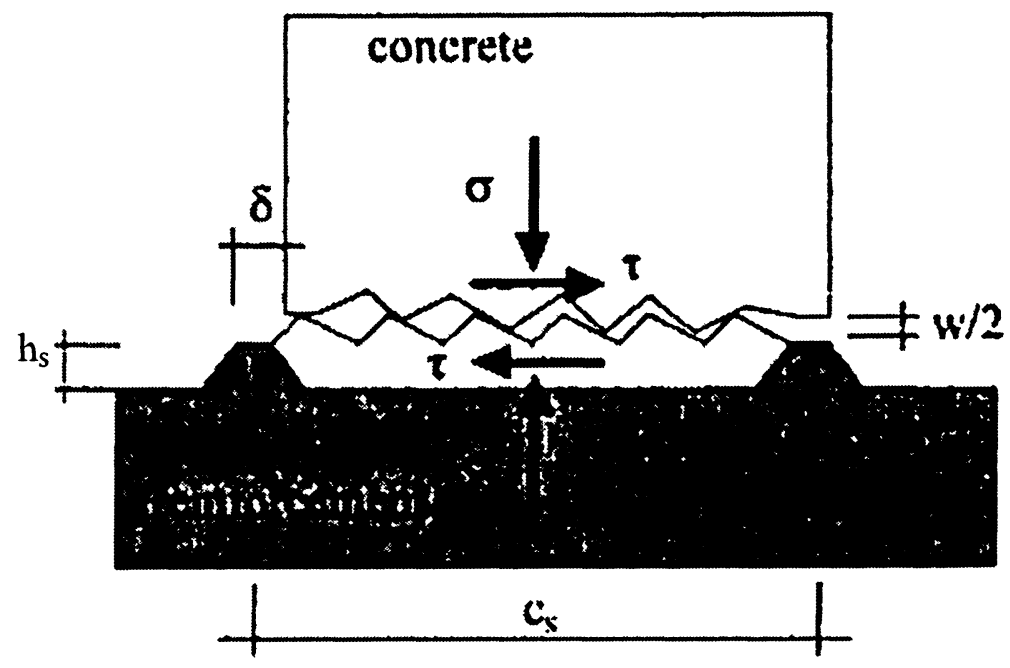

Figure 3.5: The contact stresses $\tau$ and $\sigma$ (Idda, 1999)

\subsubsection{Lundgren and Gylltofts' Bond Model (2000)}

Lundgren and Gylltoft (2000) developed a model which describes the three dimensional analysis of bond stress at the steel-concrete interface. In this model, splitting stresses of the bond action and the radial deformation between reinforcement bar and concrete were included. The model is a frictional model, using elasto-plastic theory to describe the relations between the stresses and the deformations. The relation between traction $t$ and the relative displacements $u$ is expressed in equation 3.25 and is shown in Figure 3.6.

$$
\left(\begin{array}{l}
t_{n} \\
t_{t} \\
t_{r}
\end{array}\right)=\left(\begin{array}{ccc}
D_{11} & \frac{u_{t}}{u_{t}} D_{12} & 0 \\
0 & D_{22} & 0 \\
0 & 0 & D_{33}
\end{array}\right)\left(\begin{array}{l}
u_{n} \\
u_{t} \\
u_{r}
\end{array}\right)
$$




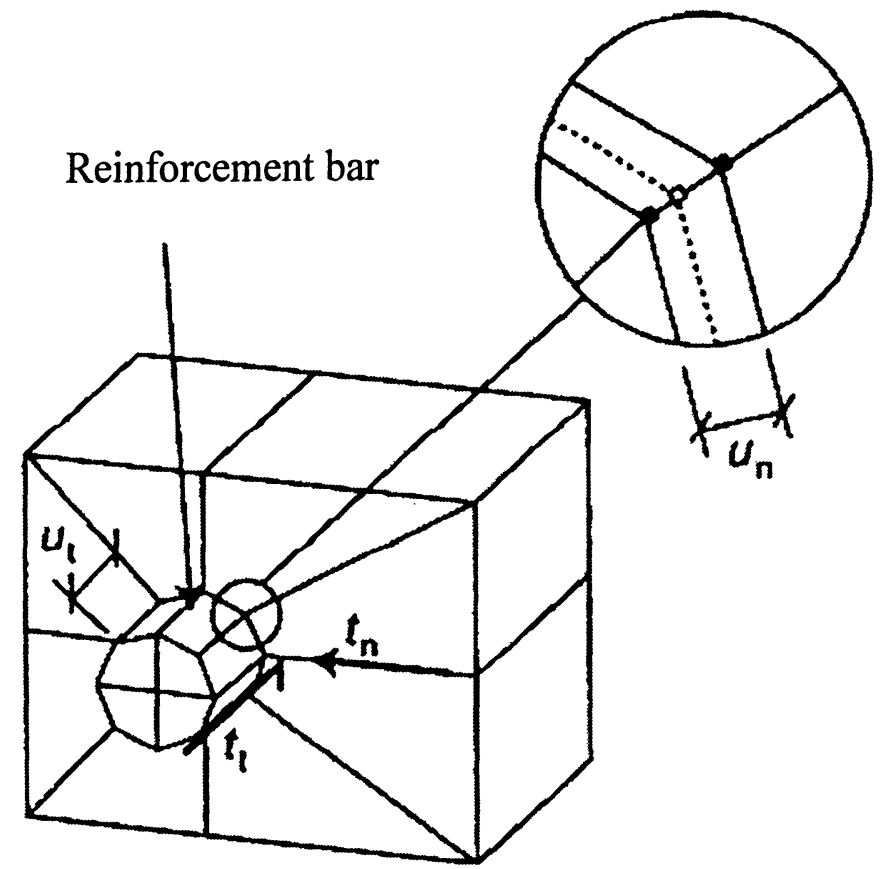

Figure 3.6: Physical interpretation of the variables $t_{n}, t_{t}, u_{n}$ and $u_{t}$ (Lundgren and Gvlltoft, 2000)
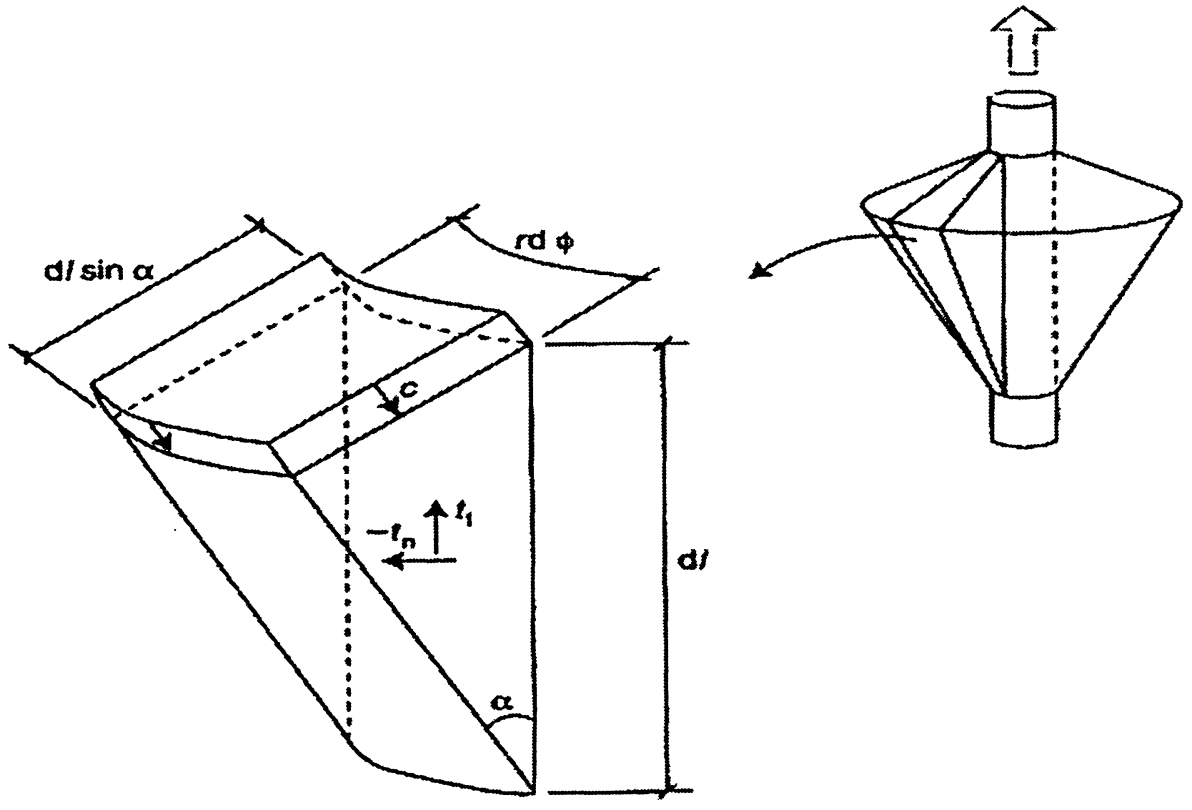

Figure 3.7: The stress in the inclined compressive struts determines the upper limit (Lundgren and Gylltoft, 2000) 


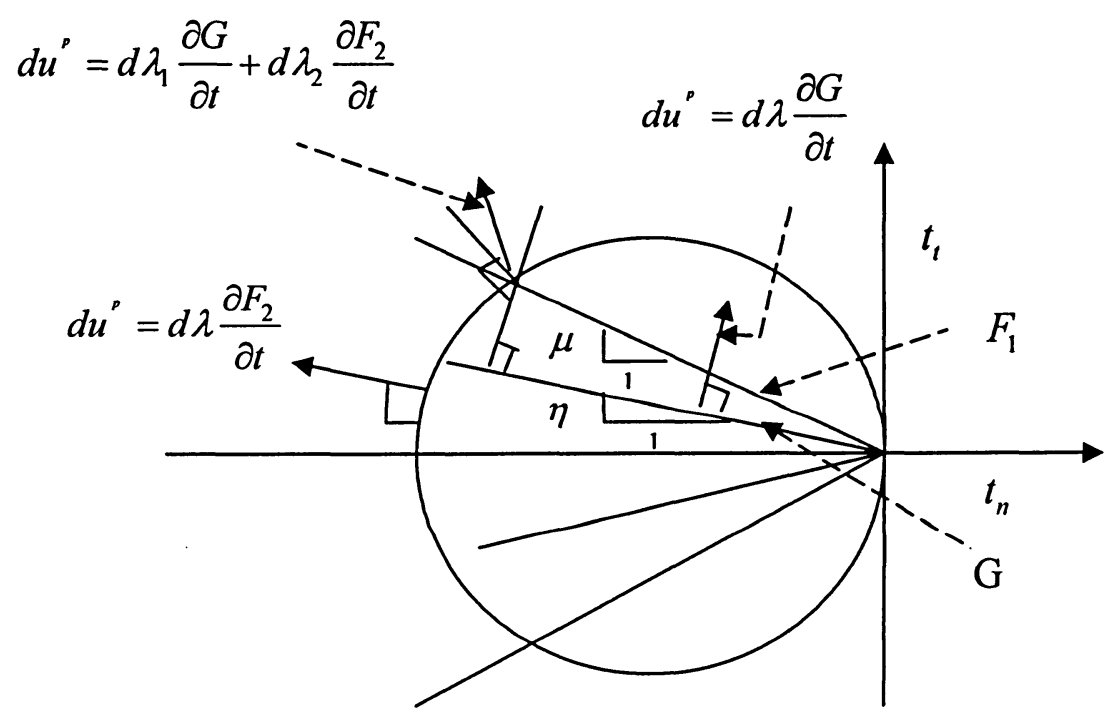

Figure 3.8: The yield lines (Lundgren and Gylltoft, 2000)

The model has yield lines, flow rules and hardening laws. The yield lines are described by two functions. One is friction $F_{1}$ which is as follows when the adhesion is neglected.

$$
F_{1}=\left|t_{t}\right|+\mu t_{n}=0
$$

The other yield line $F_{2}$, the upper limit at a pull-out failure is determined from the stress in the inclined compressive struts that results from bond action which is shown in Figure 3.7. The $\mathrm{F} 2$ is expressed as follows:

$$
\begin{aligned}
& F_{2}=t_{t}^{2}+t_{n}^{2}+c t_{n} \\
& d u^{p}=d \lambda \frac{\partial G}{\partial t}, G=\frac{\left|u_{t}\right|}{u_{t}} t_{t}+\eta t_{n}=0
\end{aligned}
$$


where $d \lambda$ is the incremental plastic multiplier. The yield lines together with the plastic parts of the deformations are shown in Figure 3.8

For the hardening rule of the model a hardening parameter is expressed as follows:

$$
d k=\sqrt{d u_{n}^{p^{2}}+d u_{t}^{p^{2}}}
$$

The variables $\mu$ and $\mathrm{c}$ in the yield functions are assumed to be functions of $k$.

\subsubsection{Russo and Paulettas' Model (2002)}

The bond stress-slip relationship, $\tau-s$ proposed by the CEB (1990) can be expressed by

$$
\tau=\tau_{1} \cdot\left(\frac{S}{S_{1}}\right)^{\alpha}
$$

where,

$$
\begin{aligned}
& \tau_{1}=\text { maximum bond strength } \\
& \mathrm{s}_{1}=\text { minimum slip corresponding to } \tau_{1} \\
& \alpha=\text { exponent }
\end{aligned}
$$

The differential equations governing bond problem are

$$
\begin{aligned}
& s^{\prime \prime}-\chi \cdot \tau[s(x)]=0 \\
& \psi \cdot A_{c} \cdot \frac{d \sigma_{c}}{d x}=-A_{s} \cdot \frac{d \sigma_{s}}{d x}
\end{aligned}
$$

where,

$$
s^{n}=\frac{d^{2} s}{d x^{2}}
$$




$$
\begin{aligned}
& \chi=\frac{4 \cdot(1+\xi)}{d_{b} \cdot E_{s}} \\
& \xi=\frac{E_{s} \cdot A_{s}}{\psi \cdot E_{c} \cdot A_{c}}
\end{aligned}
$$

with

$$
\begin{aligned}
& A_{c}=\text { concrete cross-sectional area } \\
& A_{s}=\text { reinforcing bar area } \\
& d_{b}=\text { reinforcing bar diameter } \\
& \psi=0.75 \\
& E_{s} \text { and } E_{c}=\text { steel and concrete elastic moduli, respectively }
\end{aligned}
$$

For local bond law expressed by equation 3.36 , the equations solving the problem of a bar pulled out embedded in tension concrete are (Russo and Pauletta, 2002):

$$
x=B \mp \frac{1}{\sqrt{2 \cdot \gamma}} \cdot \sum_{k=0}^{\infty}\left(k^{\frac{1}{2}}\right) \cdot\left(\frac{C}{\gamma}\right)^{k} \cdot \frac{s^{\frac{1-\alpha}{2}-k(1+\alpha)}}{\frac{1-\alpha}{2}-k(1+\alpha)} \text { for }\left|\frac{C}{\gamma}\right|^{(1+\alpha)} \leq s \cup s<\left|\frac{C}{\gamma}\right|^{(1+\alpha)}
$$

If the constant $C$ is zero, Figure 3.9 (a), the solution is in a closed form

$$
S=\left[\mp \frac{1-\alpha}{2} \cdot \sqrt{2 \cdot \gamma} \cdot(x-B)\right]^{\frac{2}{1-\alpha}}
$$

where $\mathrm{B}$ is a constant of integration and

$$
\gamma=\chi \cdot \frac{\tau_{1}}{(1+\alpha) \cdot s_{1}^{\alpha}}
$$

Equations 3.36 and 3.37 hold negative sign for the bar portion $O R$ and positive sign for the portion RZ or VZ (Figure 3.9).

The expressions for steel and concrete strains are respectively (Figure 3.9) 


$$
\varepsilon_{s}=\frac{D \pm \sqrt{2 \cdot\left(\gamma \cdot s^{(1+\alpha)}+C\right)}}{(1+\xi)}
$$

with positive sign for the bar portion $\mathrm{OR}$ and with the negative sign for the portion $\mathrm{RZ}$ and $\mathrm{VZ}$, and $\mathrm{D}$ an integration constant

$$
\varepsilon_{c}=\frac{D \mp \xi \sqrt{2 \cdot\left(\gamma \cdot s^{(1+\alpha)}+C\right)}}{(1+\xi)}
$$

with negative sign for the bar portion $\mathrm{OR}$ and with the positive sign for the portion $\mathrm{RZ}$ and VZ.
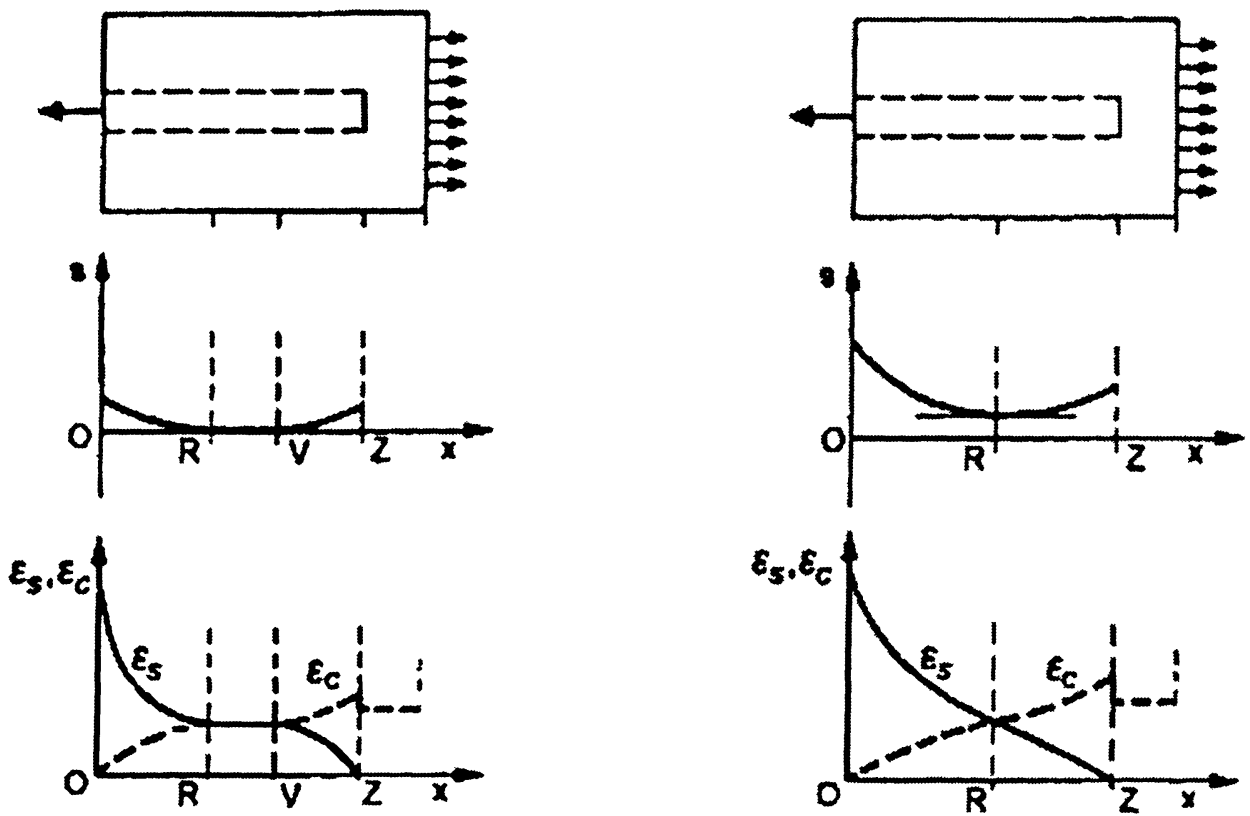

(a)

(b)

Figure 3.9: Typical slip and strain for pull-out of a bar embedded in tensioned concrete (Russo and Romano, 1990) 


\subsection{Review of Bond Models in Corroded Bars}

This section reviewed some models describing the bond strength for corroded reinforcing steel.

\subsubsection{Coronelli's Model for Bond Strength of Corroded Rebar (2002)}

Coronelli (2002) developed a model which predicted the bond strength for corroded bars in reinforced concrete structures. For this purpose he studied the interface pressure caused by the expansion of corrosion product at different confinement situations.

\subsubsection{Bar-Concrete pressure}

Crack width calculation- Coronelli (2002) used the relationship between the depth X of the corrosion attack and total crack width $\mathrm{W}_{\mathrm{cr}}$ which was established by Molina et. al (1993) and presented in equation 3.41

$$
W_{c r}=\sum_{i} u_{i_{c o r r}}=2 \pi t
$$

with

$$
t=\left(V_{r s}-1\right) X
$$

where,

$$
\begin{aligned}
& t=\text { thickness of corrosion product } \\
& u_{i c o r r}=\text { opening of each single radial crack; } \\
& V_{r s}=\text { ratio between the volumes of corroded and virgin steel }
\end{aligned}
$$

Equation 3.41 is established assuming that all corrosion products accumulate around the corroded bar. But the corrosion products tend to penetrate into the cracks and reach to the 
external surface of the cover. Hence, Coronelli modified the Equation 3.41 which is presented in equation 3.42 and is shown in Figure 3.10 and 3.11 .

$$
\begin{aligned}
& 2 \pi r_{b} v_{r s} X=2 \pi r_{b}(X+t)+2 \pi t c \\
& t=\frac{r_{b}\left(v_{r s}-1\right)}{r_{b}+c} X
\end{aligned}
$$

where,

$$
\begin{aligned}
& c=\text { extension of the crack across the cover; } \\
& r_{b}=\text { bar radius }
\end{aligned}
$$
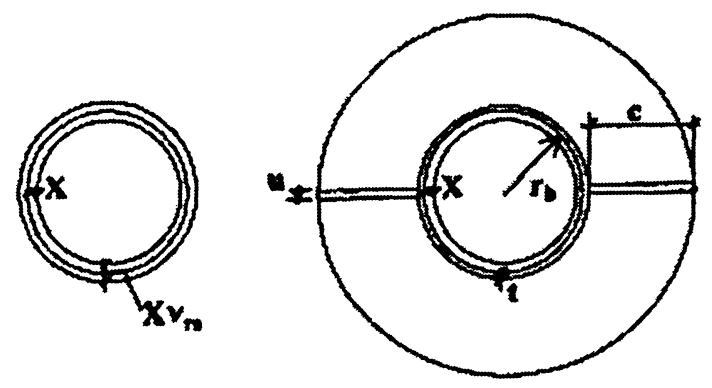

Figure 3.10: Corrosion depth $X$ and bar expansion $t$

(Coronelli, 2002)

$>$ Corrosion crack

Final splitting crack

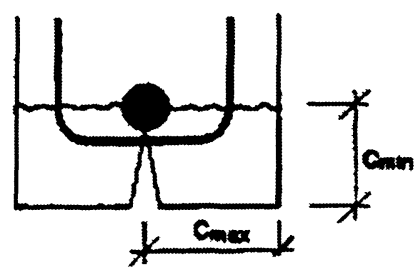

(a)

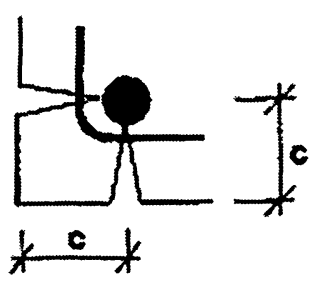

(b)

Figure 3.11: Corrosion-crack patterns: (a) corrosion cracks smaller cover; and (b) corrosion cracks both sides (Coronelli, 2002) 
Pressure Development in Confined Concrete- Coronelli modeled the concrete cover as a beam, with the cross section defined by the two orthogonal directions (Figure 3.12 (a)). The beam is loaded by a distributed force representing the resultant of the pressure caused by the expansion of the corrosion products, and rests on evenly spaced supports that represent the confinement exerted by the surrounding concrete. The beam is also restrained by evenly spaced rods that model the legs of the stirrups.

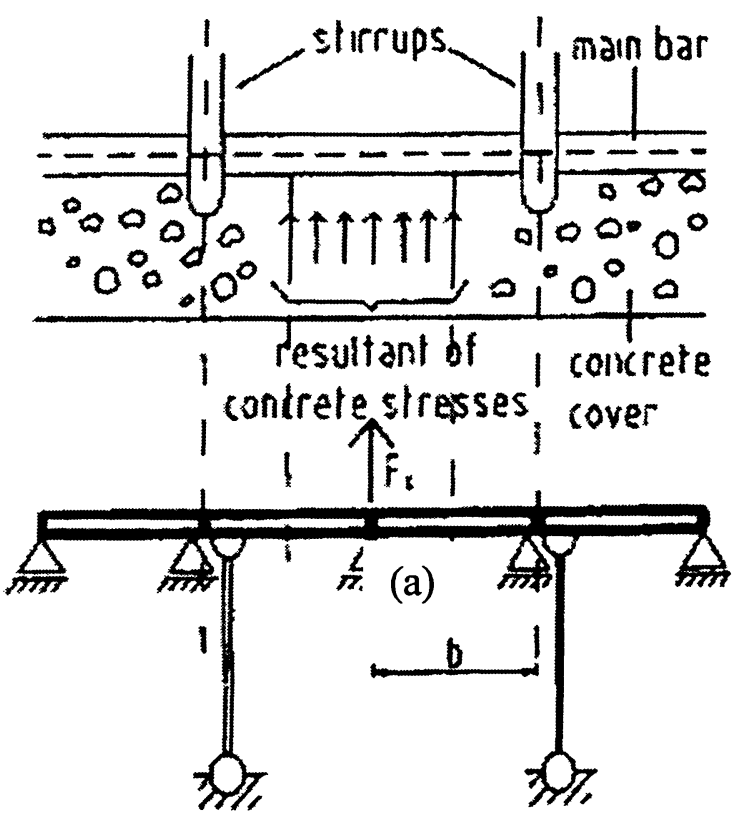

(a)

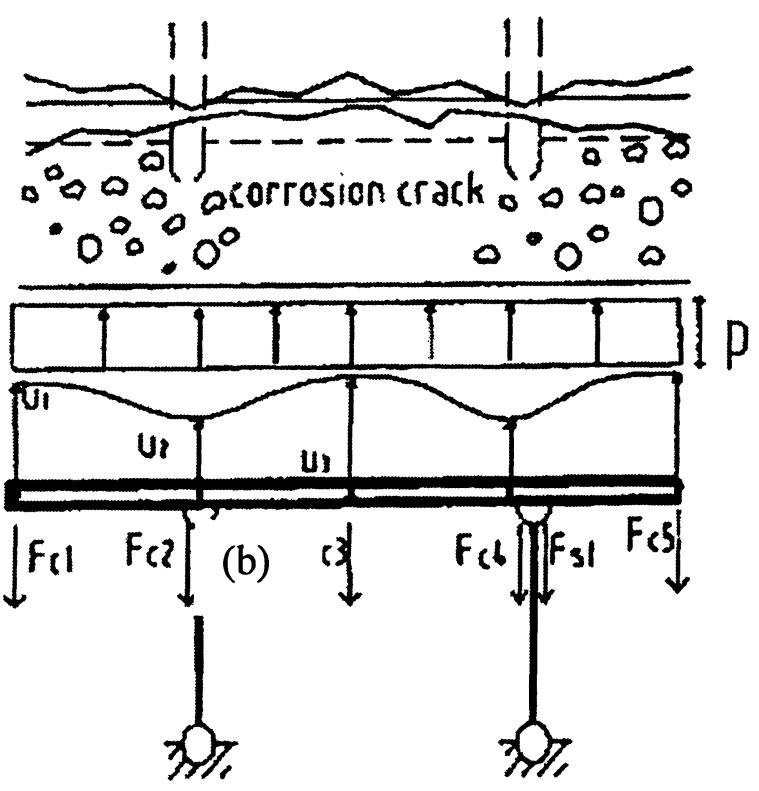

(b)

Figure 3.12: Beam model for concrete cover (Coronelli, 2002) 
According to Coronelli, the force required to initiate the crack along the portion of the cover pertaining to each node is calculated by equation 3.43 .

$$
F_{c}^{\max }=\beta f_{c t} c_{\min } b
$$

where,

$f_{c t}=$ concrete tensile strength

$c_{\min }=$ cover thickness

$b=$ distance between two nodes

$\beta$ takes into account the nonuniform distribution of the hoop stresses in the cover at the onset of cracking

\subsubsection{Bond Capacity of Anchored Bar}

Coronelli modified the model of Cairns and Abdullah (1996) to consider corroded bar. Bond Strength for uncorroded bar is evaluated as

$$
\tau_{b u}=k p^{\max }+\tau_{b}^{0}
$$

$p^{\max }$ is the maximum pressure at bond failure and with

$$
\begin{aligned}
& \tau_{b}^{0}=n A_{r} f_{c o h}[\cot \delta+\tan (\phi+\delta)] /\left(\pi d_{b} s_{r}\right) \\
& k=n c_{r} \tan (\phi+\delta) / \pi
\end{aligned}
$$

where,

$$
\begin{aligned}
& n=\text { number of transverse ribs at section } \\
& s_{r}=\text { rib spacing } \\
& A_{r}=\text { rib area in the plane at right angles to bar axis } \\
& c_{r}=\text { coefficient, depending on the rib shape and area }
\end{aligned}
$$




$$
\begin{aligned}
& \delta=\text { orientation of the ribs } \\
& \phi=\text { friction angle between steel and concrete } \\
& f_{c o l}=\text { adhesion strength }
\end{aligned}
$$

The bond strength of corroded bar is as follows,

$$
\begin{aligned}
& \tau_{b u}=k(X) p^{\max }(X)+\tau_{b}^{0}(X)+\mu(X) p_{c o r r}(X) \\
& \mu=\tan \phi=B-C\left(X-X_{c r}\right) \\
& f_{c o h}=D-E\left(X-X_{c r}\right)
\end{aligned}
$$

where,

$$
\begin{aligned}
& X=\text { depth of corrosion } \\
& X_{c r}=\text { depth of corrosion at cracking }
\end{aligned}
$$

\subsubsection{Lundgren's Model for Bond between Corroded Reinforcement and Concrete} (2002)

The free increase of the radius; i.e. how much the radius would increase if the normal stresses were zero is calculated from equation 3.50

$$
a=-r+\sqrt{r^{2}+(v-1) \cdot\left(2 r x-x^{2}\right)}
$$

where,

$$
\begin{aligned}
& x=\text { corrosion penetration } \\
& v=\text { volume of rust } / \text { volume of steel } \\
& a=\text { free increase of the radius } \\
& u_{n c o r r}=\text { real increase of the radius }
\end{aligned}
$$


The different variables that are used in corrosion model is shown in Figure 3.13. The volume of the rust relative to the uncorroded steel and the corrosion penetration as a function of time is given as input.

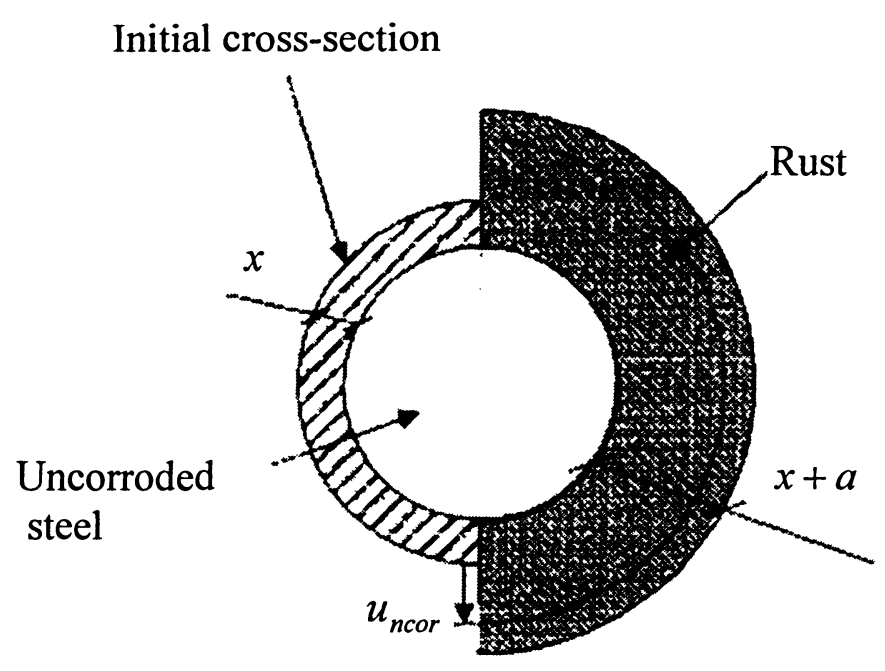

Figure 3.13: Physical interpretation of the variables in the corrosion model (Lungren, 2002)

The strain in the rust is calculated from the equation 3.51

$$
\varepsilon_{c o r}=\frac{u_{n c o r}-a}{x+a}
$$

From the strain in the rust, the normal stresses in the layer are determined.

The corrosion layer was combined with a model of the bond mechanism that is described in section 3.2.5. The deformations are related as:

$$
\begin{aligned}
& u_{n}=u_{n c o r}+u_{n b o n d} \\
& u_{t}=u_{t c o r}, u_{t c o r}=0
\end{aligned}
$$


Corrosion of the reinforcement was assumed to influence the coefficient of friction and it is calculated by introducing a function $k(x / r)$ and it is shown in equation 3.54.

$$
\mu(k)=k(x / r) \cdot \mu_{0}(k), b u t \mu(k) \geq 0.4
$$

\subsection{Summary}

The analytical models that were developed to discuss the bond strength of uncorroded and corroded bars are reviewed. Corrosion of steel causes the change in contact pressure and friction coefficient at steel-concrete interface which are very important parameters of bond. Detailed research is needed to model the change of contact pressure and friction coefficient due to corrosion of steel in concrete. 


\section{Chapter 4}

\section{Finite Element Modeling of Bond Stress between Concrete and Uncorroded or Corroded Reinforcing Steel}

A finite element (FE) model, describing the average bond stress at the steel-concrete interface and the effect of corrosion on the bond stress, is developed. The nonlinear FE software "ABAQUS" is used for this purpose. The results of the experimental study performed by Amleh (2000) on pull-out tests of concrete cylinders with uncorroded and corroded steel bars have been analyzed by finite element method. This chapter describes the procedure of developing the bond stress model for concrete and uncorroded or corroded reinforcing steel.

\subsection{Modeling the Bond at the Steel-Concrete Interface}

The forces acting on the steel-concrete interface are shown in Figure 4.1. The radial force and the vertical component of reaction of lug cause the contact pressure at steel concrete interface which is modeled in the analysis.

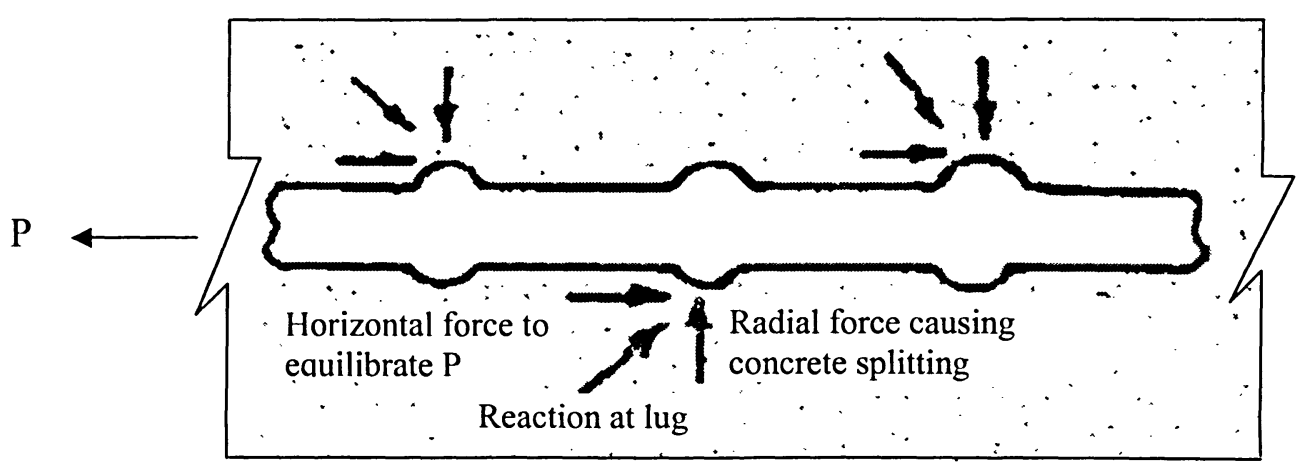

Figure 4.1: Forces acting at steel-concrete interface 
The bond stress is computed by modeling the normal contact pressure and the friction at the steel-concrete interface. These phenomena are modeled for both uncorroded and corroded steel. Both elastic and plastic properties are assigned to express the nonlinear behaviour of steel and concrete.

The analysis is carried out by the performing following tasks:

1) Details of specimens

2) Assigning the material properties of steel and concrete

3) Defining the contact surfaces and assigning the properties at steel concrete contact interface

4) Assigning boundary conditions and loads

5) Making the mesh

\subsection{Details of Pullout Specimens}

Amleh, (2000) used two types of concrete mixtures, 60MPa and $50 \mathrm{MPa}$ for her pullout specimens. For each concrete mixture, four specimens with $25 \mathrm{~mm}, 50 \mathrm{~mm}, 75 \mathrm{~mm}$ and $100 \mathrm{~mm}$ thick concrete cover were used. The reinforcing steel used for all specimens are $20 \mathrm{~mm}$ diameter bars which are embedded concentrically in each cylinder. The embedded length of the bar is also fixed at $280 \mathrm{~mm}$. The details of the test specimens are shown in Figure 4.2.

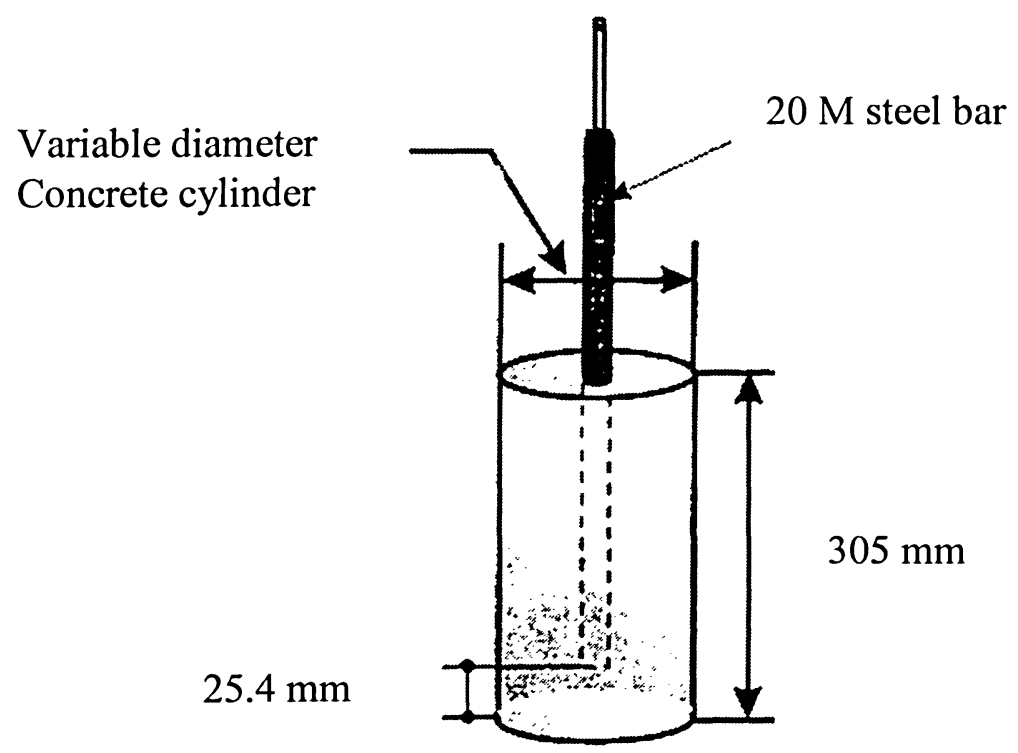

Figure 4.2: Typical pullout specimen tested by Amleh (2000) 


\subsection{Modeling the Material Properties of Concrete}

Two types of properties are used to express the nonlinear behaviour of steel and concrete.

1) Elastic properties

2) Plastic properties

Table 4.1 presents the concrete properties obtained from the experimental data (Amleh, 2000).

Table 4.1: Properties of concrete obtained from experimental data

\begin{tabular}{|c|c|}
\hline Name of specimens & Compressive strength \\
\hline Specimens of 60 MPa concrete & 60 \\
\hline Specimens of 50 MPa concrete & 50 \\
\hline
\end{tabular}

\subsubsection{Elastic Properties}

For normal density concrete with a density of about $2300 \mathrm{~kg} / \mathrm{m}^{3}$, CSA A23.3, Cl. 8.6.2.3 allows the approximate modulus of elasticity of concrete as

$$
E_{c}=4500 \sqrt{f_{c}^{\prime}} M P a
$$

For $60 \mathrm{MPa}$ concrete, modulus of elasticity, $\mathrm{E}_{\mathrm{c}}=34857 \mathrm{MPa}$

For $50 \mathrm{MPa}$ concrete, modulus of elasticity, $\mathrm{E}_{\mathrm{c}}=31820 \mathrm{MPa}$ 


\subsubsection{Plastic Properties}

\subsubsection{Compressive Behaviour}

Popovics (1970) and Thorenfeldt, et. al (1987) developed some expressions to derive a compressive stress-strain curve of concrete. The relationship between the concrete stress, $f_{c}$ and the corresponding strain, $\varepsilon_{c}$ is as follows:

$$
\frac{f_{c}}{f_{c}^{\prime}}=\frac{n\left(\varepsilon_{c} / \varepsilon_{c}^{\prime}\right)}{n-1+\left(\varepsilon_{c} / \varepsilon_{c}^{\prime}\right)^{n k}}
$$

where,

$f_{c}^{\prime}=$ concrete compressive strength, $\mathrm{MPa}$

$\varepsilon_{c}^{\prime}=$ strain when $f_{c}$ reaches $f_{c}^{\prime}$

$n$ = a curve fitting factor equal to $E_{c} /\left(E_{c}-E_{c}^{\prime}\right)$

$E_{c}=$ initial tangent modulus (when $\varepsilon_{c}=0$ )

$E_{c}^{\prime}=f_{c}^{\prime} / \varepsilon_{c}^{\prime}$

$k=\mathrm{a}$ factor to control the slope of the descending branch of the stress-strain curve

The constants $\varepsilon_{c}^{\prime}$, $\mathrm{n}, \mathrm{k}$ can be obtained from the relationships given by Collins and Mitchell (1990) which are shown in equations 4.3 to 4.5 . For normal density concrete $n$ and $k$ can be taken as

$$
\begin{array}{ll}
\text { For } \varepsilon_{c} / \varepsilon_{c}^{\prime} \leq 1.0, & k=1.0 \\
\text { For } \varepsilon_{c} / \varepsilon_{c}^{\prime}>1.0, & k=0.67+\frac{f_{c}^{\prime}}{62} \geq 1.0 \\
n=0.8+\frac{f_{c}^{\prime}}{17} &
\end{array}
$$


If $\mathrm{n}, f_{c}^{\prime}$ and $E_{\dot{c}}$ are known, the strain at peak stress can be computed as:

$$
\varepsilon_{c}^{\prime}=\frac{f_{c}^{\prime}}{E_{c}}\left(\frac{n}{n-1}\right)
$$

By calculating $k, n$ and $\varepsilon_{c}^{\prime}$ from equations $4.3,4.4$ and 4.5 , concrete compressive stresses $f_{c}$ for different strains are calculated from equation 4.6

$$
f_{c}=\frac{n\left(\varepsilon_{c} / \varepsilon_{c}^{\prime}\right) \times f_{c}^{\prime}}{n-1+\left(\varepsilon_{c} / \varepsilon_{c}^{\prime}\right)^{n k}}
$$

Figures 4.3 and 4.4 show the relationship between compressive stress and strain for 60 $\mathrm{MPa}$ and $50 \mathrm{MPa}$ concrete respectively.

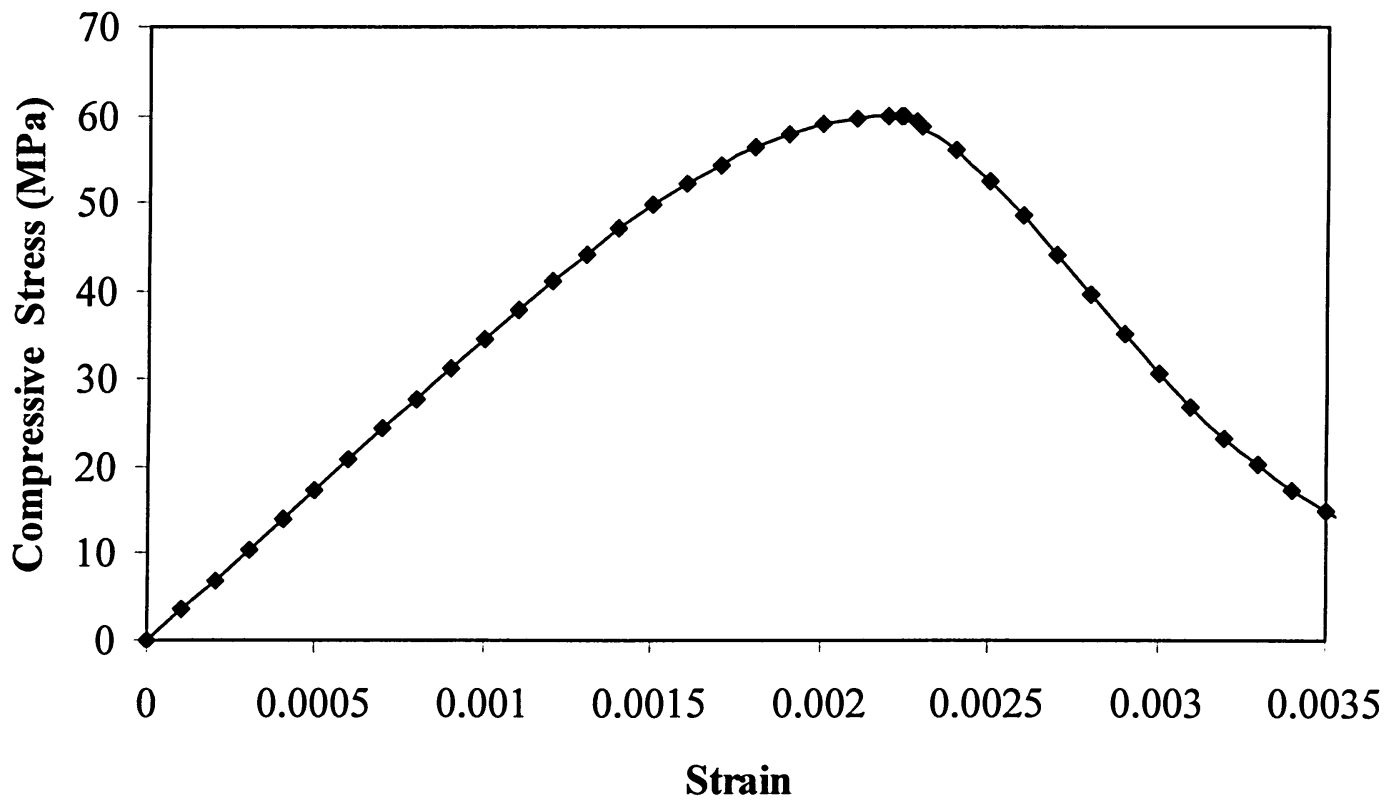

Figure 4.3: Variation of compressive stress with strain for $60 \mathrm{MPa}$ concrete 


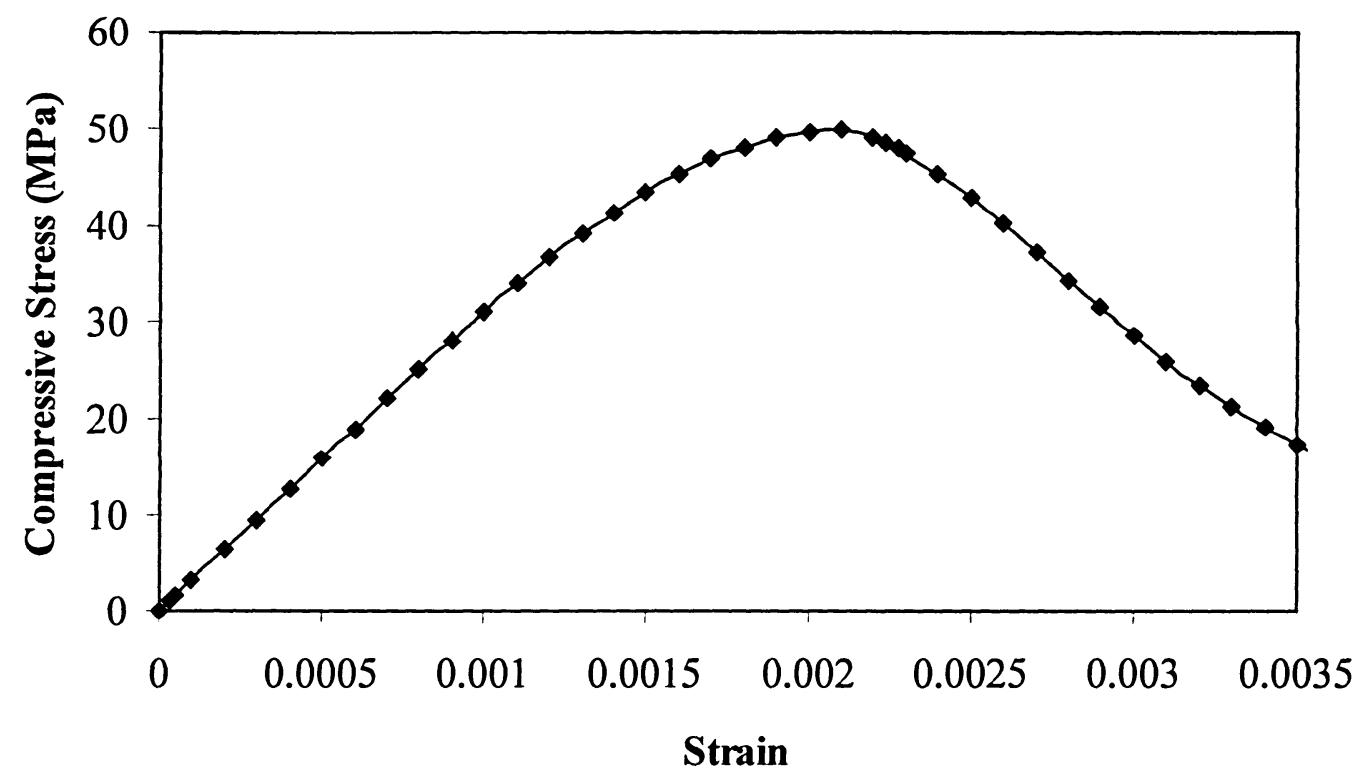

Figure 4.4: Variation of compressive stress with strain for 50 MPa concrete

From the total strain, the plastic strain is calculated using the following equations.

$$
\begin{aligned}
& \varepsilon_{p l}=\varepsilon_{t}-\varepsilon_{e l} \\
& \varepsilon_{e l}=\frac{f_{c}}{E_{c}}
\end{aligned}
$$

where,

$$
\begin{aligned}
& \varepsilon_{t}=\text { total strain } \\
& \varepsilon_{e l}=\text { elastic strain } \\
& \varepsilon_{p l}=\text { plastic strain } \\
& f_{c}=\text { compressive stress at } \varepsilon_{t} \\
& E_{c}=\text { modulus of elasticity }
\end{aligned}
$$


The plastic strains are calculated using equation 4.7 and plots of the compressive stress versus the plastic strain for both $60 \mathrm{MPa}$ and $50 \mathrm{MPa}$ concrete, respectively, are obtained (Figure 4.5 and 4.6).

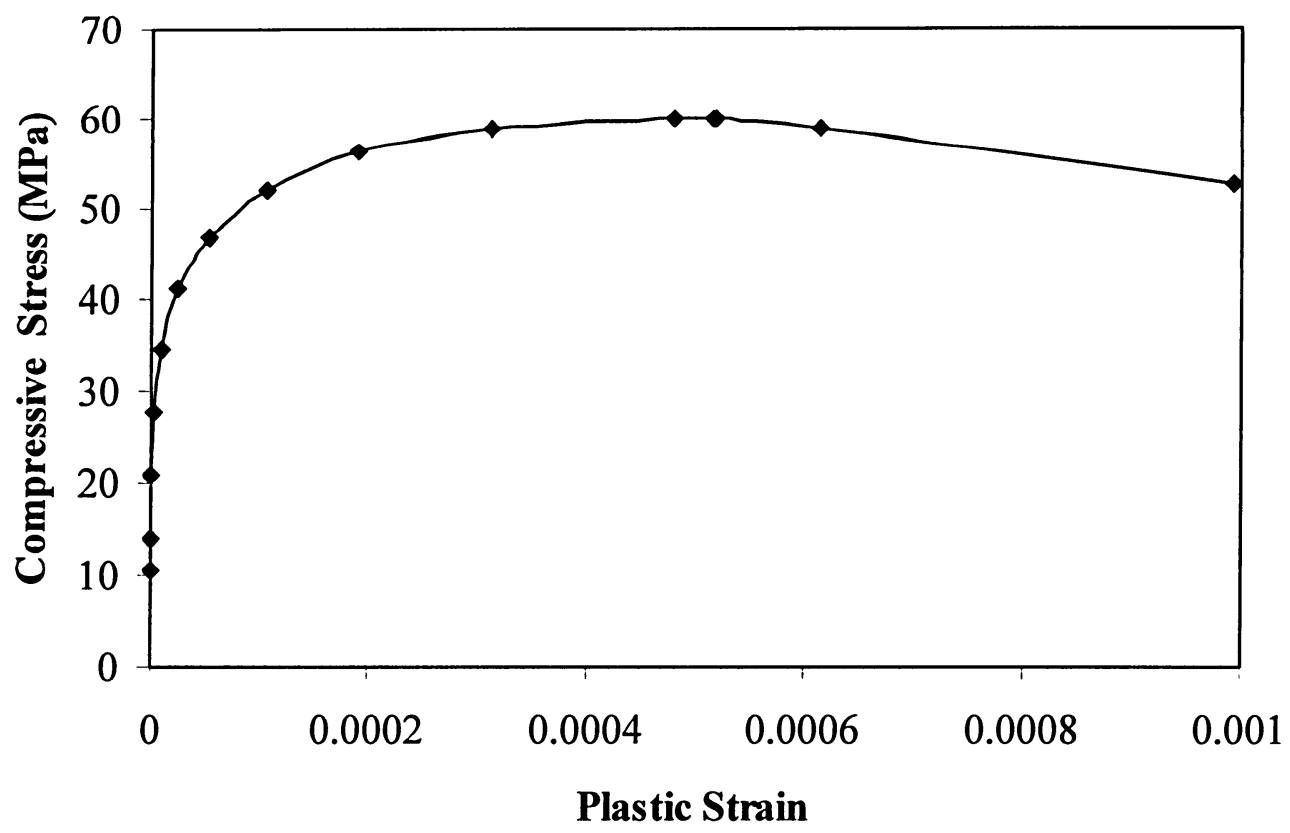

Figure 4.5: Variation of compressive stress with plastic strain for 60 MPa concrete

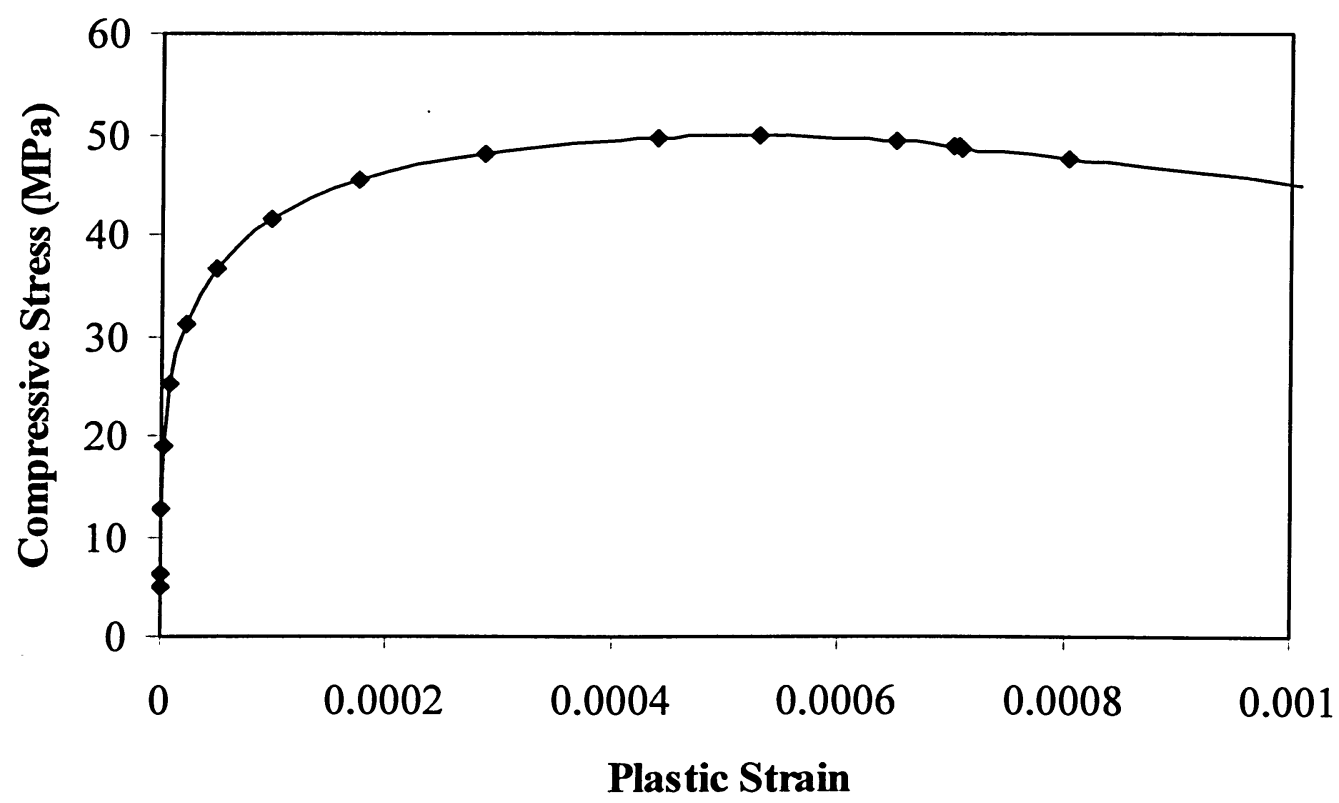

Figure 4.6: Variation of compressive stress with plastic strain for 50 MPa concrete 


\subsubsection{Concrete Smeared Cracking Model}

The concrete smeared cracking model was used to express the behaviour of concrete after cracking. In smeared crack model, the individual microcracks are not considered. The constitutive characteristic calculations are performed independently at each integration point of the finite element model and the presence of cracks enters into these calculations in which the cracks influence the stress and material stiffness associated with the integration point.

The model consists of following parameters:

- Tension stiffening

- Stress ratios and strain ratio to define failure surfaces

\subsection{Tension Stiffening}

The tensile force in a reinforced concrete member is carried by both the reinforcing steel and the surrounding concrete. The tension stiffening effect represents the capacity of the concrete between cracks to continue to carry tensile stresses and contribute to the overall stiffness. Figure 4.7 represents the variation of tensile stress with tensile strain for both the bare bar and the embedded bar. Figure 4.7 shows that at same tensile stress, the strain in the embedded bar is less than the strain in the bare bar. This smaller strain in the embedded bar is due to the contribution of concrete in carrying tensile stress. This phenomenon is termed as tension stiffening.

Tension stiffening option is used to define the behaviour of concrete after cracking. The postfailure behaviour for direct straining across cracks is modeled with the tension stiffening option which defines the strain-softening behaviour for the cracked concrete. This option is used to define the residual tensile stress of the concrete normal to a crack as a function of the deformation in the direction of the normal to the crack. Tension stiffening describes the reinforcement interaction with concrete in a simple manner. 


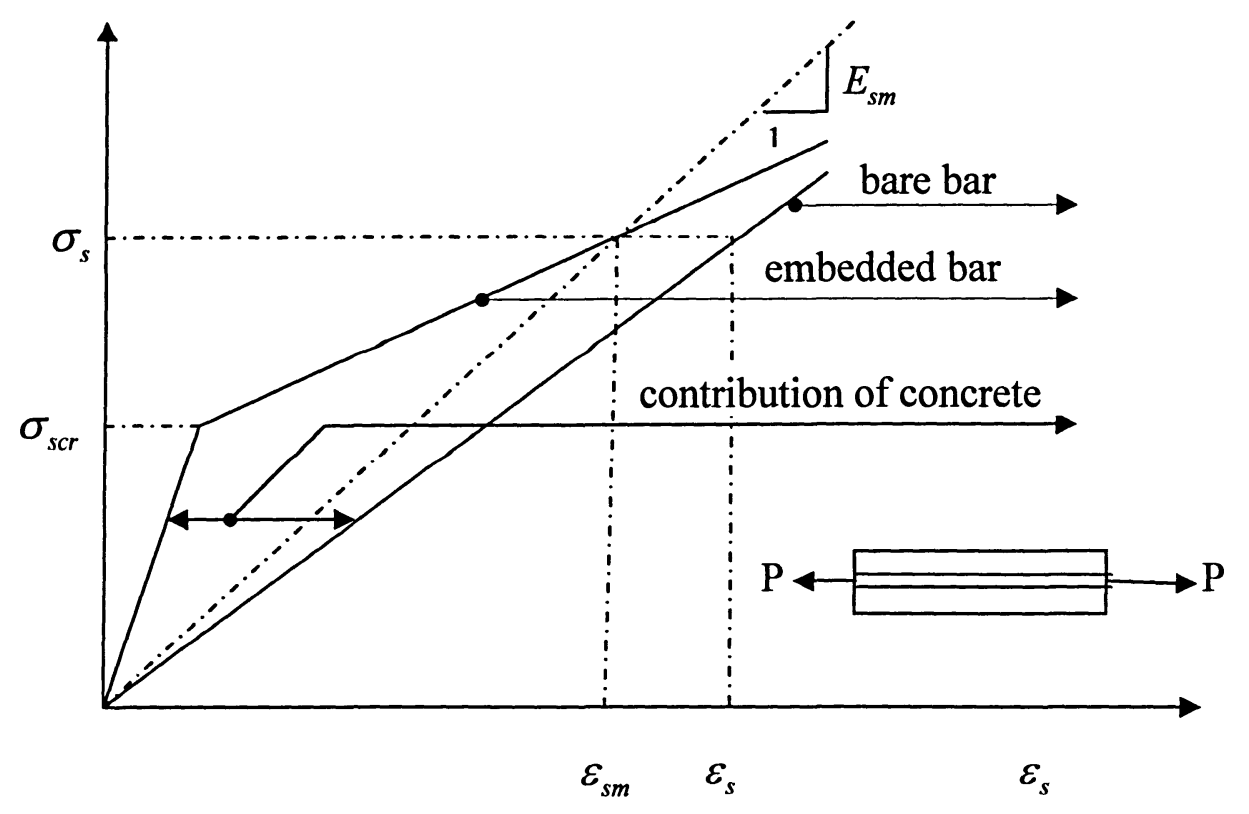

Figure 4.7: Tensile stiffening: Tensile stress versus tensile strain

The postfailure stress-strain relationship is used to express the tension stiffening. In postfailure stress-strain relationship, postfailure stress is used as a function of strain across the crack. Figure 4.8 shows the tension stiffening model where the tensile stress of concrete is a function of the tensile strain. In Figure 4.8 the concrete starts crack when it reaches the tensile strength $\sigma_{1}^{u}$ and after that point tensile stress at the crack is assumed to decrease to zero linearly, which describes the strain softening behaviour of concrete. 


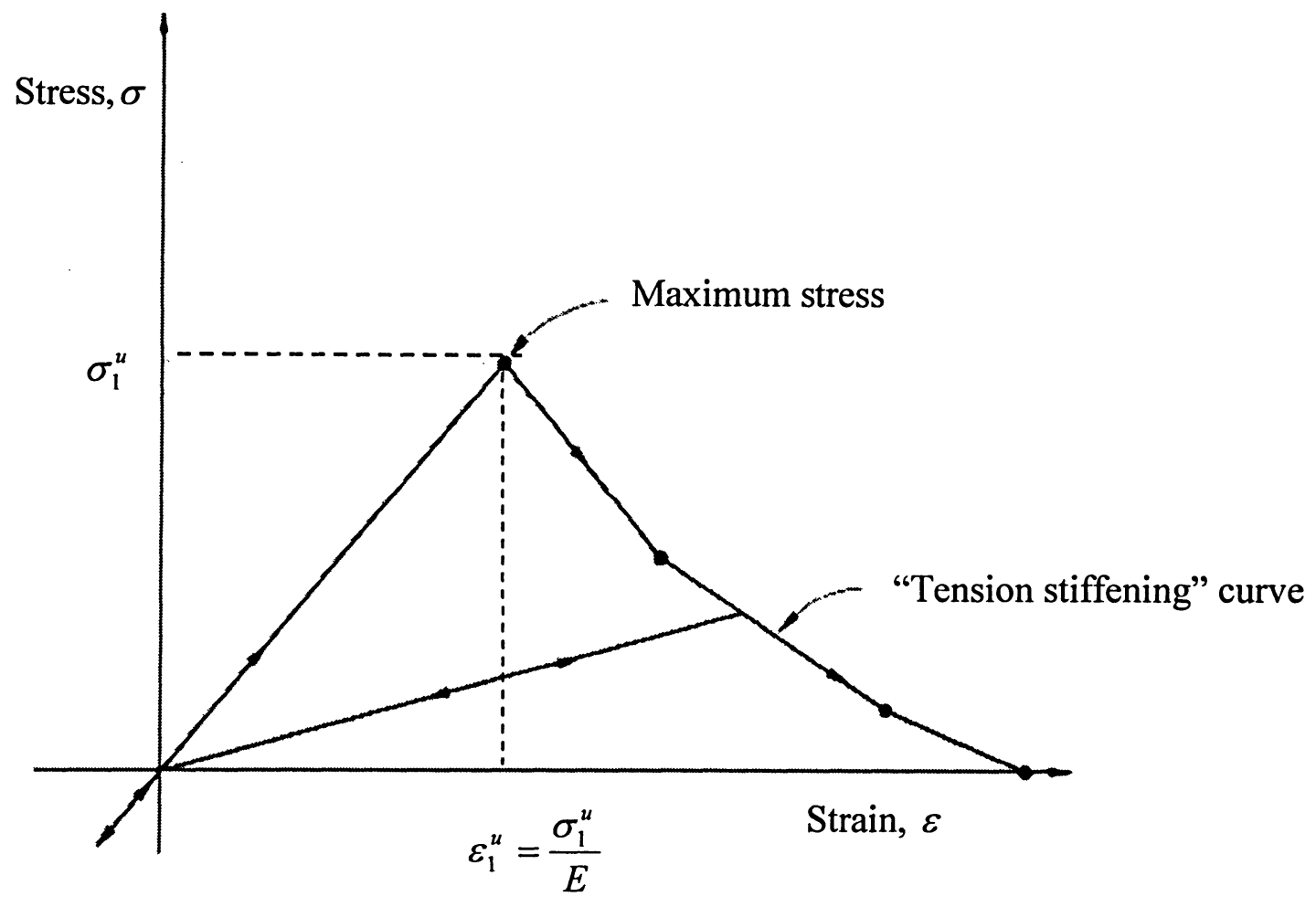

Figure 4.8: Tension Stiffening model using post failure stress-strain characteristics (Abaqus/Standard Manual, Volume 2)

\section{Input for tension stiffening}

Figure 4.9 shows the variation of the ratio of tensile stress to the cracking tensile strength $\left(\sigma / \sigma_{1}^{u}\right)$ with the difference between the direct strain and the cracking strain $\left(\varepsilon-\varepsilon_{1}^{u}\right)$. It is assumed that the strain softening after failure reduces the stress linearly to zero at a total strain of about 10 times the strain at the maximum stress. The strain at failure in standard concretes is typically $10^{-4}$, which suggests that tension stiffening that reduces the stress to zero at a total strain of about $10^{-3}$ is reasonable (Abaqus/Standard User Manual, Volume 2). According to the manual, the difference between the strain at failure and the strain at zero tensile stress is 0.0009 . However, in the present investigation, this parameter is calibrated to 0.001 where it gave very good match with the experimental results. In Figure 4.8, the point $\mathrm{A}$ is the maximum stress point and the point $\mathrm{B}$ is the point when 
tensile stress is reduced to zero. The coordinates of points A and B are defined in the analysis and are shown in Table 4.2.

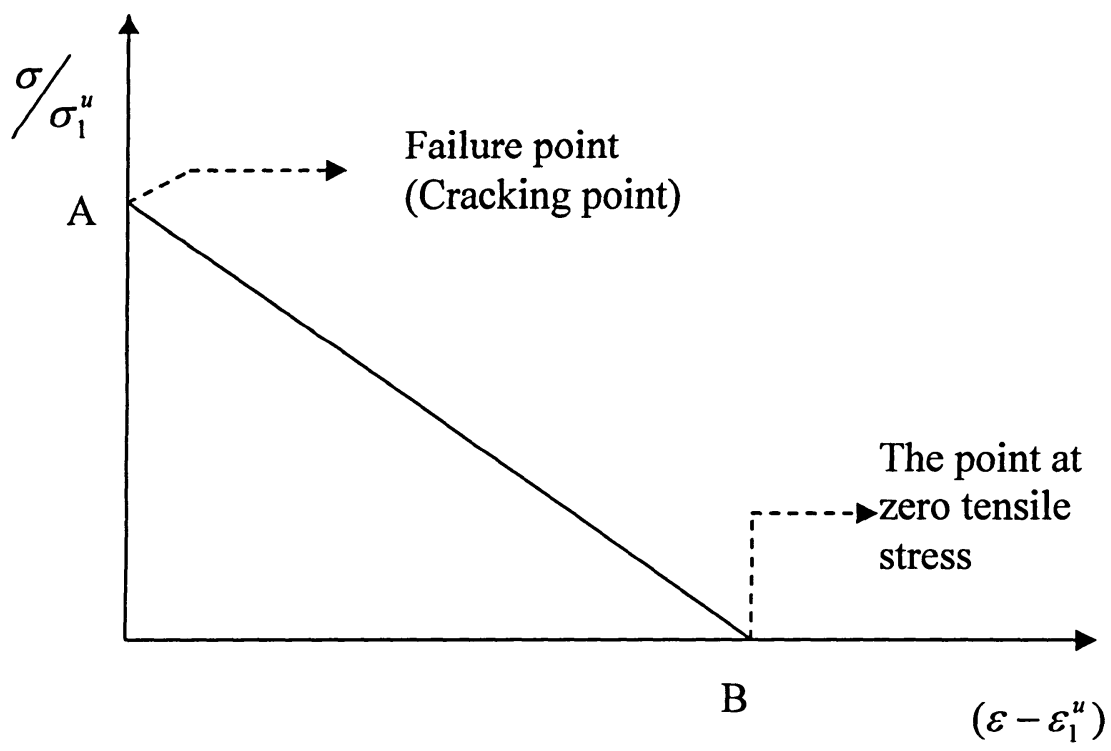

Figure 4.9: Variation of the ratio of tensile stress to cracking tensile strength with the difference between direct strain and the cracking strain

Table 4.2: Input data for tension stiffening

\begin{tabular}{|c|c|}
\hline $\begin{array}{c}\text { Fraction of remaining stress to stress at } \\
\text { cracking }\end{array}$ & $\begin{array}{c}\text { Absolute value of the direct strain minus the } \\
\text { direct strain at cracking }\end{array}$ \\
\hline 1 & 0 \\
\hline 0 & 0.001 \\
\hline
\end{tabular}




\subsection{Stress Ratios and Strain Ratio to Define Failure Surface}

ABAQUS uses failure ratios to define the shape of the failure curves for the concrete model. Four values can be entered as data for this option:

1) The ratio of the ultimate biaxial compressive stress to the ultimate uniaxial compressive stress. The default value is 1.16 .

2) The absolute value of the ratio of the uniaxial tensile stress at failure to the ultimate uniaxial compressive stress.

3) The ratio of the magnitude of a principal component of plastic strain at ultimate stress in biaxial compression to the plastic strain at ultimate stress in uniaxial compression. The default value is 1.28 .

4) The ratio of the principal tensile stress at cracking, in plane stress, when the other principal stress is at the ultimate compressive value, to the cracking tensile stress under uniaxial tension. The default value is $1 / 3$.

The Figure 4.10 represents the failure surfaces for the concrete where $\sigma_{1}$ and $\sigma_{2}$ represent the principle stresses in directions 1 and 2, respectively. The point 'biaxial tension stress' means pure tension in both directions 1 and 2. Similarly 'biaxial compression stress' means pure compression in both directions 1 and 2. 'Compressive yield surface' represents the inelastic response of the concrete when the principal stresses are dominantly compressive. 'The crack detection surface' determines the stress at which crack takes place. 


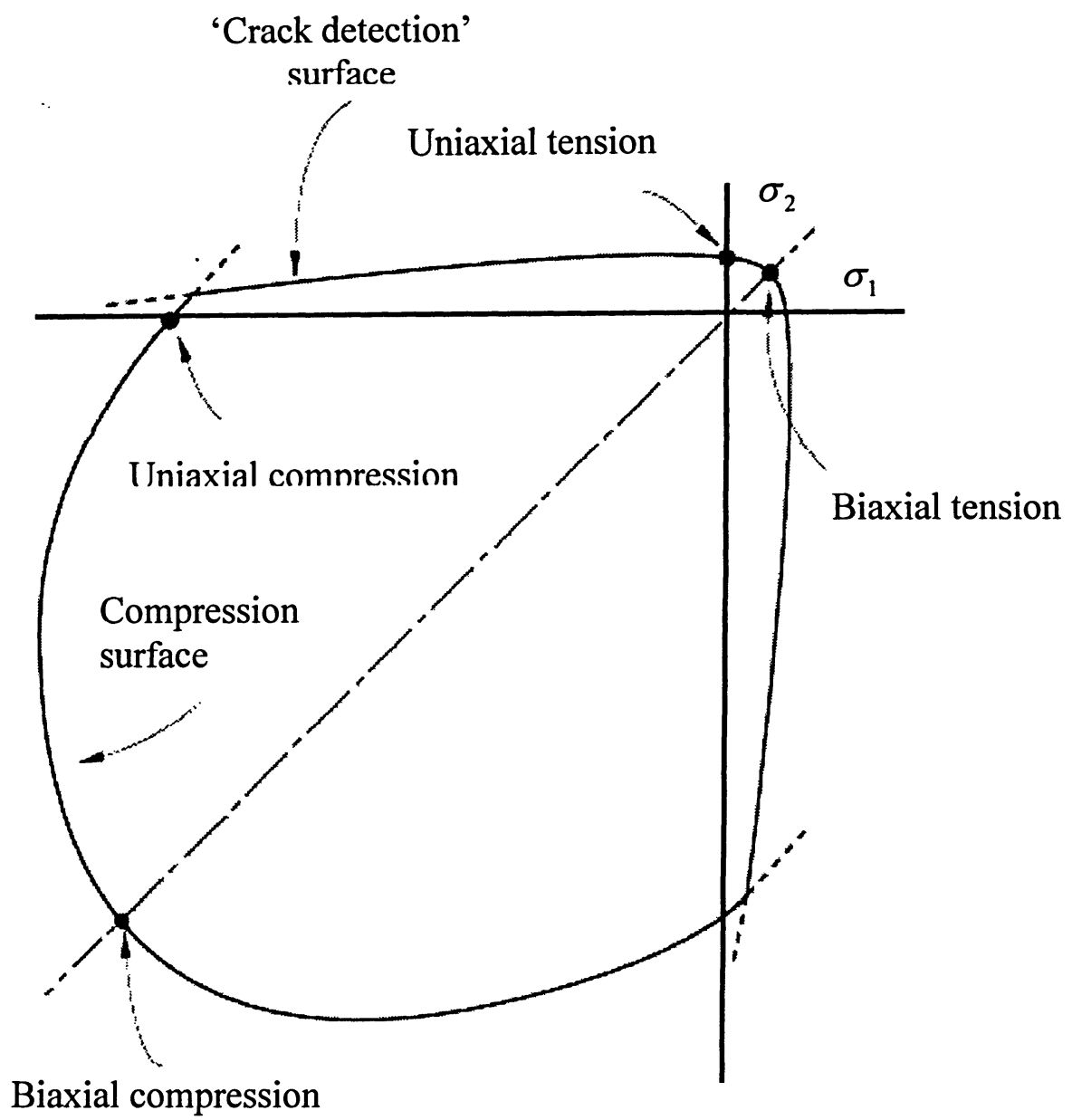

Figure 4.10: Failure surfaces in plane stress

(Abaqus/Standard Manual, Volume 2)

Input data for bond model:

Default values are used for stress ratio 1 and 4 and strain ratio 3 due to the unavailability of data. Stress ratio 2 was calculated, for example for $60 \mathrm{MPa}$ concrete:

Stress ratio $2=($ Uniaxial tensile stress at failure $) /$ (Ultimate uniaxial compressive stress)

$$
=\frac{f_{t}^{\prime}}{f_{c}^{\prime}}=\frac{0.6 \sqrt{60}}{60}=0.07745
$$


Where tensile strength of concrete is estimated using the following expression

$$
f_{t}^{\prime}=0.6 \sqrt{f_{c}^{\prime}}
$$

The input data for the stress ratios and the strain ratio are shown in Table 4.3.

Table 4.3: Data input of stress ratios and strain ratio

\begin{tabular}{|c|c|c|c|c|}
\hline Concrete type & Stress ratio 1 & Stress ratio 2 & Strain ratio 3 & Stress ratio 4 \\
\hline $60 \mathrm{MPa}$ concrete & 1.16 & 0.07745 & 1.28 & 0.3333 \\
\hline $50 \mathrm{MPa}$ concrete & 1.16 & 0.08489 & 1.28 & 0.3333 \\
\hline
\end{tabular}

\subsection{Material Properties of Reinforcing Steel}

Two types of properties are used.

1) Elastic properties

2) Plastic properties

The properties of reinforcing steel obtained from the experimental data that are used in the analysis are:

Bar size: $20 \mathrm{~mm}$ diameter

Yield strength: $433 \mathrm{MPa}$

Modulus of elasticity, $\mathrm{E}_{\mathrm{s}}: 200,000 \mathrm{MPa}$

\subsection{Modeling Contact Interface between Reinforcing Steel and Concrete}

Many engineering problems involve contact between two or more components. In these problems, a force normal to the contact surfaces acts on the two bodies, when they touch each other. If there is friction between the surfaces, shear forces can be created that resist the tangential motion (sliding) of the bodies. 
There are three steps in defining a contact simulation:

1) Defining the surfaces of the bodies that could potentially be in contact.

2) Specifying which surfaces interact with one another.

3) Defining the mechanical and thermal surface interaction models that govern the behaviour of the surfaces when they are in contact.

\subsubsection{Defining Contact Surfaces}

The inner surface of concrete cylinder and the outer surface of steel bar, which are in contact with each other, are defined in the model.

ABAQUS uses a pure master-slave contact algorithm. Nodes on one surface (the slave) cannot penetrate the segments that make up the other surface (the master), as shown in Figure 4.11.

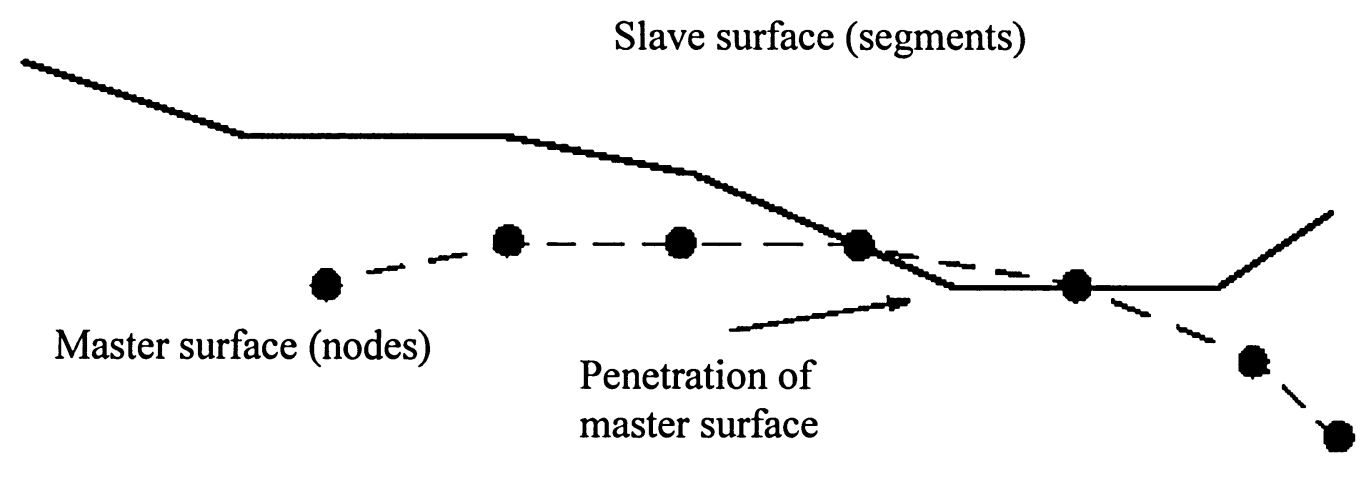

Figure 4.11: Master surface and slave surface

(Abaqus/Standard User's Manual Volume 3)

Criteria for choosing the master and the slave surface of a contact pair between two bodies:

When both surfaces are deformable, the master surface should be chosen as the surface of the stiffer body or as the surface with a coarser mesh. In the case of reinforced concrete 
the two surfaces in contact are the inner surface of the concrete cylinder and the outer surface of the steel bar.

The stiffness of the concrete cylinder, $K_{1}=\frac{A E}{L}=3.69 \times 10^{5} \mathrm{~N} / \mathrm{mm}$ (considering $25 \mathrm{~mm}$ cover specimen and compressive strength as $50 \mathrm{MPa}$ )

The stiffness of steel bar, $K_{2}=\frac{A E}{L}=2.2 \times 10^{5} \mathrm{~N} / \mathrm{mm}$

Because the concrete cylinder is stiffer than the bar, the analysis used the inner surface of concrete cylinder as the master surface and the outer surface of steel bar as the slave surface. Figure 4.12 and 4.13 show the slave and master surfaces that were used in the analysis.

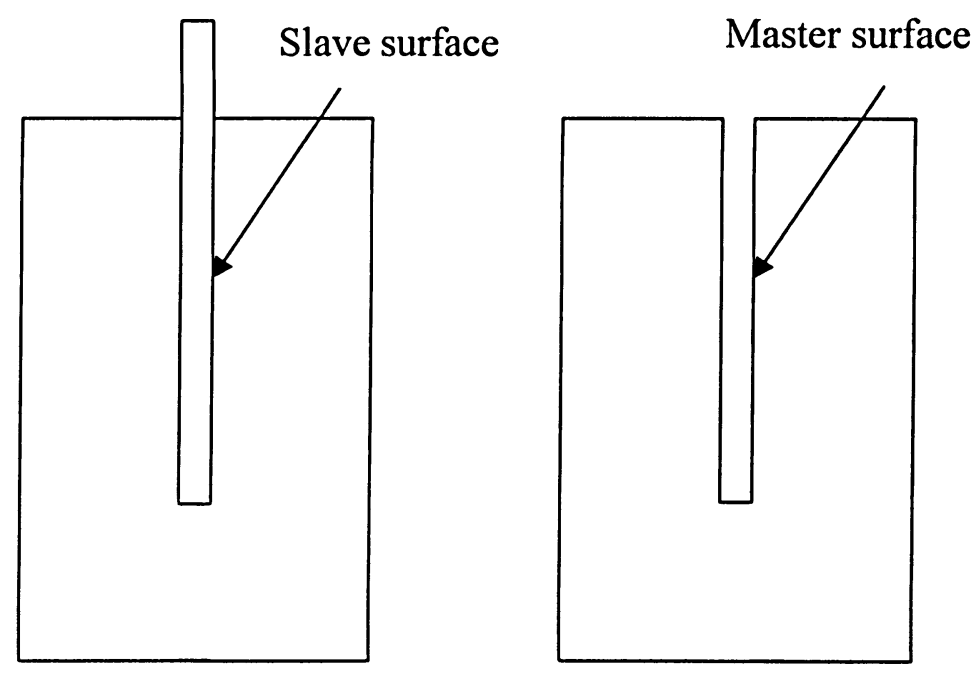

Figure 4.12: Master and slave surface used in the analysis 


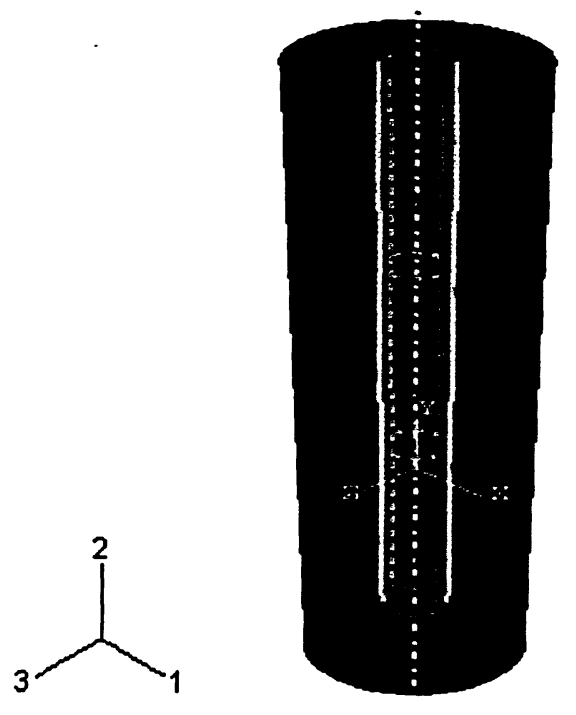

Master surface: the red surface

Slave surface: the pink surface

Figure 4.13: Master and slave surface in three dimensions

\subsubsection{Modeling Contact Pressure and Friction}

There are different methods for defining the components of a mechanical surface interaction model (Abaqus/Standard User's Manual, Volume 3)

- Friction (Interaction tangential to the surface)

- Relative surface motion

- Softened contact (Interaction normal to the surface)

\subsubsection{Modeling the Contact Pressure}

The following contact pressure-overclosure relationships are used in ABAQUS to define the contact model:

- The "hard" contact relationship, which allows no penetration of the slave nodes into the master surface and no transfer of tensile stress across the interface; 
- A modified "hard" contact relationship, which allows some limited penetration of the slave nodes into the master surface and some transfer of tensile stress across the interface;

- A "softened" contact relationship in which the contact pressure is a linear function of the clearance between the surfaces;

- A "softened" contact relationship in which the contact pressure is an exponential function of the clearance between the surfaces;

- A "softened" contact relationship in which the contact pressure is a piecewise linear (tabular) function of the clearance between the surfaces;

- A relationship in which there is no separation of the surfaces once they contact;

- A clearance-dependent viscous damping relationship.

In this model, the softened contact, in which the contact pressure is an exponential function of the clearance between the surfaces, is used.

\section{"Softened" Contact Model}

Three types of "softened" contact relationships are available. The pressure-overclosure relationship can be prescribed by:

- Using an exponential law.

- Using a tabular piecewise- linear law.

- Using a linear law.

\section{Softened Contact Defined With an Exponential Law}

Figure 4.14 shows the softened contact at the contact interface where the $\mathrm{X}$ axis defines the clearance between the contact surfaces and $\mathrm{Y}$ axis defines the contact pressure which acts normal to the contact surfaces.

In softened contact, the surfaces begin to transmit contact pressure once the clearance between them, measured in the contact (normal) direction, reduces to $\mathrm{c}$. The contact 
pressure transmitted between the surfaces then increases exponentially as the clearance continues to diminish. Here, $\mathrm{p}^{0}$ is the contact pressure at zero clearance and $\mathrm{c}$ is the clearance between the surfaces at which contact pressure decreases to zero.

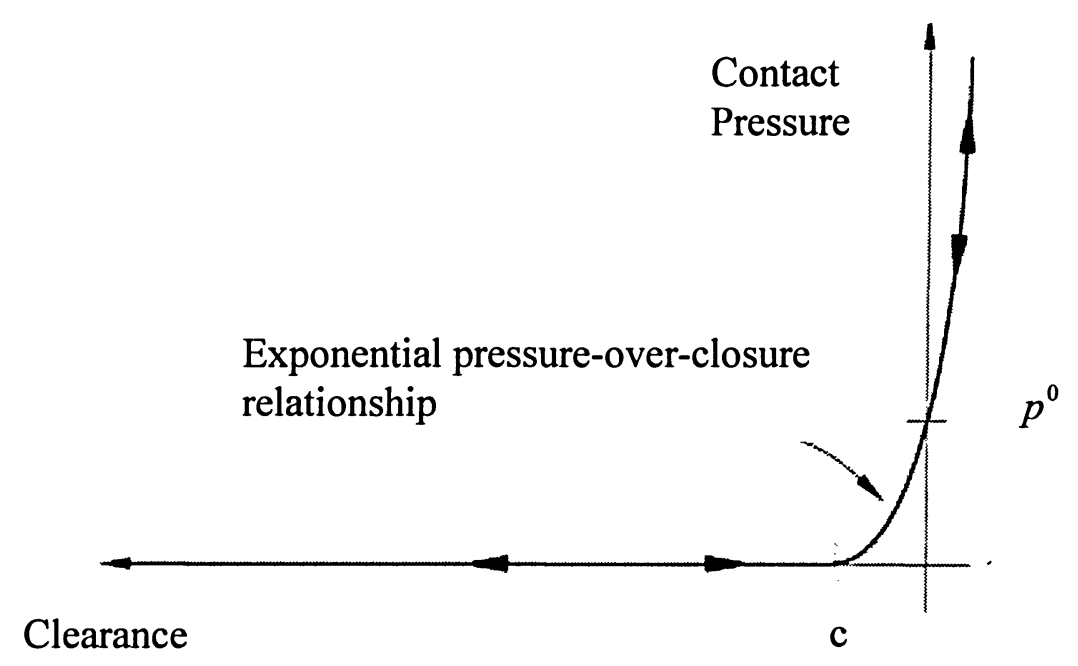

Figure 4.14: "Softened" pressure-overclosure relationship (Abaqus/Standard User Manual, Volume 3)

The equations showing the relationship between contact pressure and clearance are as follows.

$$
\begin{array}{ll}
p=0 & \text { for } h \leq-c \\
p=\frac{p^{0}}{(\exp (1)-1)}\left[\left(\frac{h}{c}+1\right)\left(\exp \left(\frac{h}{c}+1\right)-1\right)\right] & \text { for } h>-c
\end{array}
$$




$$
\begin{array}{ll}
\frac{d p}{d h}=0 & \text { for } h \leq-c \\
\frac{d p}{d h}=\frac{p^{0}}{(\exp (1)-1)}\left[\frac{1}{c}\left(\frac{h}{c}+2\right) \exp \left(\frac{h}{c}+1\right)-\frac{1}{c}\right] & \text { for } h>-c
\end{array}
$$

where,

$\mathrm{h}=$ the clearance between master and slave surface.

$\mathrm{c}=$ the clearance between master and slave surface at which contact pressure decreases to zero

\subsection{Modeling Contact Pressure at the Uncorroded-Steel Concrete Interface}

In the bond model, $\mathrm{p}^{0}$ varies with concrete cover thickness as it is the only variable. Different values of $\mathrm{p}^{0}$ are taken as a trial and the results are compared with the experimental results. When the results give better agreement with the experimental results then the data is taken as an input. Using regression analysis, an equation expressing the relationship between contact pressure at zero overclosure and the concrete cover thickness is derived which can be used to calculate contact pressure for any concrete cover thickness. Figure 4.15 shows the relationship between the contact pressure and the concrete cover thickness. 


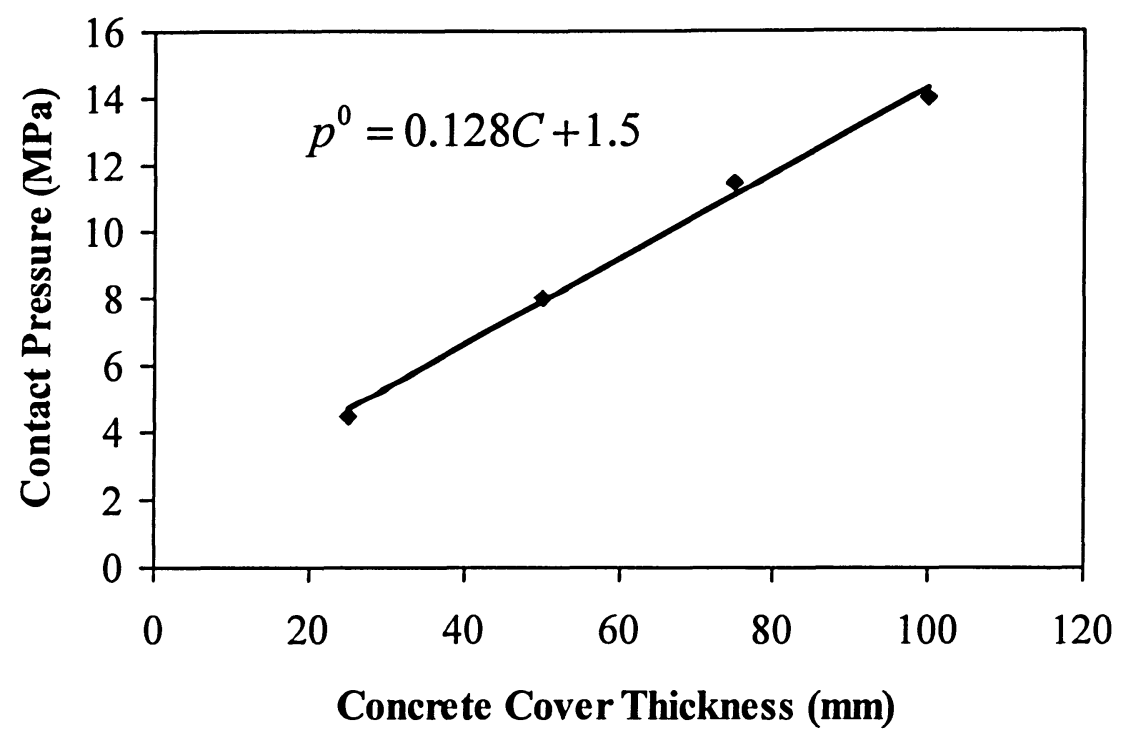

Figure 4.15: Variation of contact pressure with concrete cover thickness at the uncorroded steel-concrete interface

The equation 4.11 defines the relation of the contact pressure and the concrete cover thickness

$$
p^{0}=0.128 C+1.5
$$

where,

$$
\begin{aligned}
& p^{0}=\text { contact pressure } \\
& C=\text { concrete cover thickness }
\end{aligned}
$$

\subsection{Modeling Contact Pressure at the Corroded Steel-Concrete Interface}

The contact pressure at the steel-concrete interface decreases due to the corrosion of reinforcing steel. The expanded volume of corrosion products on the steel surface 
produces the radial and hoop stresses which cause high tensile forces in concrete and the longitudinal cracks are formed in concrete. With further volume expansion of corrosion products the width of longitudinal cracks increases and it propagates; this reduces the contact pressure gradually. At higher level of corrosion, the rib height decreases significantly due to the deterioration of the ribs. Due to large amount of degradation of lugs, the deformed bar act as a plain bar and the horizontal component of bearing force produced by mechanical interlocking is significantly reduced. Therefore, the deterioration of the rib height and the loss of effective cross-sectional area of reinforcing steel cause a significant decrease in the contact pressure. The flaky layer of the corrosion products decreases the holding capacity of the concrete which also reduces the contact pressure. The loss of contact pressure due to corrosion depends on several factors such as the mass loss of reinforcing steel, concrete cover thickness, compressive strength of concrete and the diameter of the steel bar. In the present analysis the variables are concrete cover thickness, mass loss of steel and compressive strength of concrete. For each concrete cover thickness, different contact pressures are used and compared with the experimental results. When the results match well with experimental results it is taken as an input. Figure 4.16 shows the variation of loss of contact pressure with mass loss of reinforcing steel for $60 \mathrm{MPa}$ concrete specimens. Equations showing how loss of contact pressure varies with mass loss for different concrete cover thickness are developed. For $60 \mathrm{MPa}$ concrete, equations $(4.12$, a) to $(4.12, d)$ show the loss of contact pressure with mass loss of steel for different concrete cover thickness and are:

$$
\begin{array}{ll}
L_{1}=3.88 M & \text { for } 25 \mathrm{~mm} \text { cover } \\
L_{2}=3.5 M & \text { for } 50 \mathrm{~mm} \text { cover } \\
L_{3}=3.1 M & \text { for } 75 \mathrm{~mm} \text { cover } \\
L_{4}=2.45 M & \text { for } 100 \mathrm{~mm} \text { cover }
\end{array}
$$

where,

$L_{1}, L_{2}, L_{3}, L_{4}=$ percentage loss of contact pressure for different cover thickness $M=$ percentage mass loss of reinforcing steel 
The constants of equations $(4.12$, a) to $(4.12$, d) are plotted against concrete cover thickness and by using regression analysis a general equation for all covers is developed as:

$$
L=(-0.0172 C+4.3) M
$$

where,

$L=$ percentage loss of contact pressure

$C=$ concrete cover thickness

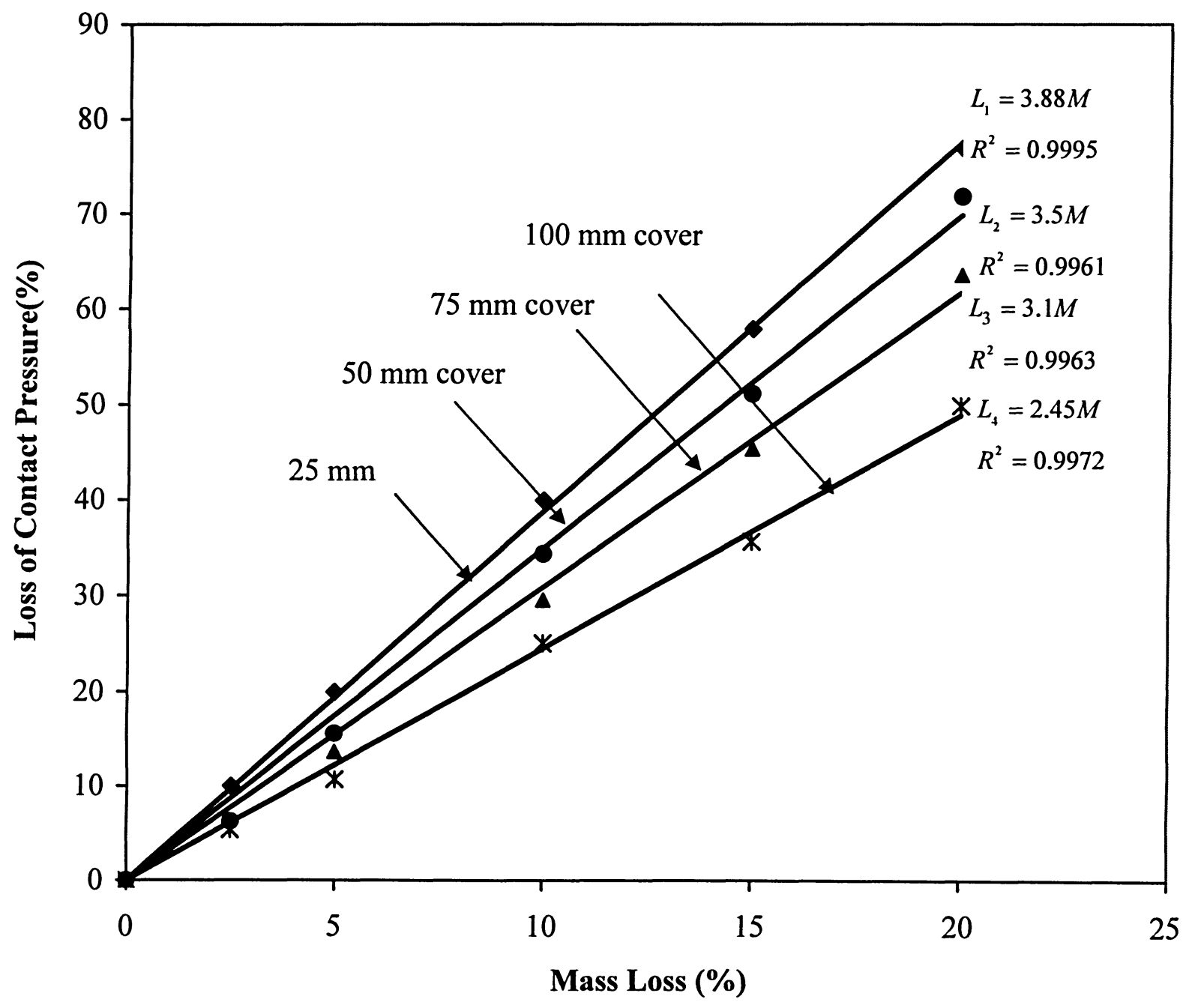

Figure 4.16: Loss of contact pressure at different level of corrosion for $60 \mathrm{MPa}$ concrete mixture 


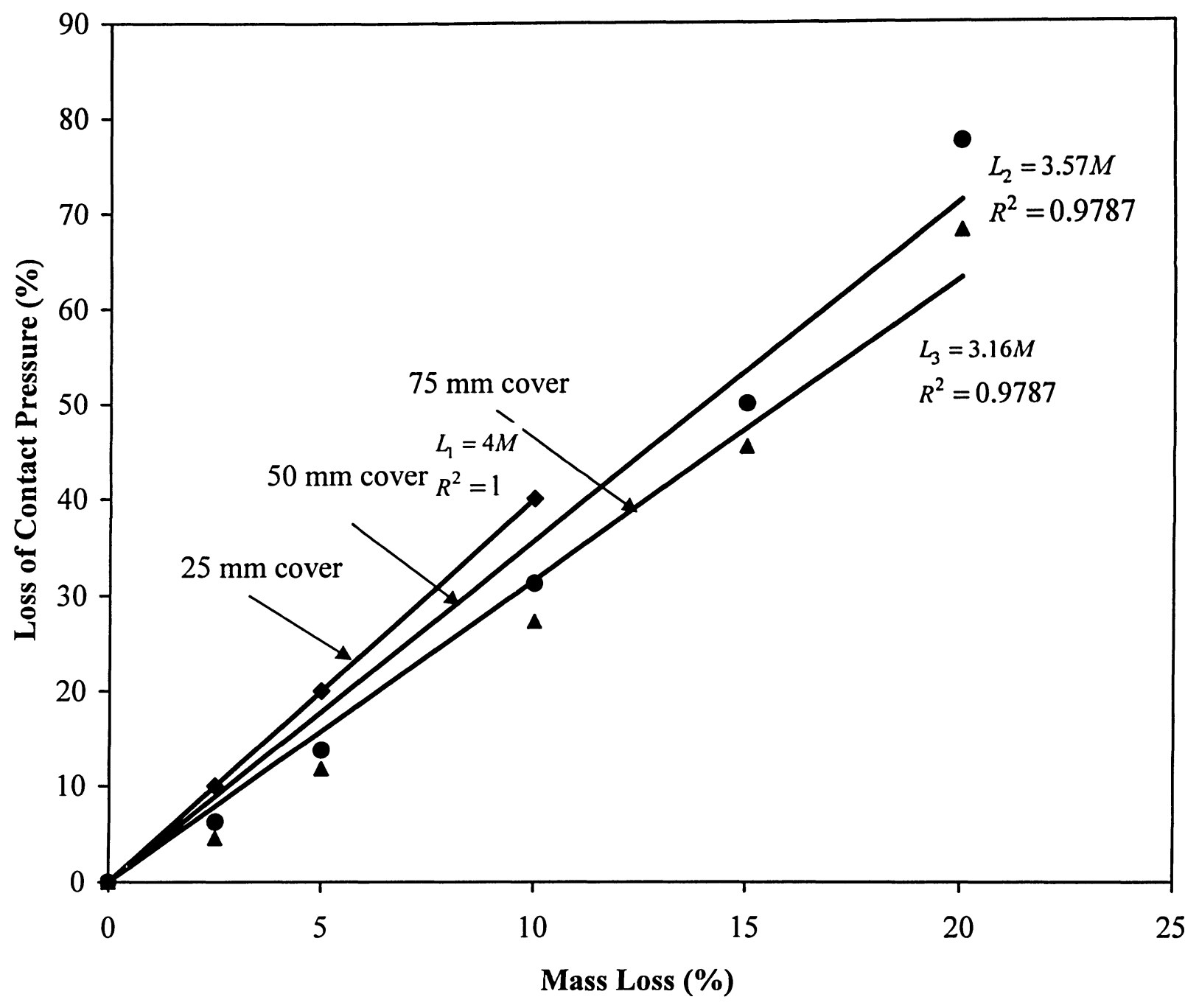

Figure 4.17: Loss of contact pressure at different level of corrosion for 50 MPa concrete mixture

The relationship between the losses of contact pressure with mass loss for different concrete cover thickness of $50 \mathrm{MPa}$ specimens are shown in Figure 4.17 and equations $(4.14$, a) to $(4.14, \mathrm{c})$.

$$
\begin{array}{ll}
L_{1}=4 M & \text { for } 25 \mathrm{~mm} \text { concrete cover thickness } \\
L_{2}=3.57 \mathrm{M} & \text { for } 50 \mathrm{~mm} \text { concrete cover thickness } \\
L_{3}=3.16 \mathrm{M} & \text { for } 75 \mathrm{~mm} \text { concrete cover thickness }
\end{array}
$$


By using regression analysis of the constants of equation $(4.14, a)$ to $(4.14$, c) with concrete cover thickness a general equation for $50 \mathrm{MPa}$ specimens is derived as:

$$
L=(-0.0148 C+4.3) M
$$

where,

$$
\begin{aligned}
& L=\text { percentage loss of contact pressure } \\
& C=\text { concrete cover thickness } \\
& M=\text { percentage mass loss of reinforcing steel }
\end{aligned}
$$

Combining equations (4.13) and (4.15), a general equation for all specimens is developed as:

$$
L=\left(\left(-0.00024 f_{c}^{\prime}-0.0028\right) C+4.3\right) M
$$

where,

$$
f_{c}^{\prime}=\text { compressive strength of concrete }
$$

So using the above equation, the loss of contact pressure at different level of corrosion for any specimen can be calculated.

\subsubsection{Modeling Friction at the Steel-Concrete Interface}

When surfaces are in contact, they usually transmit shear as well as normal forces across their interface. There is generally a relationship between these two force components. The relationship, known as the friction between the contacting bodies, is usually expressed in terms of the stresses at the interface of the bodies. The available friction model in ABAQUS (Abaqus /Standard User Manual volume, 3) is as follows:

- Extended version of the classical isotropic Coulomb friction model 
- Friction coefficient in terms of the slip, contact pressure, average surface temperature at the contact point and field variables

- Exponential decay friction model in which user can define a static and kinetic friction coefficient with a smooth transition zone defined by an exponential curve

- Shear stress limit which is the maximum value of shear stress that can be carried by the interface before the surfaces begin to slide

- Anisotropic friction model

- A stiffness (penalty) method

- Lagrange multiplier method to model sticking conditions exactly

Exponential decay friction model is the best for analyzing the friction at the steelconcrete interface.

\subsection{Modeling Friction Coefficient at the Uncorroded Steel-Concrete Interface}

In this model, it is assumed that the friction coefficient decays exponentially from the static value to the kinetic value according to the equation:

$$
\mu=\mu_{k}+\left(\mu_{s}-\mu_{k}\right) e^{-d_{c} \dot{\gamma}_{e q}}
$$

where,

$\mu_{k}$ is the kinetic friction coefficient - the friction coefficient at highest slip rate.

$\mu_{s}$ is the static friction coefficient - the friction coefficient that opposes the

initiation of slipping from a sticking condition. In the default model the static

friction coefficient corresponds to the value given at zero slip rates

$d_{c}$ is a user defined decay coefficient.

$\dot{\gamma}_{e q}$ is the slip.

Lundgren and Gylltoft (2000) developed a relationship between the friction coefficient and the slip using some tests results of Tepfers and Olsson (1992). The relationship is shown in Figure 4.18. 


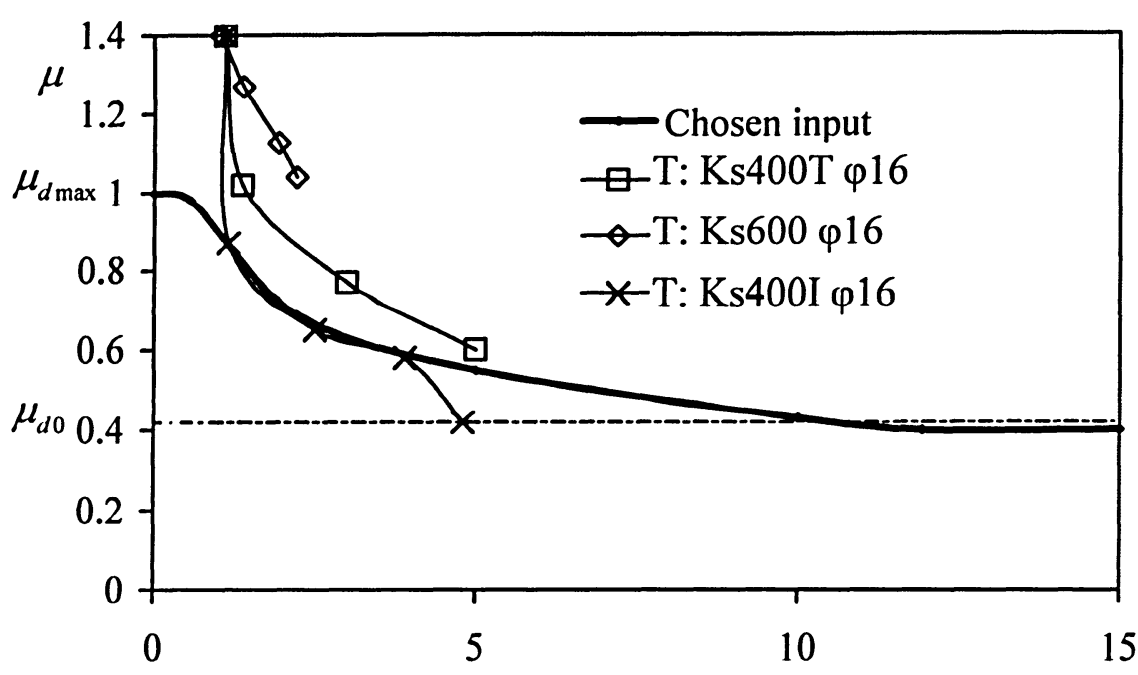

Slip, K: mm

Figure 4.18: The coefficient of friction as a function of the slip evaluated from tests of Tepfers and Olsson (1992) together with the chosen function of Lundgren and Gylltoft (2000)

From the graph developed by Lundgren and Gylltoft, it is clear that the value of static friction coefficient, $\mu_{s}=1$, Kinetic friction coefficient, $\mu_{k}=0.4$ and the values vary exponentially from the static to the kinetic condition.

In this model, these values of friction coefficient were adapted and used in equation 4.17. Different values of the decaying function, which should be less than 1 , are used. Figure 4.19 shows the variation of friction coefficient with slip for different values of $d_{c}$. It is clear from the figure that the curve with $d_{c}=0.45$ matches well with the Lundgren and Gylltoft's curve. Therefore $d_{c}=0.45$ is used. 


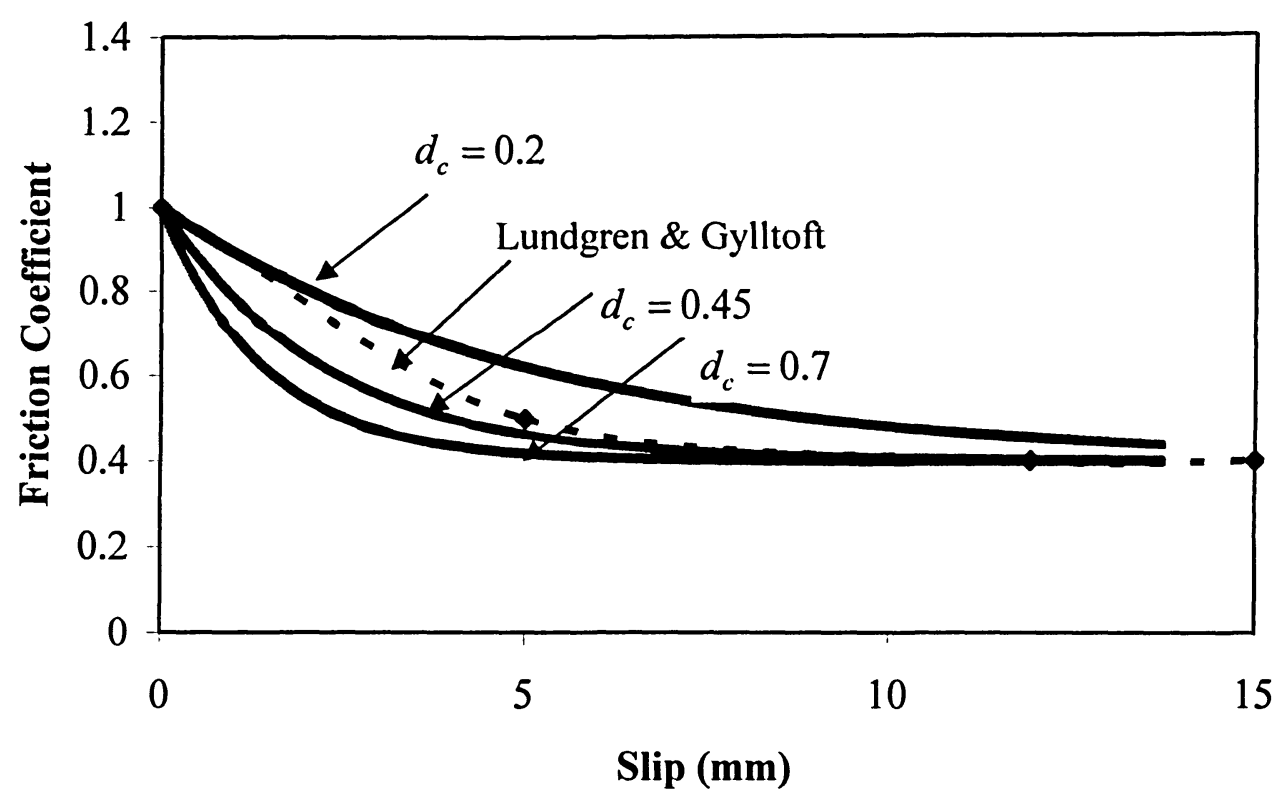

Figure 4.19: Friction model for different decay coefficients

The chosen inputs are:

Static friction coefficient, $\mu_{s}=1$

Kinetic friction coefficient, $\mu_{k}=0.4$

Decay coefficient, $d_{c}=0.45$

The above inputs are used in equation 4.17 and the friction coefficients for different slip are calculated. Figure 4.20 show the variation of friction coefficient with slip at the uncorroded steel concrete interface. 


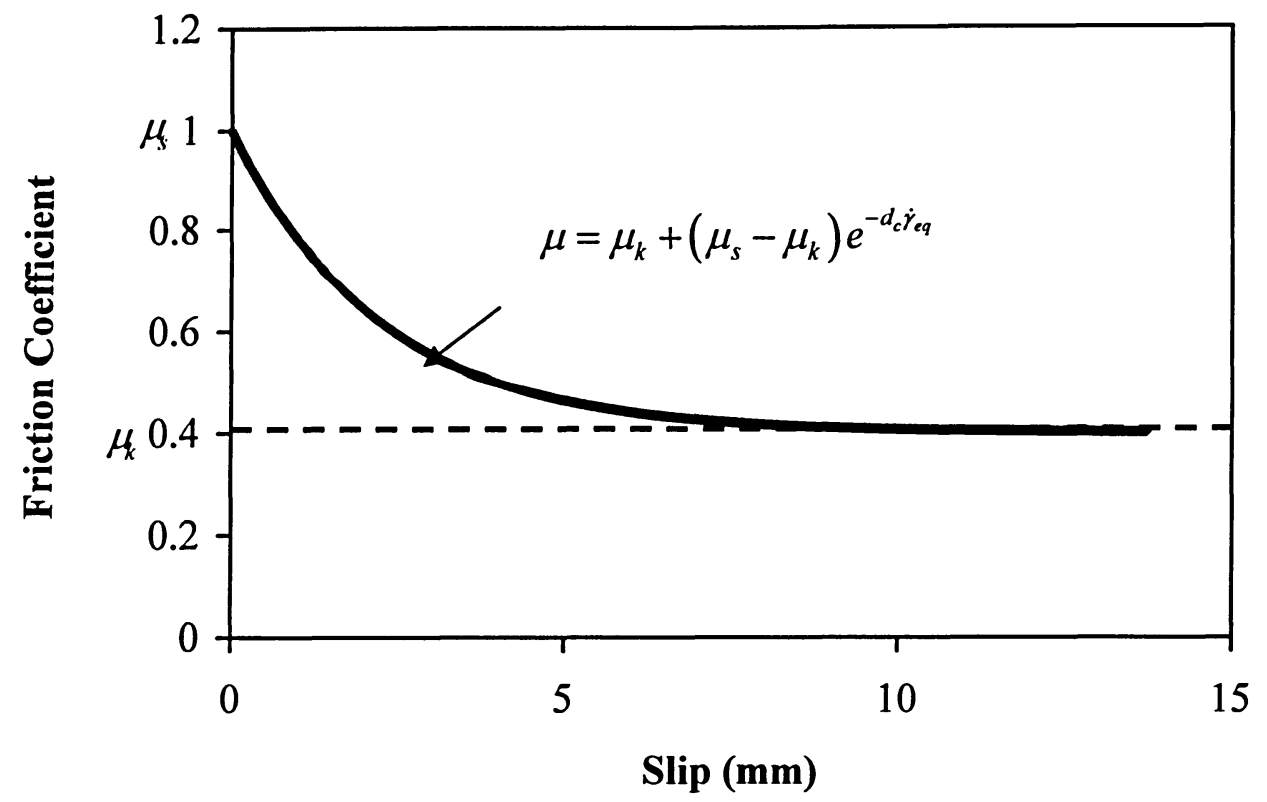

Figure 4.20: Exponential decay friction model used at the uncorrodedsteel-concrete interface

\subsection{Modeling Friction Coefficient at the Corroded Steel-Concrete Interface}

When the reinforcing steel is corroded, the accumulation of a heavy layer of the flaky corroded material around the bars acts as a lubricant and reduces the friction at the steelconcrete interface. The value of the kinetic friction coefficient is constant at 0.4 . The value of static friction coefficient decreases with the mass loss. Using parametric studies, the relationship between the static friction coefficient and mass loss is obtained. The variation of the decaying coefficient with mass loss is also obtained by parametric studies. Figures 4.21 and 4.22 show the variations of the static friction coefficient and the decaying function at different mass losses, which are obtained by regression analysis. 


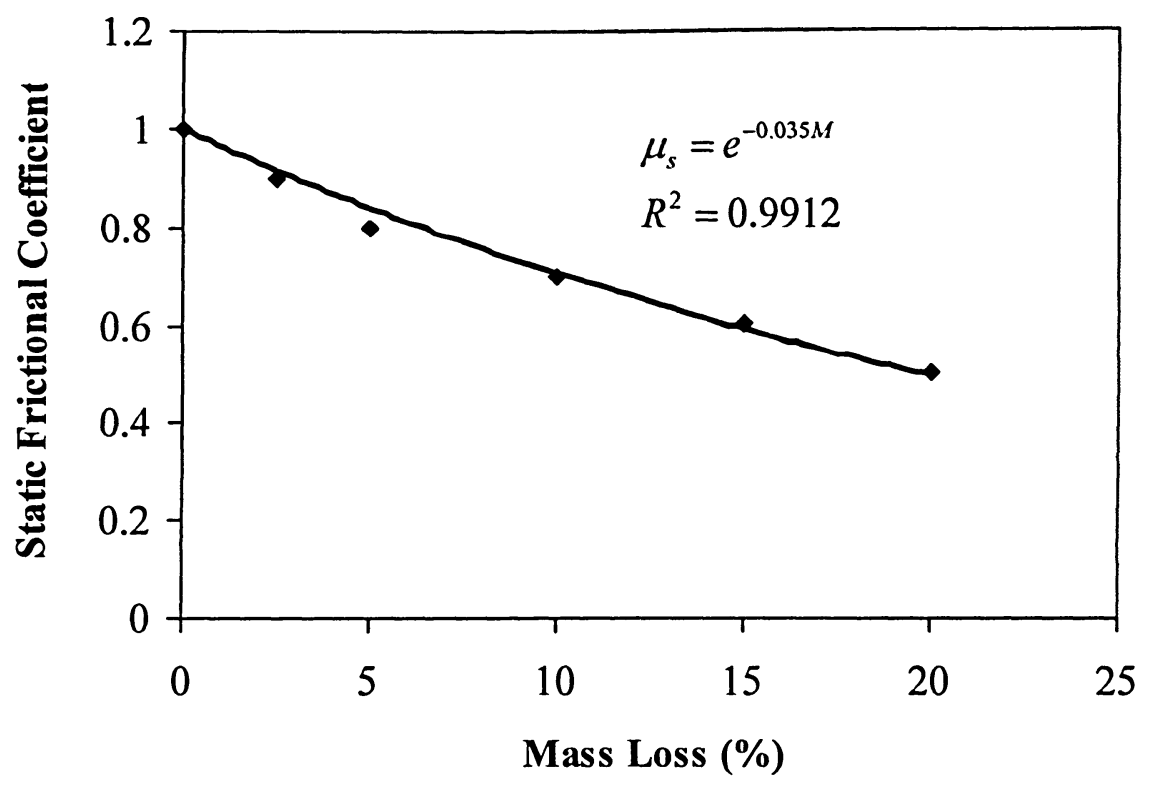

Figure 4.21: Variation of static friction coefficient with mass loss

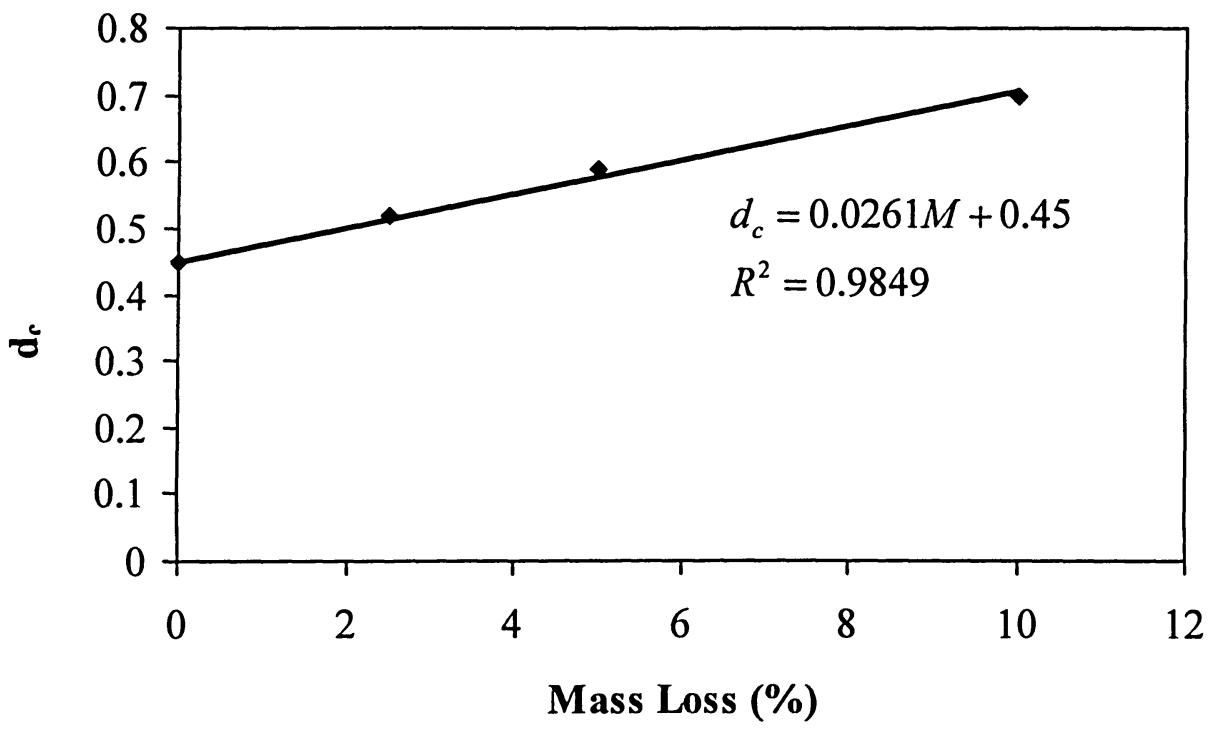

Figure 4.22: Variation of $d_{c}$ with mass loss 
From Figure 4.21, the relationship between the static friction coefficient and mass loss is obtained as:

$$
\mu_{s}=e^{-0.035 M}
$$

where,

$$
\begin{aligned}
& \mu_{s}=\text { static friction coefficient } \\
& M=\text { percentage of mass loss }
\end{aligned}
$$

Figure 4.22 shows the relationship between decaying coefficient and mass loss as:

$$
d_{c}=0.0261 M+0.45
$$

where,

$$
\begin{aligned}
& d_{c}=\text { decaying coefficient } \\
& M=\text { percentage of mass loss }
\end{aligned}
$$

Based on the above formulations (putting the value $\mu_{s}$ and $d_{c}$ from equations 4.18 and 4.19 into equation 4.17) an equation describing the effect of corrosion is developed as follows:

$$
\mu=\mu_{k}+\left(e^{(-0.035 M)}-\mu_{k}\right) e^{-(0.0261 M+0.45) \dot{r}_{e q}}
$$

Figure 4.23 shows the variation of friction coefficient with slip at different mass losses. From Figure 4.23 , it is clear that up to 5 to $10 \%$ mass loss, the decrease of friction coefficient is not significant. However when the mass loss is more than $10 \%$ the friction coefficient becomes very small, because at high level of corrosion, the flaky corroded layers of steel act as a lubricant which reduces the friction significantly. 


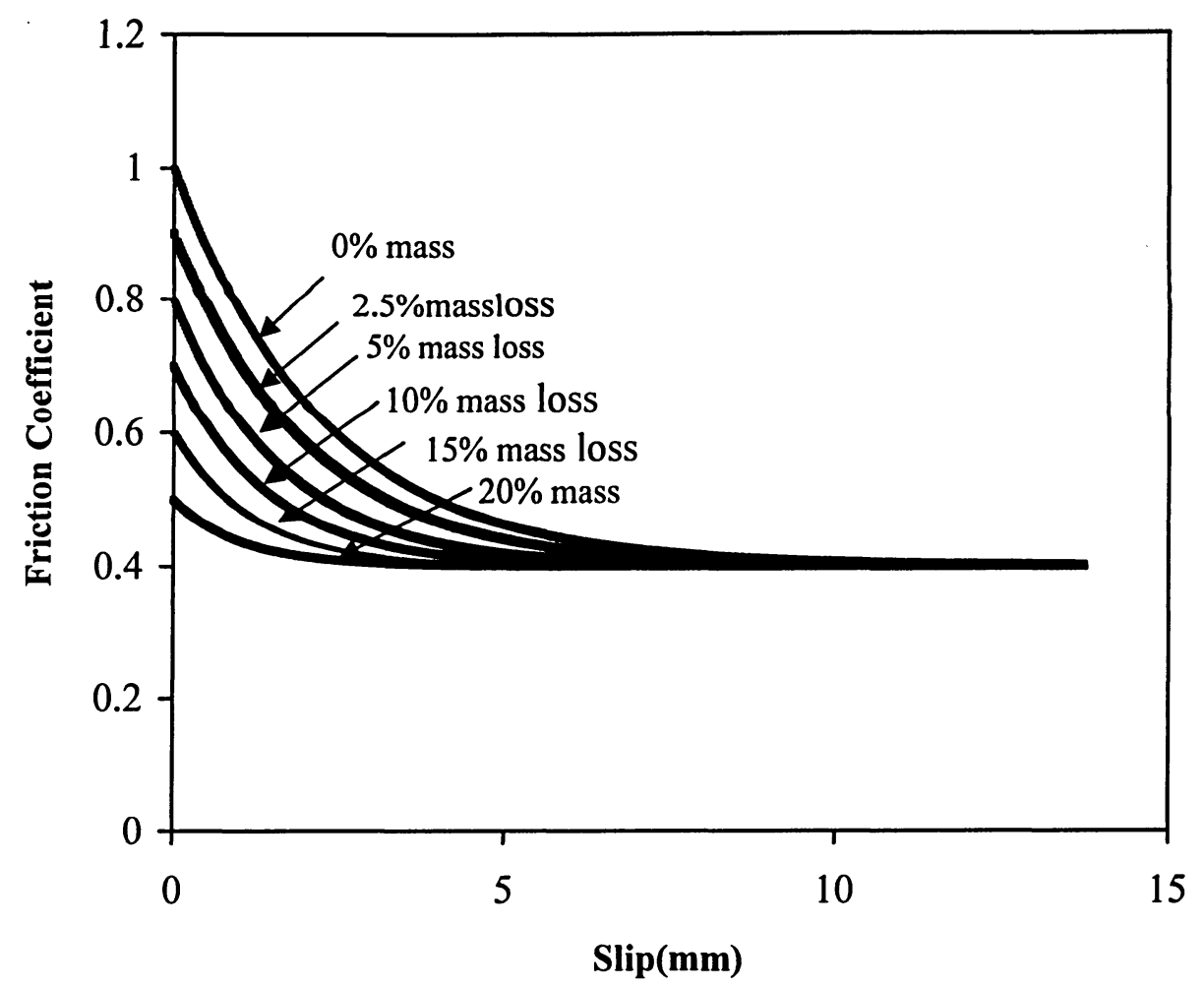

Figure 4.23: Variation of friction coefficient with slip at different mass losses

\subsection{Boundary Conditions of the Pull-out Test}

The top concrete surface of the cylinder was made fixed and a monotonic load was applied on the top surface of the reinforcement. For each load increment, the slip was measured at the loaded end of the reinforcing steel. Figure 4.24 and 4.25 show the specimen with the boundary condition and the load at the top surface. 

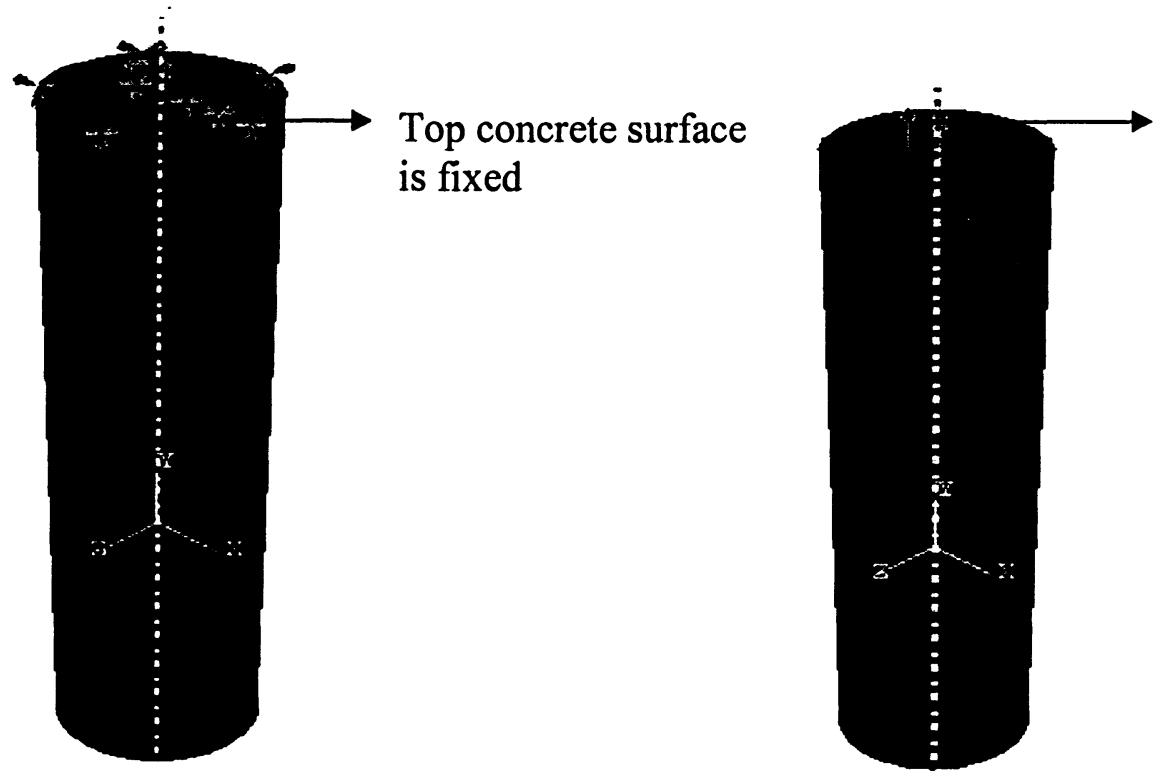

Load is applied on the top of the bar

Figure 4.24: Specimen with top surface fixed

Figure 4.25: Specimen with load at top of the reinforcement

\subsection{Developing the Mesh}

After applying the load and boundary conditions, the mesh for the specimen was developed using small elements as shown in Figure 4.26. Solid elements with eight nodes are used for developing mesh for both concrete and reinforcing steel.

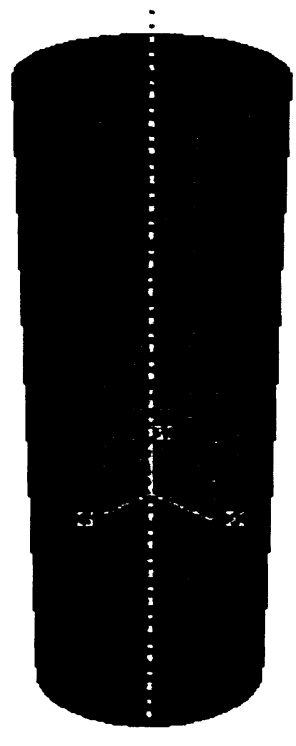

(a)

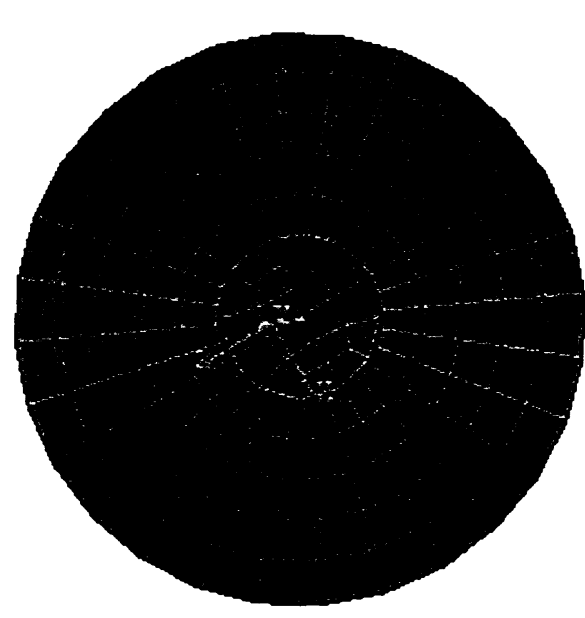

(b)

Figure 4.26: Specimen with finite element mesh (a) specimen in three dimension (b) Top view 


\subsection{Input File}

The input file for $25 \mathrm{~mm}$ cover specimen of $60 \mathrm{MPa}$ concrete is given below as a sample:

*Heading

** Job name: moni Model name: Model-1

$*$ Preprint, echo $=\mathrm{NO}$, model $=\mathrm{NO}$, history $=\mathrm{NO}$, contact $=\mathrm{NO}$

**

** PARTS

$* *$

*Part, name=bar

*End Part

*Part, name $=$ cylinder

*End Part

**

** ASSEMBLY

**

*Assembly, name=Assembly

**

*Instance, name $=$ cylinder -1 , part $=$ cylinder

*Node

$\begin{array}{rrrr}1, & 0 ., & 200 ., & -10 . \\ 2, & 0 ., & -80 ., & -10 . \\ 3, & 10 ., & -80 ., & 0 . \\ 4, & 10 ., & 200 ., & 0 .\end{array}$

*Element, type $=\mathrm{C} 3 \mathrm{D} 8$

$1,8,48,127,58,1,23,119,40$

** Region: (cylinder:Picked)

*Elset, elset=_PickedSet4, internal, generate

$1,92,1$

** Section: cylinder

*Solid Section, elset=_PickedSet4, material=concrete

1 .,

*End Instance

**

*Instance, name $=$ bar- 1 , part $=$ bar

*Node

$1, \quad 0 ., \quad-80 ., \quad 10$.

$2, \quad 0 ., \quad-80 ., \quad 0$.

$3, \quad 10 ., \quad-80 ., \quad 0$.

$4, \quad 0 ., \quad 200 ., \quad 10$.

$*$ Element, type $=\mathrm{C} 3 \mathrm{D} 8$

$1,76,13,68,142,11,1,12,67$

** Region: (bar:Picked) 
*Elset, elset $=$ _PickedSet2, internal, generate

$1,108,1$

** Section: bar

*Solid Section, elset=_PickedSet2, material=ster 1

1.

*End Instance

*Nset, nset $=$ PickedSet 8 , internal, instance $=$ cylinc $\cdot 3 r-1$

$1,4,7, \overline{8}, 9,12,15,16,40,58,76,94,0.5,97,99,101$

*Elset, elset $=$ PickedSet 8 , internal, instance $=$ cylind $t \mathrm{r}-1$

$1,10,19,28,45,54,63,72$

*Elset, elset $=$ _ PickedSurf6_S2, internal, instance $=$ cylinder-1, generate

$1,72,1$

*Surface, type=ELEMENT, name=_PickedSurf6, inter ral PickedSurf6 S2, S2

*Elset, elset $=$ PickedSurf7_S3, internal, instance $=$ bar $\cdot$ :

$1,2,3,4, \overline{13}, 14,15,16, \overline{17}, 23,24,25,26,27,28,2$ )

$30,31,45,46,47,48,49,63,64,65,66,77,78,79,80,81$

90, 91, 92, 93

*Elset, elset $=$ PickedSurf7_S4, internal, instance $=$ bar-1

$9,10,11, \overline{12}, 36,37,3 \overline{8}, 39,50,51,52,53,54,5: 60,61$

$62,72,73,74,75,76,86,87,88,89,94,95,96,9 ., 98,104$

105, 106, 107, 108

*Surface, type $=$ ELEMENT, name $=$-PickedSurf7, internal PickedSurf7 S3, S3

PickedSurf7_S4, S4

*Elset, elset $=$ _PickedSurf9_S3, internal, instance $=$ bar -1

18, 40, 50, 72, 94

*Elset, elset $=$ PickedSurf9 S4, internal, instance $=$ bar-1

17, 49, 71, $\overline{81}, 103$

*Elset, elset $=$ _ PickedSurf9_S2, internal, instance $=$ bar -1

23, 104

*Surface, type $=$ ELEMENT, name $=$ PickedSurf9, internal

_PickedSurf9_S3, S3

PickedSurf9 S4, S4

PickedSurf9_S2, S2

*End Assembly

**

** MATERIALS

\section{**}

$*$ Material, name $=$ concrete

*Concrete

10.46,

0.

$13.94,2.64318 \mathrm{e}-08$

$20.8954,5.37795 \mathrm{e}-07$

$27.7914,2.69795 \mathrm{e}-06$

$34.5436,8.98619 \mathrm{e}-06$ 
$41.0041,2.36424 \mathrm{e}-05$

$46.9552,5.29125 \mathrm{e}-05$

$52.117,0.000104829$

$56.1791,0.000188292$

$58.8586,0.000311418$

$59.9711,0.000479503$

$60 ., 0.000516674$

$59.9983,0.000516823$

$58.7604,0.000614238$

$52.5505,0.00099239$

*Failure Ratios

$1.16,0.07745, \quad 1.28,0.3333$

*Tension Stiffening

$1 ., \quad 0$.

$0 ., 0.001$

*Elastic

34857., 0.15

*Material, name $=$ steel

*Elastic

200000.,0.

*Plastic

433.,0.

**

** INTERACTION PROPERTIES

$* *$

*Surface Interaction, name=IntProp-1

1.,

*Friction, slip tolerance $=0.001$, exponential decay

1., $0.4,0.45$

*Surface Behavior, pressure-overclosure=EXPONENTIAL

2., 4.5

**

** BOUNDARY CONDITIONS

$* *$

** Name: BC-1 Type: Symmetry/Antisymmetry/Encastre

* Boundary

_PickedSet8, ENCASTRE

$\bar{*} *$

** INTERACTIONS

$* *$

** Interaction: Int-1

*Contact Pair, interaction=IntProp-1, small sliding, adjust $=25$.

_PickedSurf7,_PickedSurf6

**

** STEP: Step-1 


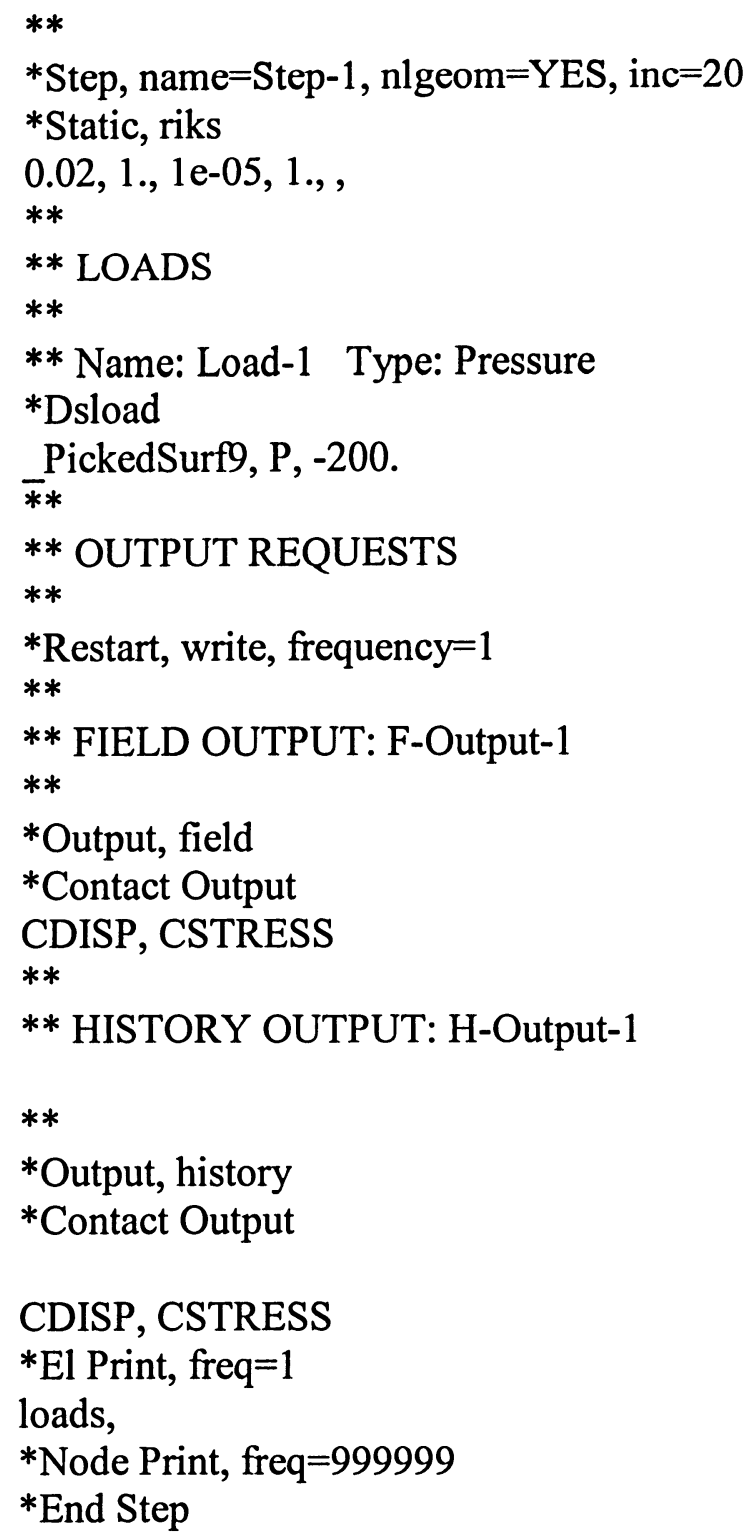

\subsection{Summary}

The bond stress at the steel-concrete interface is modeled by developing the contact properties such as contact pressure and friction at the steel-concrete interface. The effect of corrosion on contact pressure and friction is also modeled at the corroded steelconcrete interface. The elastic and plastic properties of both the reinforcing steel and the concrete are assigned to provide nonlinear analysis. 


\section{Chapter 5}

\section{Analysis of Results of Finite Element Analysis}

This chapter presents the results obtained from finite element analysis of some pullout tests, performed by Amleh (2000) to investigate the effect of corrosion on the bond strength at the steel-concrete interface. The results of finite element model are compared with experimental results. The model is also validated by analyzing some pullout tests of Cabrera and Ghoddoussis (1992) and Al-Sulaimani et al. (1990).

\subsection{Analysis of Results of Uncorroded Specimens}

\subsubsection{Relationship of Bond Stress and Slip}

In pull-out tests, slip is measured at the loaded end for each load increment up to failure, which can be due to the splitting of the concrete or pullout of the bar from the specimen or yielding of steel bar. The average bond stress is obtained by dividing the applied load by the total surface area of embedded portion of the bar. The average bond stress is given by:

$$
u=\frac{P}{L\left(\pi d_{b}\right)}
$$

where,

$$
\begin{aligned}
& u=\text { average bond stress } \\
& P=\text { maximum load } \\
& L=\text { embedded length of reinforcing steel } \\
& d_{b}=\text { diameter of reinforcing bar, (\# } 20 \text { bar was used for all specimens) }
\end{aligned}
$$


The bond stress at each load level is plotted against the loaded end slip for the experimental values and the results from the finite element analysis. Figures 5.1 to 5.6 show the comparison of the experimental results with those of FE analysis. The failure is defined as the point of maximum bond stress and corresponding slip is called the slip at failure.

Good agreement is noted between the results obtained from FE analysis and experiments. As can be seen from Figures 5.1 to 5.6, the bond stress-slip curves obtained experimentally and from FE analysis show a linear relationship between bond stress and slip up to 50 to $70 \%$ of the maximum bond stress. Thereafter, the bond stress increases gradually with the increase in slip. When the point of maximum bond stress is reached, the slip increases with constant bond stress.

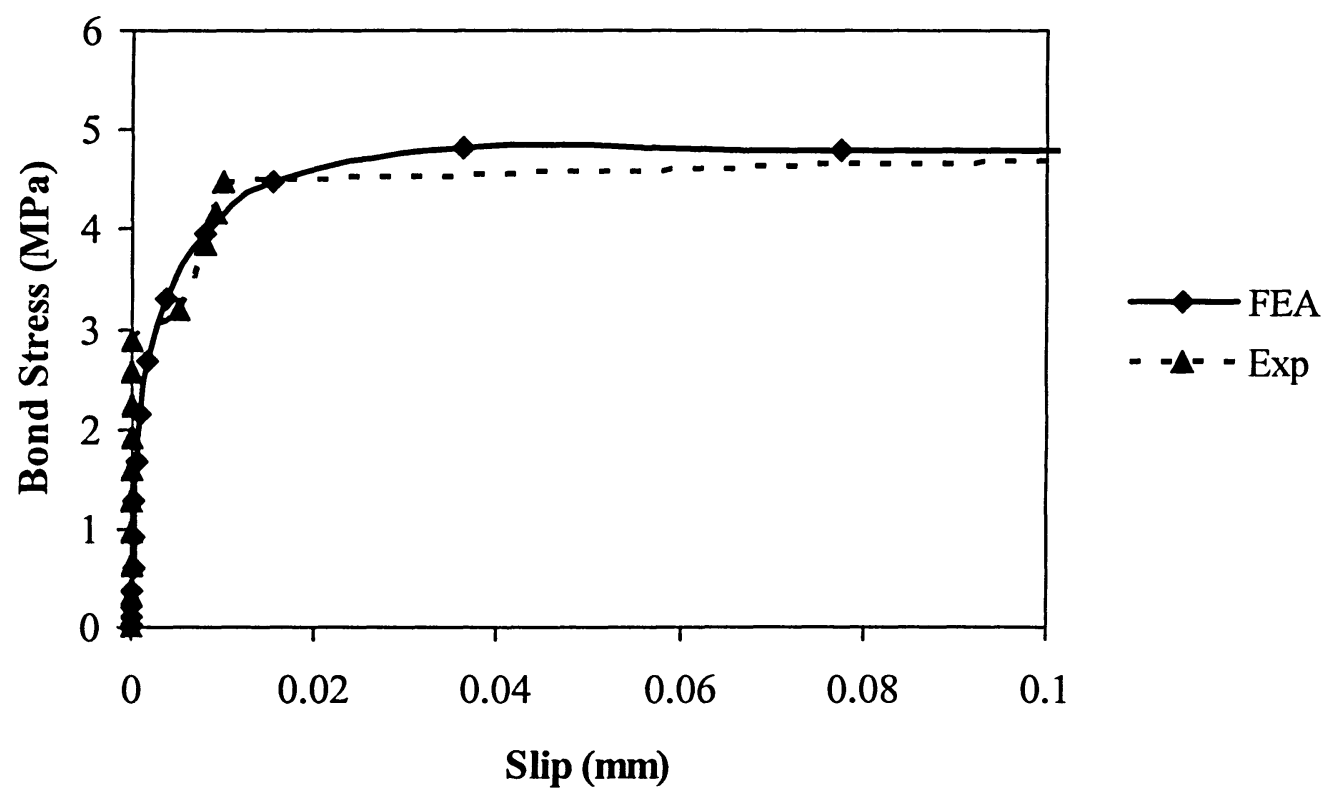

Figure 5.1: Variation of average bond stress with slip for $25 \mathrm{~mm}$ concrete cover thickness for $60 \mathrm{MPa}$ concrete mixture 


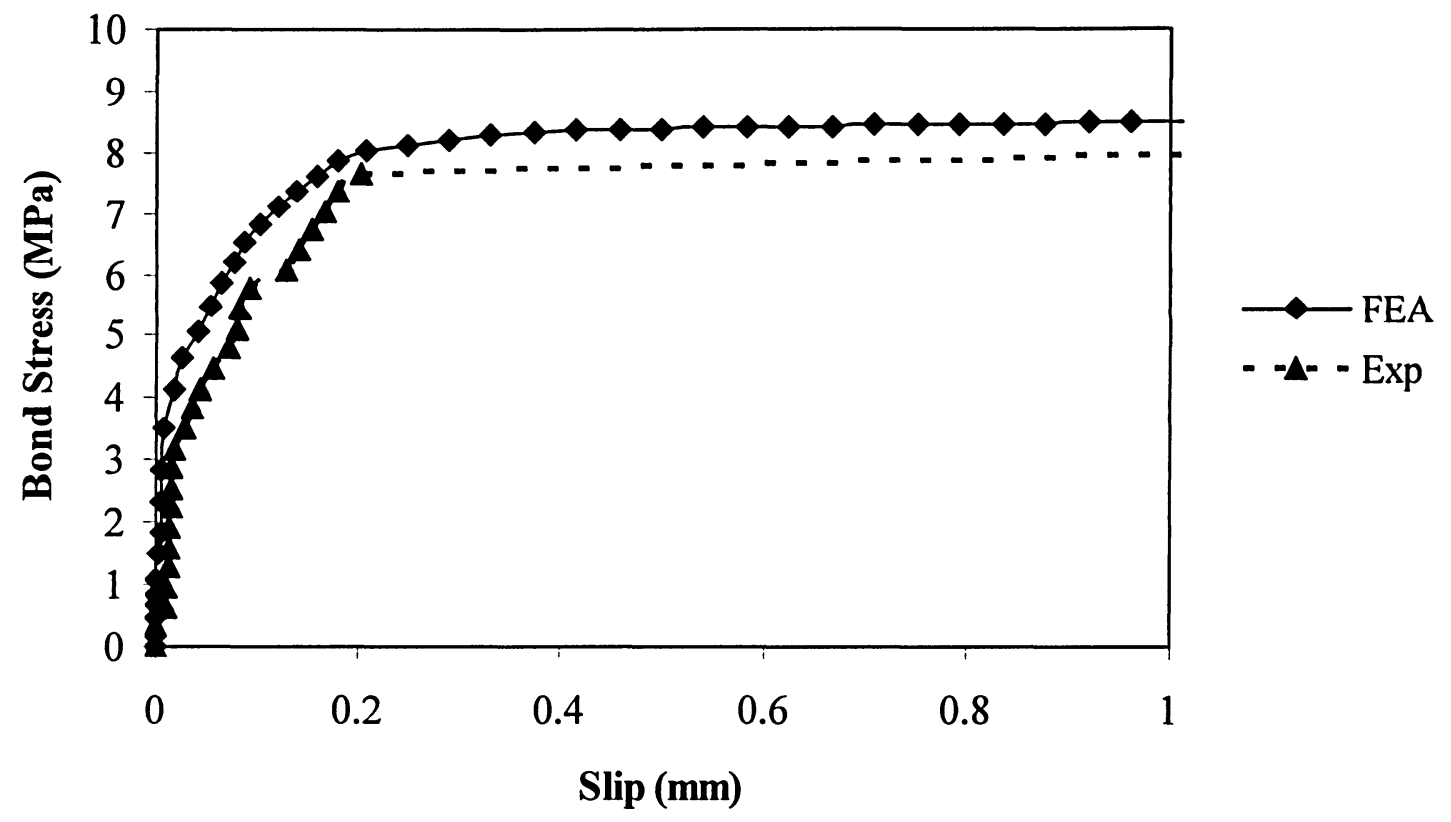

Figure 5.2: Variation of average bond stress with slip for $50 \mathrm{~mm}$ concrete cover thickness for 60 MPa concrete mixture

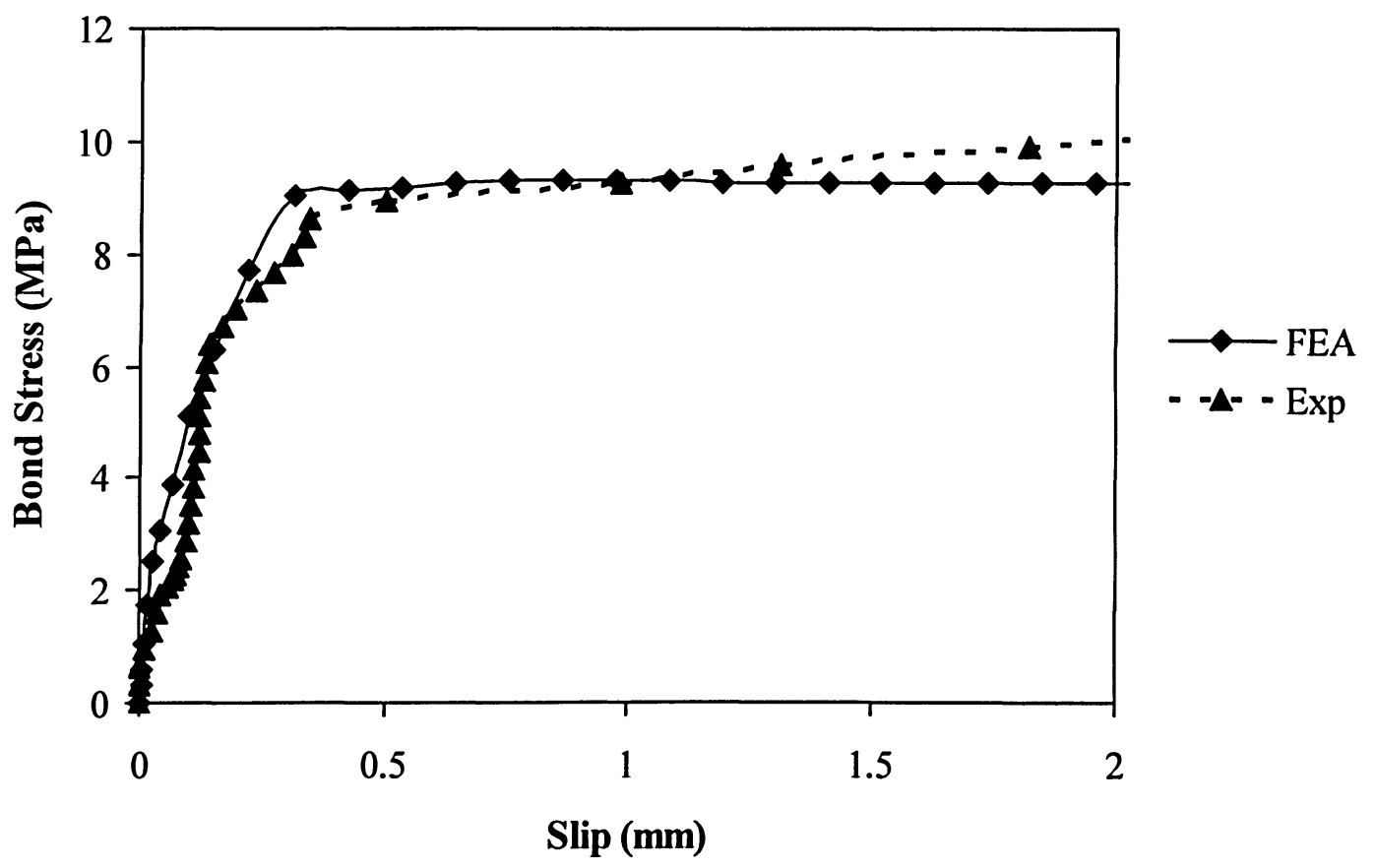

Figure 5.3: Variation of average bond stress with slip for $75 \mathrm{~mm}$ concrete cover thickness for $60 \mathrm{MPa}$ concrete mixture 


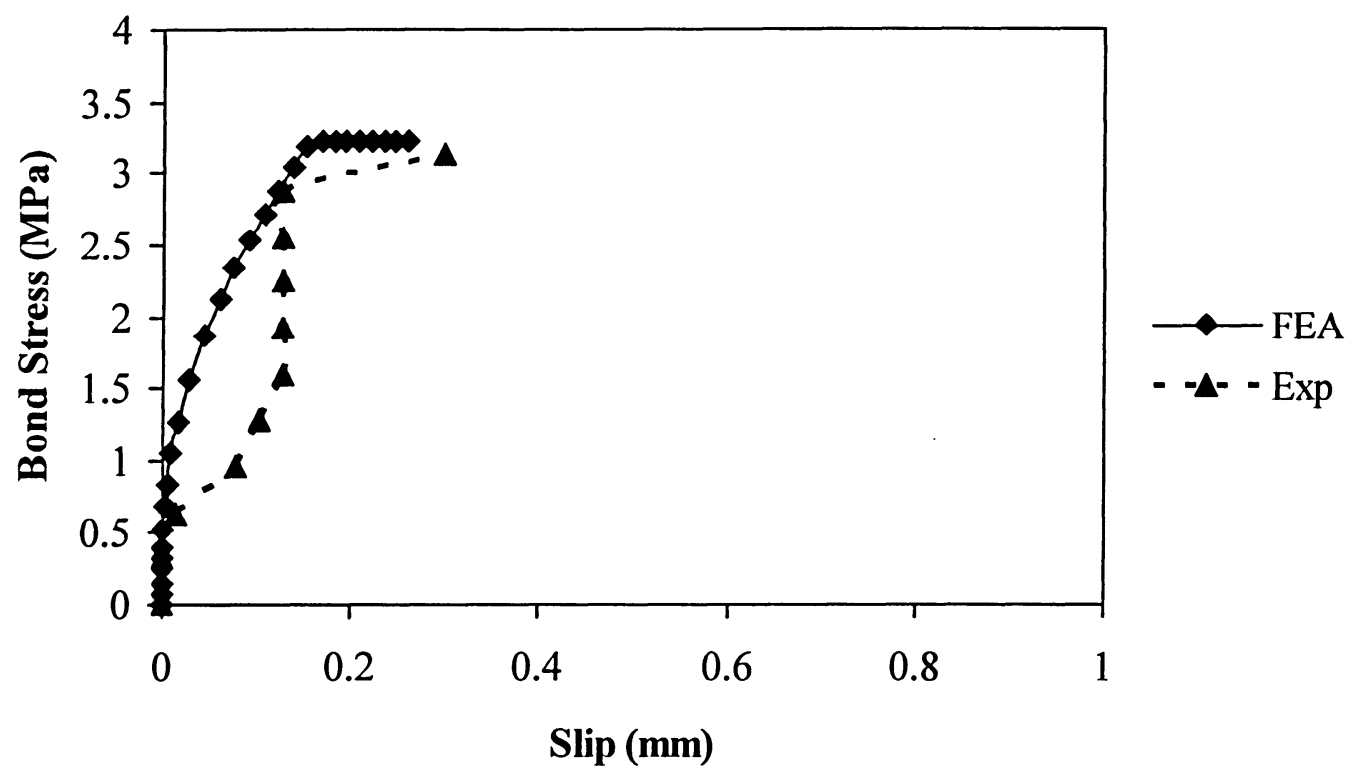

Figure 5.4: Variation of average bond stress with slip for $25 \mathrm{~mm}$ concrete cover thickness for $50 \mathrm{MPa}$ concrete mixture

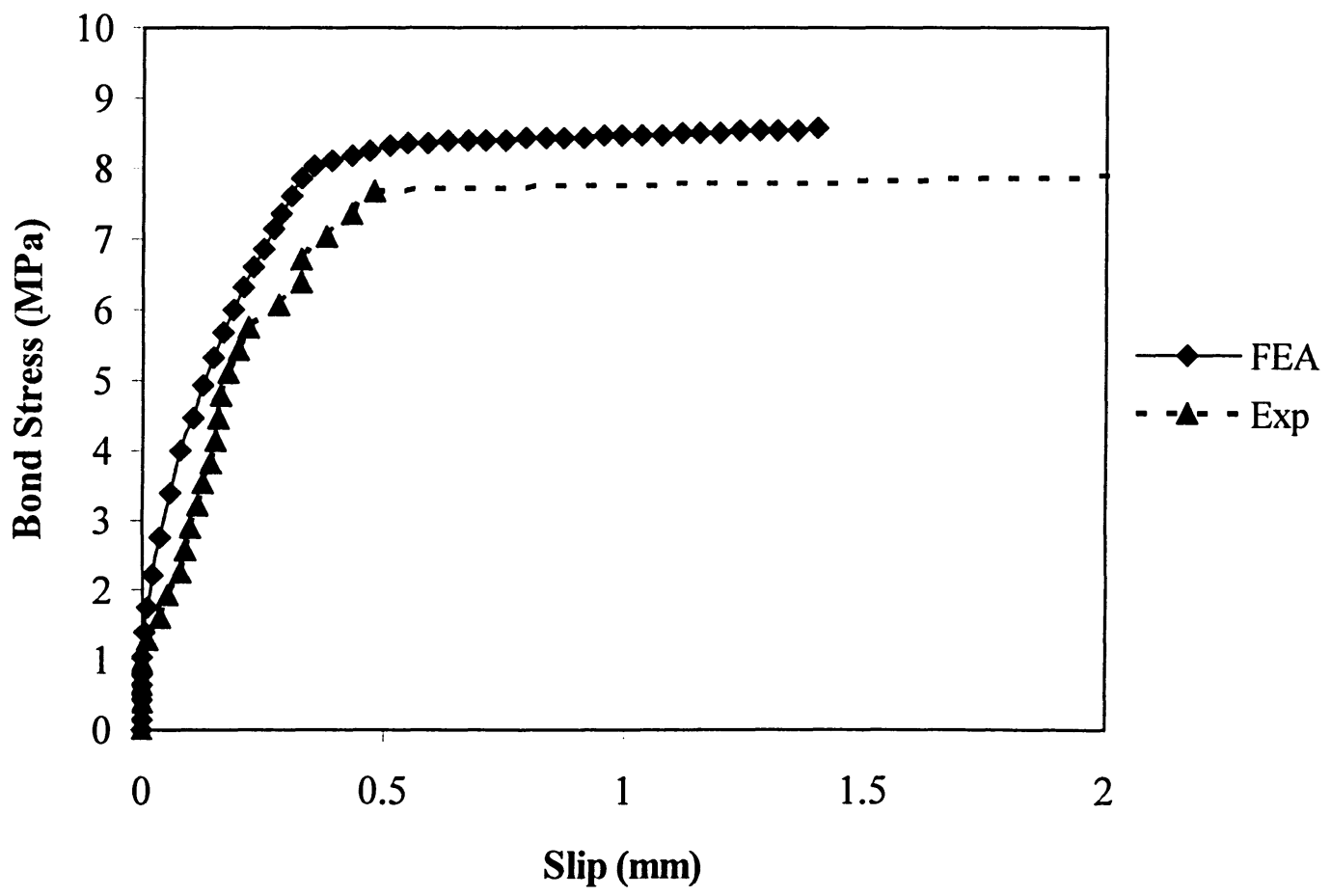

Figure 5.5: Variation of average bond stress with slip for $50 \mathrm{~mm}$ concrete cover thickness for 50 MPa concrete mixture 


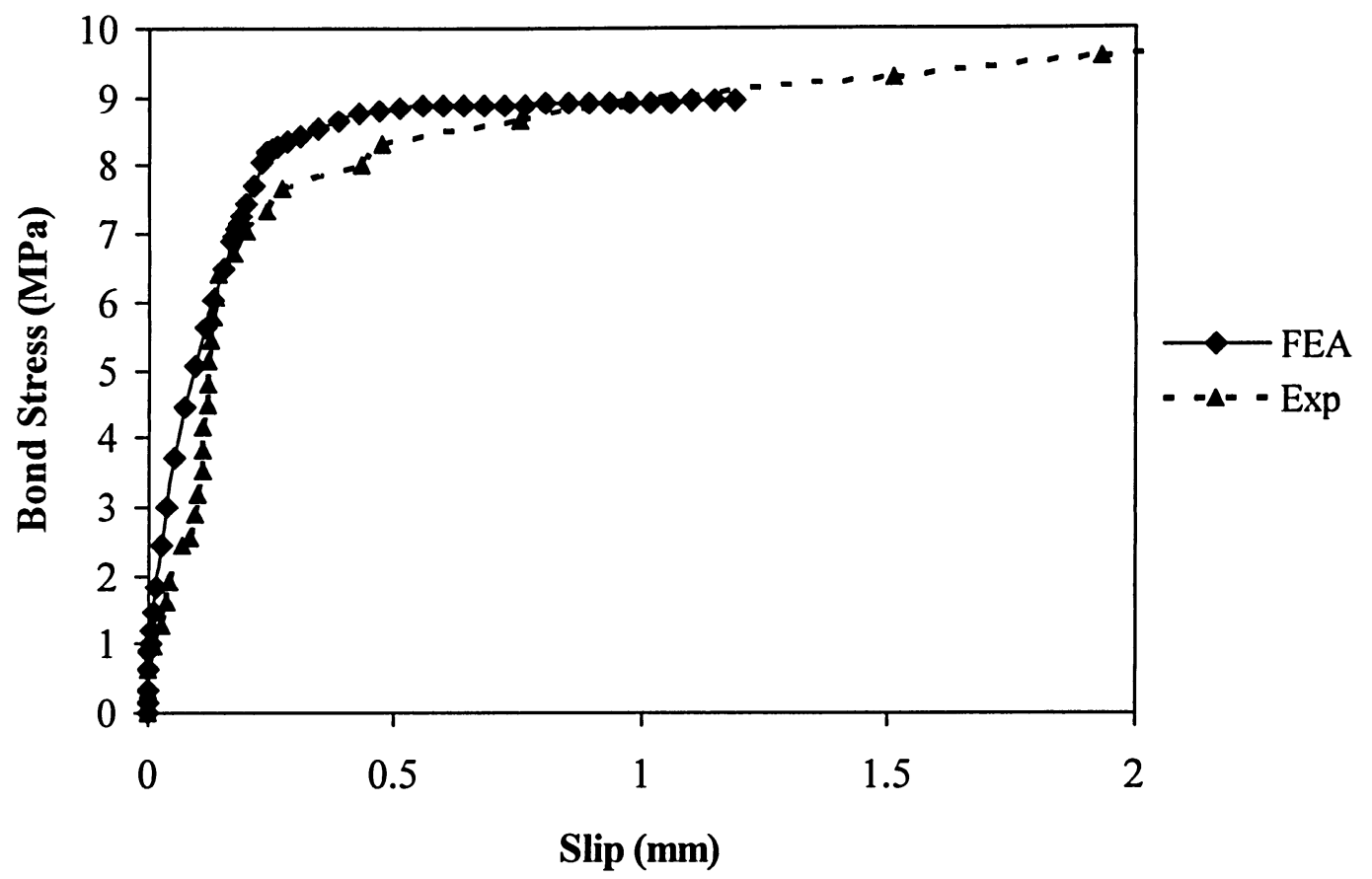

Figure 5.6: Variation of average bond stress with slip for $75 \mathrm{~mm}$ concrete cover thickness for 50 MPa concrete mixture

\subsubsection{Bond Stress and Slip using Very Fine Mesh}

The variation of bond stress with slip for $25 \mathrm{~mm}$ cover is obtained using very fine mesh. Then the result is compared with that of relatively coarser mesh and also with experimental results which is shown in Figure 5.7. The Figure 5.7 shows that both the curves obtained using very fine mesh and relatively coarser mesh match well with experimental results. Therefore, the coarser mesh is used as it is time effective. 


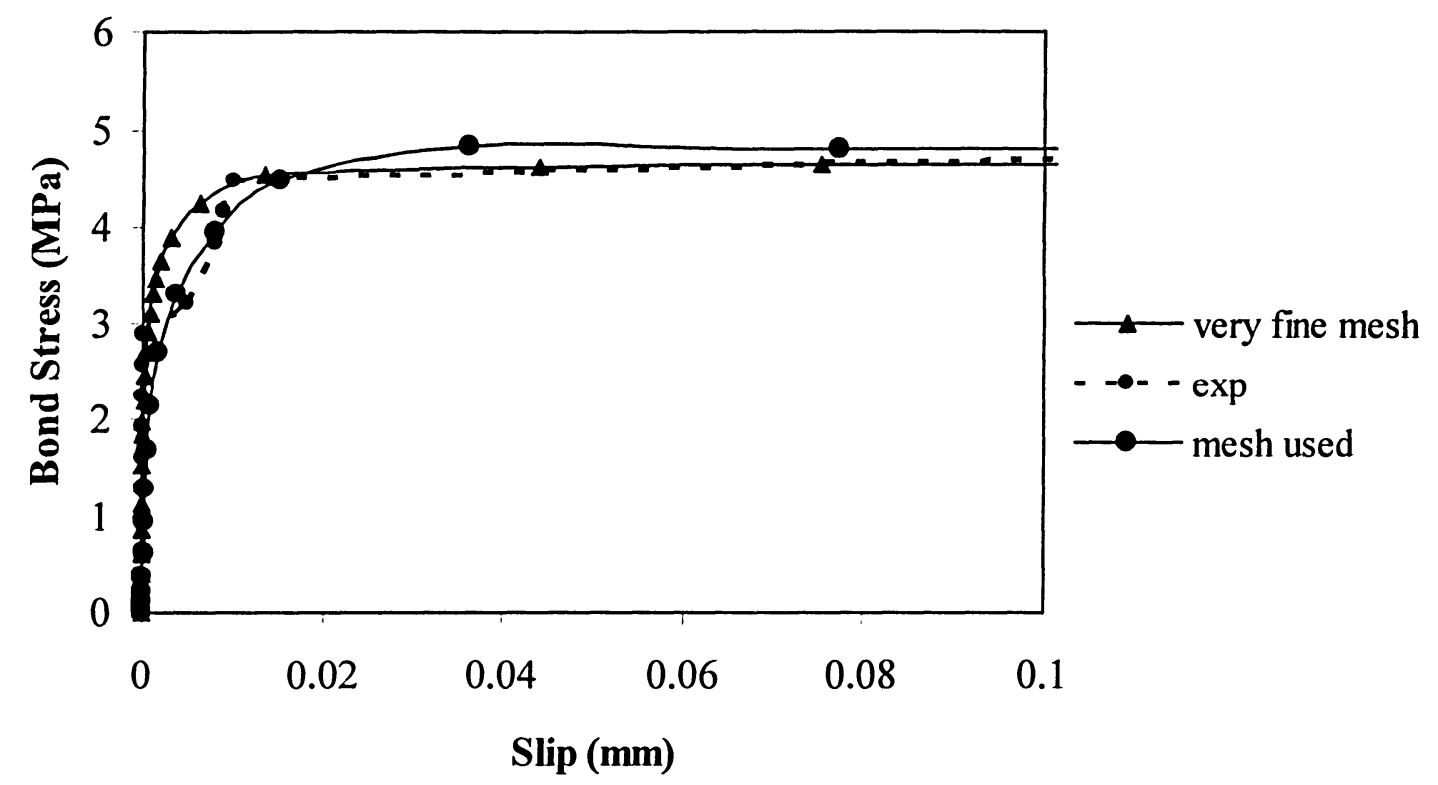

Figure 5.7: Variation of average bond stress with slip for $25 \mathrm{~mm}$ concrete cover thickness for $60 \mathrm{MPa}$ concrete mixture using very fine mesh

\subsubsection{Effect of Concrete Cover Thickness on Bond Strength}

Concrete cover is an important parameter for bond strength. Figures 5.8 to 5.11 show that the average bond strength increases with the increase of concrete cover thickness for both $60 \mathrm{MPa}$ and $50 \mathrm{MPa}$ concretes.

In Figure 5.10, both the computed and experimentally observed results show that bond strength increases with the increase of concrete cover thickness. In FE analysis, with 60 $\mathrm{MPa}$ concrete, the average bond strengths for $25 \mathrm{~mm}, 50 \mathrm{~mm}$ and $75 \mathrm{~mm}$ thick concrete cover are 4.8 MPa, 8.6 MPa and 9.2 $\mathrm{MPa}$ respectively. Bond strength for $50 \mathrm{~mm}$ cover is $78.8 \%$ higher than that of the $25 \mathrm{~mm}$ cover, whereas bond strength of $75 \mathrm{~mm}$ cover is $7.3 \%$ larger than that of $50 \mathrm{~mm}$ concrete. Therefore, the model predicts well the effect of concrete cover thickness on bond strength that is typical of that observed in the experiments. 
The FE analysis reveals that with the $50 \mathrm{MPa}$ concrete, bond strengths for $25 \mathrm{~mm}, 50 \mathrm{~mm}$ and $75 \mathrm{~mm}$ cover are 3.2MPa, 8.6 $\mathrm{MPa}$ and 9.0 MPa, respectively, as shown in Figure 5.11. Therefore, the difference between bond strengths of 50 and $75 \mathrm{~mm}$ cover is $4.6 \%$, whereas the difference is around $165 \%$ for that of concrete covers of $25 \mathrm{~mm}$ and $50 \mathrm{~mm}$ thickness.

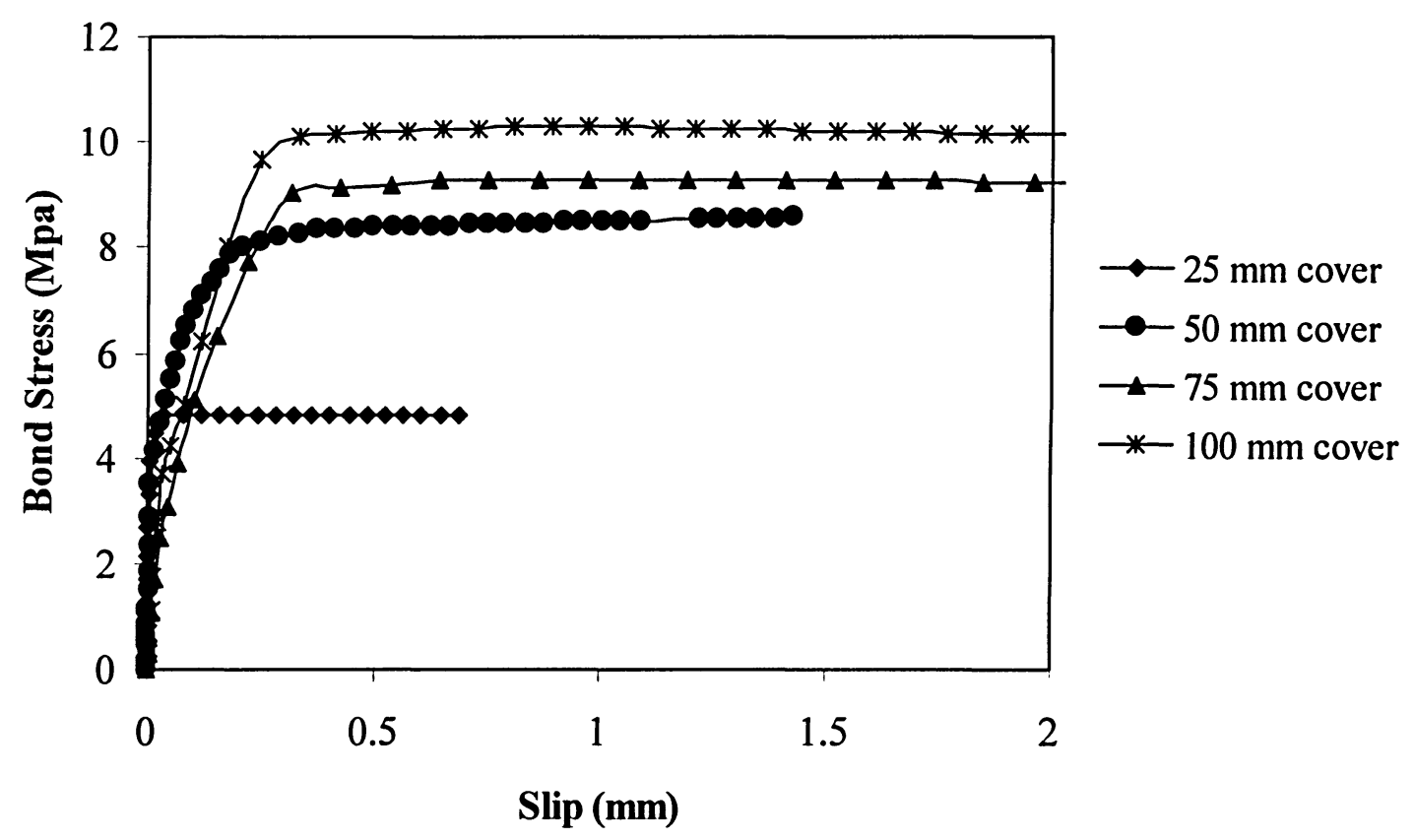

Figure 5.8: Variation of average bond stress with slip for different cover thickness for $60 \mathrm{MPa}$ concrete mixtures 


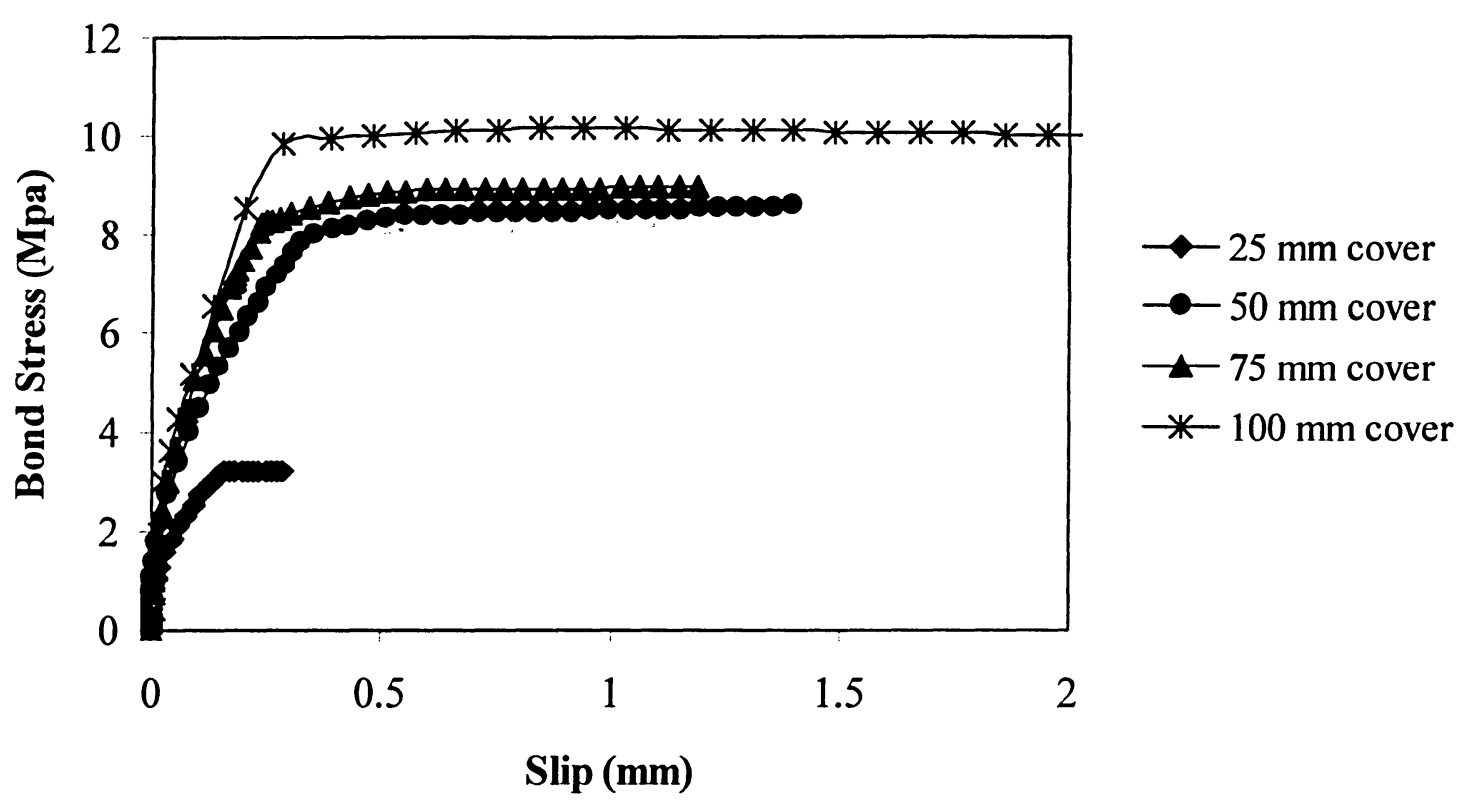

Figure 5.9: Variation of average bond stress with slip for different cover thickness for 50 MPa concrete mixtures

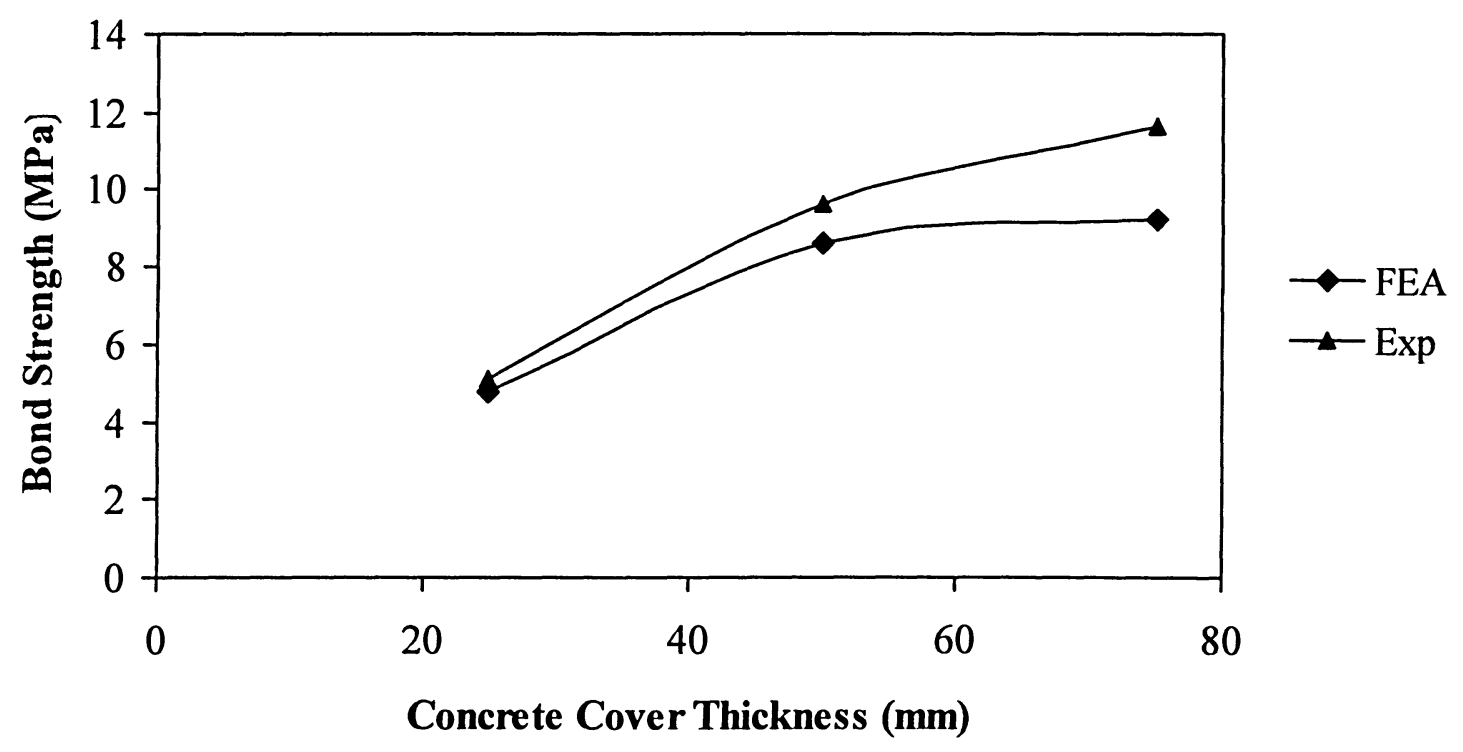

Figure 5.10: Variation of average bond strength with concrete cover thickness for $60 \mathrm{MPa}$ concrete mixtures 


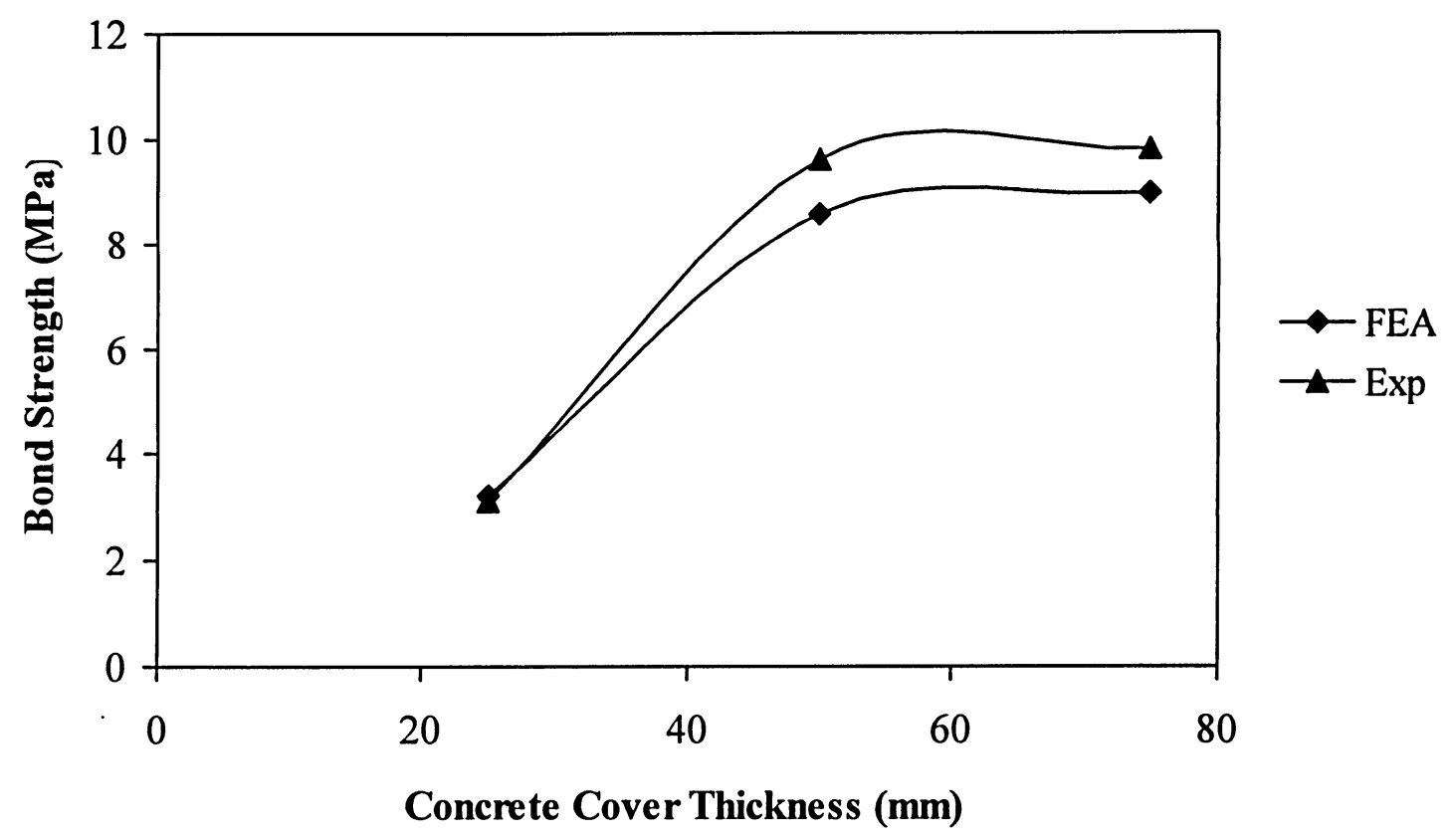

Figure 5.11: Variation of average bond strength with concrete cover thickness for 50 MPa concrete mixtures

\subsubsection{Effect of Compressive Strength on Bond Strength}

Figures 5.12 and 5.13 show the effect of compressive strength of concrete on the average bond strength at the steel-concrete interface. In FE analysis, the computed average bond strengths for $60 \mathrm{MPa}$ concrete are 54\%, 5\% and 3\% higher than those for $50 \mathrm{MPa}$ concrete for $25 \mathrm{~mm}, 50 \mathrm{~mm}$ and $75 \mathrm{~mm}$ thick concrete cover respectively. In experimental observation, these differences are $63 \%, 0 \%$ and $18 \%$ for $25 \mathrm{~mm}, 50 \mathrm{~mm}$ and $75 \mathrm{~mm}$ concrete cover respectively. 


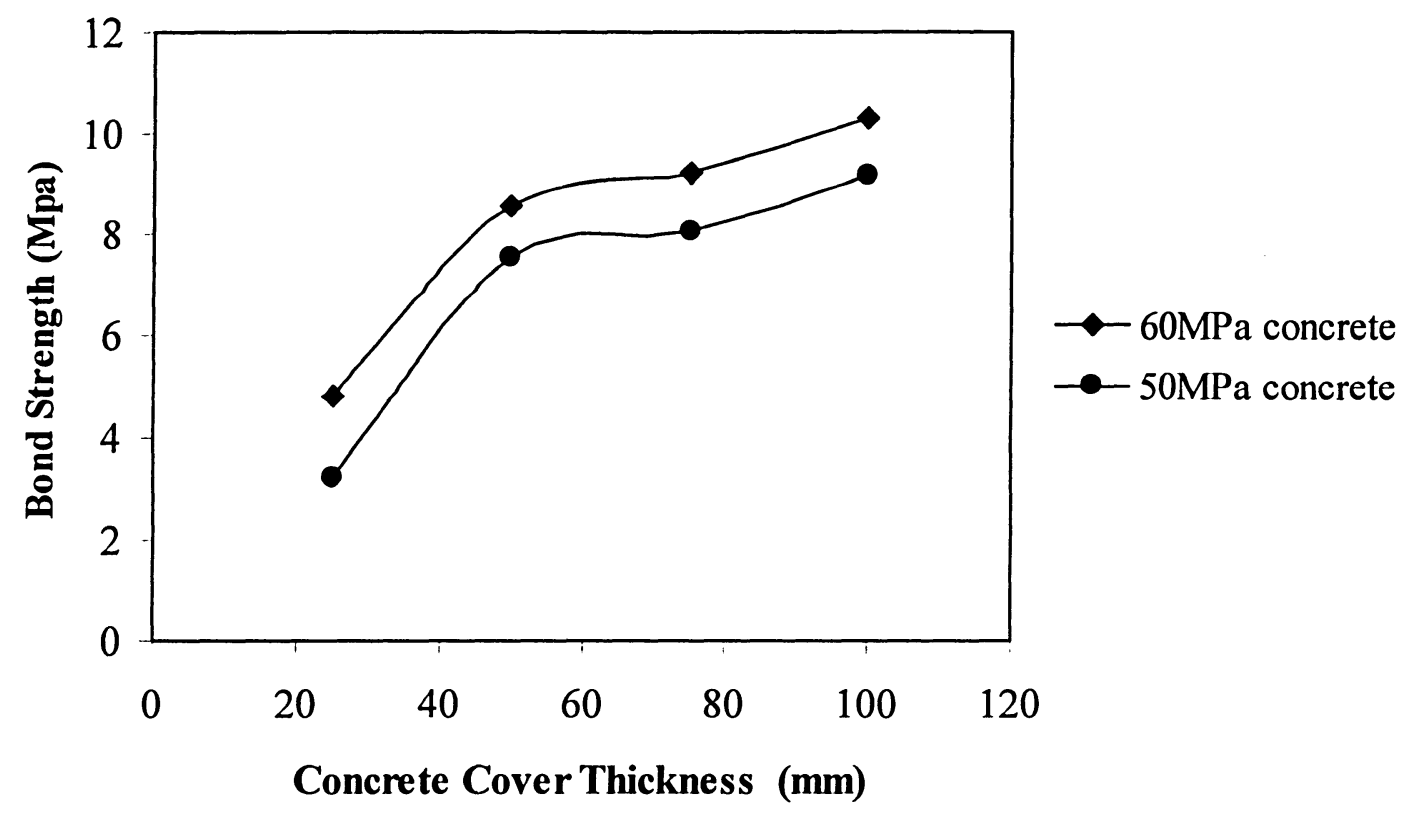

Figure 5.12: Variation of average bond strength with concrete cover thickness for different concrete mixtures

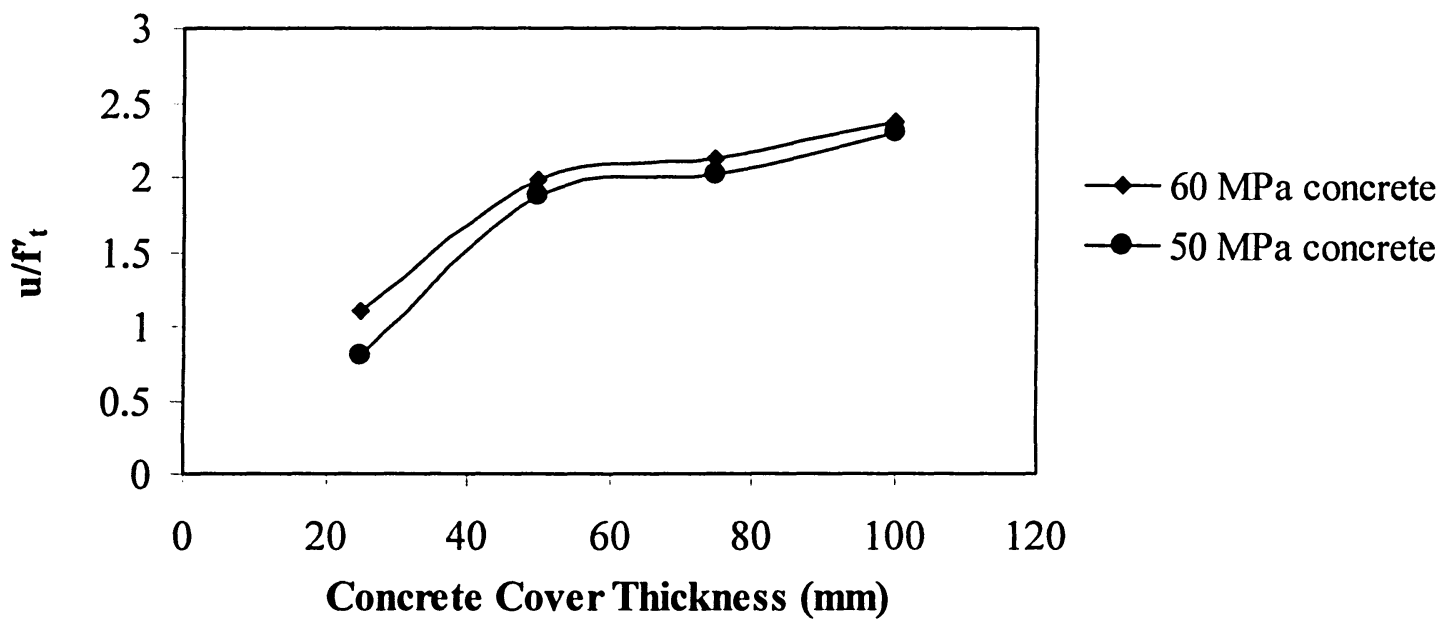

Figure 5.13: Variation of $\mathbf{u} / \mathbf{f}^{\prime}{ }_{t}$ with concrete cover thickness for different concrete mixtures 


\subsubsection{Comparison of Finite Element Analysis with Experimental Results}

The comparison between the bond strengths for different cover thickness obtained from FE analysis and experimental results is shown in Table 5.1 and 5.2. Table 5.1 shows that for $60 \mathrm{MPa}$ concrete, the differences of bond strength, obtained from the FE analysis and from the experimental results, are $6 \%, 11 \%$ and $26 \%$ for $25 \mathrm{~mm}, 50 \mathrm{~mm}$ and $75 \mathrm{~mm}$ thick concrete covers respectively. Again, Table 5.2 shows that, for $50 \mathrm{MPa}$ concrete, these differences are $2.8 \%, 10.7 \%$ and $8.8 \%$ for $25 \mathrm{~mm}, 50 \mathrm{~mm}$ and $75 \mathrm{~mm}$ thick concrete covers respectively.

The bond stress-slip curves (Figure 5.1 through 5.6) show that initial slopes of the bond stress-slip curves obtained from FE analysis are higher than those of experimental results. However the ultimate bond strengths obtained from the experiment are little bit higher than those of FE analysis.

Table 5.1: Comparison of average bond strength of finite element analysis with those of experimental results for uncorroded specimens of $60 \mathrm{MPa}$ concrete mixtures

\begin{tabular}{|c|c|c|c|}
\hline $\begin{array}{c}\text { Cover } \\
\text { thickness } \\
(\mathrm{mm})\end{array}$ & $\begin{array}{c}\text { Bond strength } \\
\text { from FEA } \\
(\mathrm{MPa})\end{array}$ & $\begin{array}{c}\text { Bond strength } \\
\text { from experimental results } \\
(\mathrm{MPa})\end{array}$ & $\begin{array}{c}\text { Difference between } \\
\text { FEA and experimental } \\
\text { results }\end{array}$ \\
\hline 25 & 4.96 & 5.11 & $6 \%$ \\
\hline 50 & 8.59 & 9.59 & $11 \%$ \\
\hline 75 & 9.21 & 11.6 & $26 \%$ \\
\hline
\end{tabular}


Table 5.2: Comparison of average bond strength of finite element analysis results with those of experimental results for uncorroded specimens of $50 \mathrm{MPa}$ concrete mixtures

\begin{tabular}{|c|c|c|c|}
\hline $\begin{array}{c}\text { Cover } \\
\text { thickness } \\
(\mathrm{mm})\end{array}$ & $\begin{array}{c}\text { Bond strength } \\
\text { from FEA } \\
(\mathrm{MPa})\end{array}$ & $\begin{array}{c}\text { Bond strength } \\
\text { from experimental results } \\
(\mathrm{MPa})\end{array}$ & $\begin{array}{c}\text { Difference between } \\
\text { FEA and experimental } \\
\text { results }\end{array}$ \\
\hline 25 & 3.22 & 3.13 & $-2.8 \%$ \\
\hline 50 & 8.56 & 9.59 & $10.7 \%$ \\
\hline 75 & 8.95 & 9.82 & $8.8 \%$ \\
\hline
\end{tabular}

\subsection{Analysis of Results of Corroded Specimens}

\subsubsection{Bond Stress-Slip Relationship for Corroded Specimens}

The variation of bond stress with slip at different levels of corrosion for different types of concrete cover thickness is shown in Figures 5.14 to 5.19. The figures also feature the comparison between experimental results and the results from the FE analysis. Good agreements are found between these two results. Specifically, $25 \mathrm{~mm}$ cover specimens showed very good agreement.

These plots show the effect of corrosion in both experiment and FE analysis, which decreases the average bond strength and increases the slip. The effect of corrosion on the initial slip is clear from the figures, as was obtained from the experimental results. The initial slope of the average bond stress-slip curve for the FE analysis decreases with corrosion and high amount of slip occurs at higher level of corrosion. It was also observed that with low level of corrosion, the average bond strength increases as the roughness of the steel bar increases slightly due to corrosion products. With higher level 
of corrosion, the initial firm layer of corrosion product converts into flaky layers. Due to the lubricating effect of flaky layer, a small amount of load causes a larger slip.

The following observations are made for the specimens with $25 \mathrm{~mm}$ thick concrete cover:

1) At $2.5 \%$ mass loss, the slip started at a very small load and in FE model the loss of bond capacity is $26 \%$ for $60 \mathrm{MPa}$ concrete where this loss is $27 \%$ for $50 \mathrm{MPa}$ concrete. The experimental bond capacity losses are $26 \%$ and $24 \%$ for $60 \mathrm{MPa}$ and $50 \mathrm{MPa}$ concretes, respectively. At this level of corrosion, the expanded volume of corroded product causes longitudinal cracks which reduce the contact pressure at the steel-concrete interface and the model showing the reduction of contact pressure with corrosion is shown in equation 4.16 in Chapter 4.

2) When the mass loss is $5 \%$, the loaded end slip is very high and almost $50 \%$ loss of bond capacity is noted both in FE analysis and experimental results. At this level of corrosion, the longitudinal crack width is so high that the contact pressure reduces significantly and failure occurs due to the splitting of the concrete.

3) At $10 \%$ mass loss, the shape of the average bond stress-slip curve is different from that for uncorroded specimen. Large amount of slip occurs from the very beginning. Around $80 \%$ bond capacity loss is noted in both FE and experimental analysis. At this level of corrosion, the degradation of lugs, accumulation of heavy flaky corroded layer and large longitudinal cracks cause a larger reduction of contact pressure and friction which are modeled as shown in equations 4.16 and 4.20 in Chapter 4.

The following observations are made for the specimens with $50 \mathrm{~mm}$ thick concrete cover:

1) At a mass loss of $2.5 \%$, the bond stress-slip behaviour is almost the same as for the uncorroded specimens with a loss of about $4 \%$ of the bond capacity in FE analysis results and a bond capacity loss of $1.5 \%$ for experimental analysis.

2) For $5 \%$ mass loss, the initial slope of the average bond stress-slip curves for both the FE analysis and experimental results decreases, but not significantly and bond capacity 
loss is around $20 \%$. At this level of corrosion, the longitudinal cracking commenced and some degradation of lug height is also noted which causes degradation of bearing pressure and contact pressure at the steel- concrete interface which are modeled following the procedures in Chapter 4.

3) For $10 \%$ mass loss due to corrosion, the shape of bond stress and slip is almost the same as for the uncorroded specimen but initial slope decreases significantly and a $50 \%$ bond capacity is lost in both FE analysis and experiment results. The width of the longitudinal crack is significant. Significant amount of degradation of lug height reduces the bearing force and mechanical interlocking between the steel and the concrete. The friction between steel and concrete also decreases.

4) The experimental and $\mathrm{FE}$ analysis results for 15 to $20 \%$ bar mass loss show that the shape of bond stress-slip curves are totally different from those for the uncorroded specimen. A large amount of slip occurs with a small application of load and about 70 to $90 \%$ bond capacity is lost. At this level of corrosion, due to large amount of degradation of lugs, the deformed bars behave similar to plain bars and the horizontal component of the bearing force produced by mechanical interlocking is significantly reduced. The pullout of the rebar is, therefore, facilitated and occurs at a lower load. Besides, the accumulation of a heavy layer of flaky corroded material around the bars acts as a lubricant and reduces the frictional component of the bond strength.

The following observations are made for the specimens with $75 \mathrm{~mm}$ thick concrete cover:

1) For a mass loss of $2.5 \%$, the results for the experimental and $\mathrm{FE}$ analysis show that the bond stress-slip curves are almost same as for the uncorroded specimen but the bond capacity increases by about $5 \%$. For this level of corrosion, the expanded volume of corroded product increases mechanical contact pressure at steel-concrete interface and the roughness of the corroded product also increases the friction which increases the bond capacity at this level of corrosion. 
2) When rebar mass loss is $5 \%$, the decrease of the initial slope of bond-slip curve is very small and around $10 \%$ of the bond capacity is lost. The longitudinal cracks start at this point, but this is not significant, and the degradation of bond capacity is also small.

3) For a rebar mass loss of $10 \%$, the initial slope of bond-slip curve decreases but not significantly and the loss of bond capacity is around $38 \%$. At this level of corrosion, the width of longitudinal cracks and degradation of lugs height are significantly larger.

4) From FE analysis and experimental results, it is observed that for $15 \%$ to $20 \%$ rebar mass loss, the decrease of bond stress- slip is very high and around $65 \%$ to $90 \%$ bond capacity losses occur. At this level of corrosion very low load causes large slip.

In the experimental results, high level of corrosion resulted in large slips from the very beginning of the test but suddenly the slope of the bond stress-slip curves increased i.e. with a small increase of slip, large amount of average bond stress was noted. This occurs because during pulling of the bar occasionally the corrosion products accumulated at some places along the rebar and grip the concrete which increased the stiffness temporarily. This phenomenon was disregarded in the FE analysis. It should be noted that in FE analysis the corrosion was assumed to be uniform over the entire embedded length. However, in experiments it was difficult to maintain uniform corrosion especially for long embedment lengths. The bars removed from the corroded specimens, show some pitting corrosion which caused sudden decrease of bond capacity at different locations. 


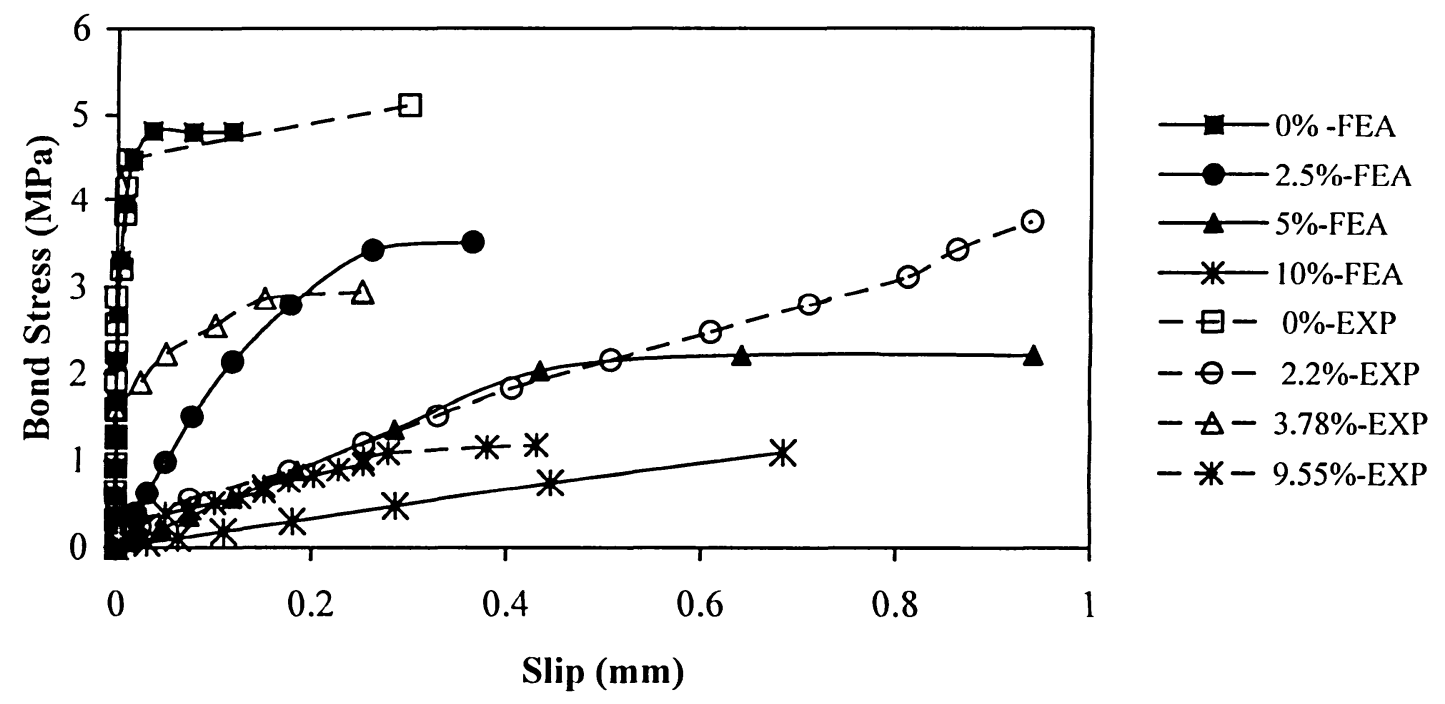

Figure 5.14: Variation of average bond stress with slip at different level of corrosion for $25 \mathrm{~mm}$ cover thickness for $60 \mathrm{MPa}$ concrete mixture

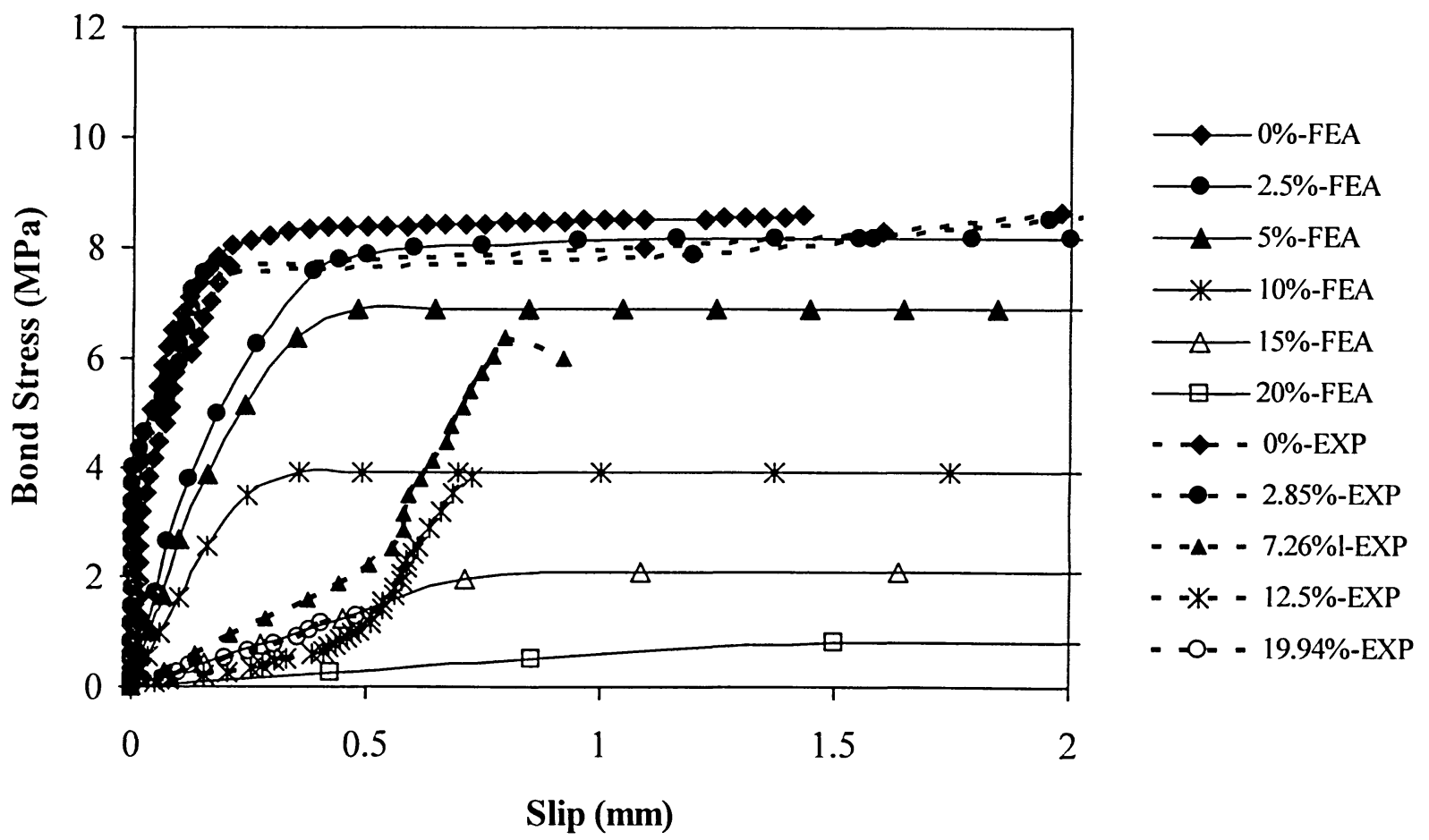

Figure 5.15: Variation of average bond stress with slip at different level of corrosion for $50 \mathrm{~mm}$ cover thickness for $60 \mathrm{MPa}$ concrete mixture 


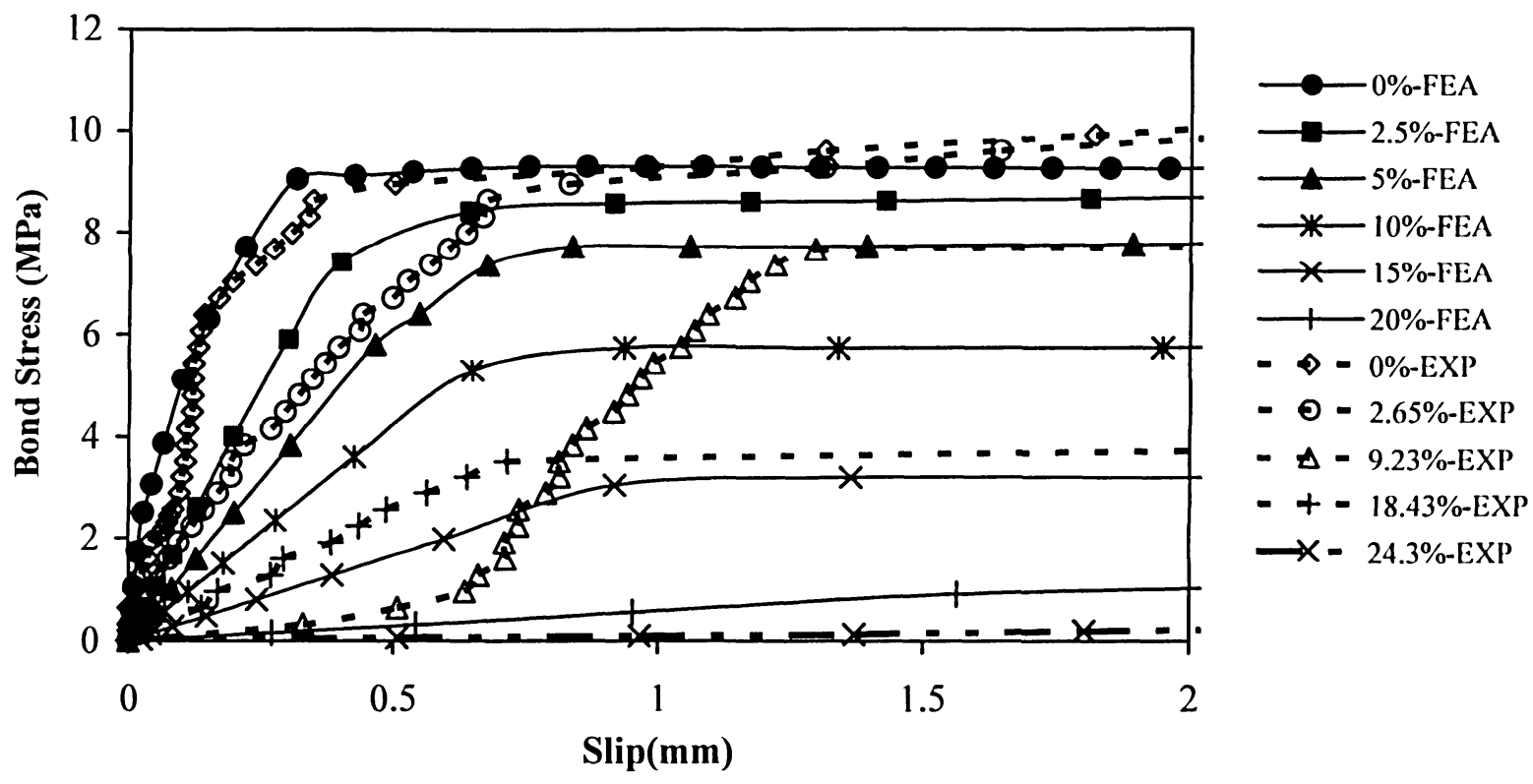

Figure 5.16: Variation of average bond stress with slip at different level of corrosion for $75 \mathrm{~mm}$ cover thickness of $60 \mathrm{MPa}$ concrete mixture

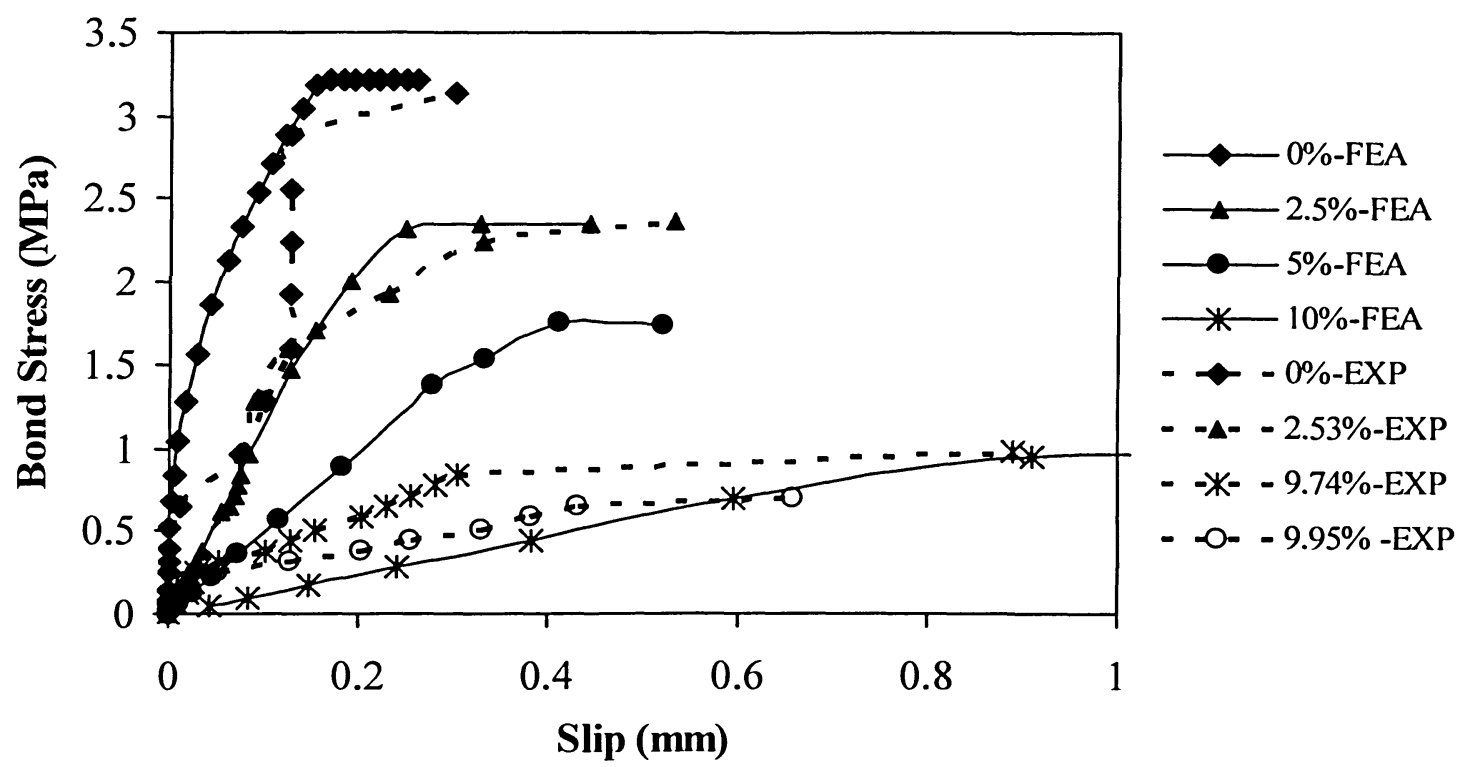

Figure 5.17: Variation of average bond stress with slip at different level of corrosion for $25 \mathrm{~mm}$ cover thickness for $50 \mathrm{MPa}$ concrete mixture 


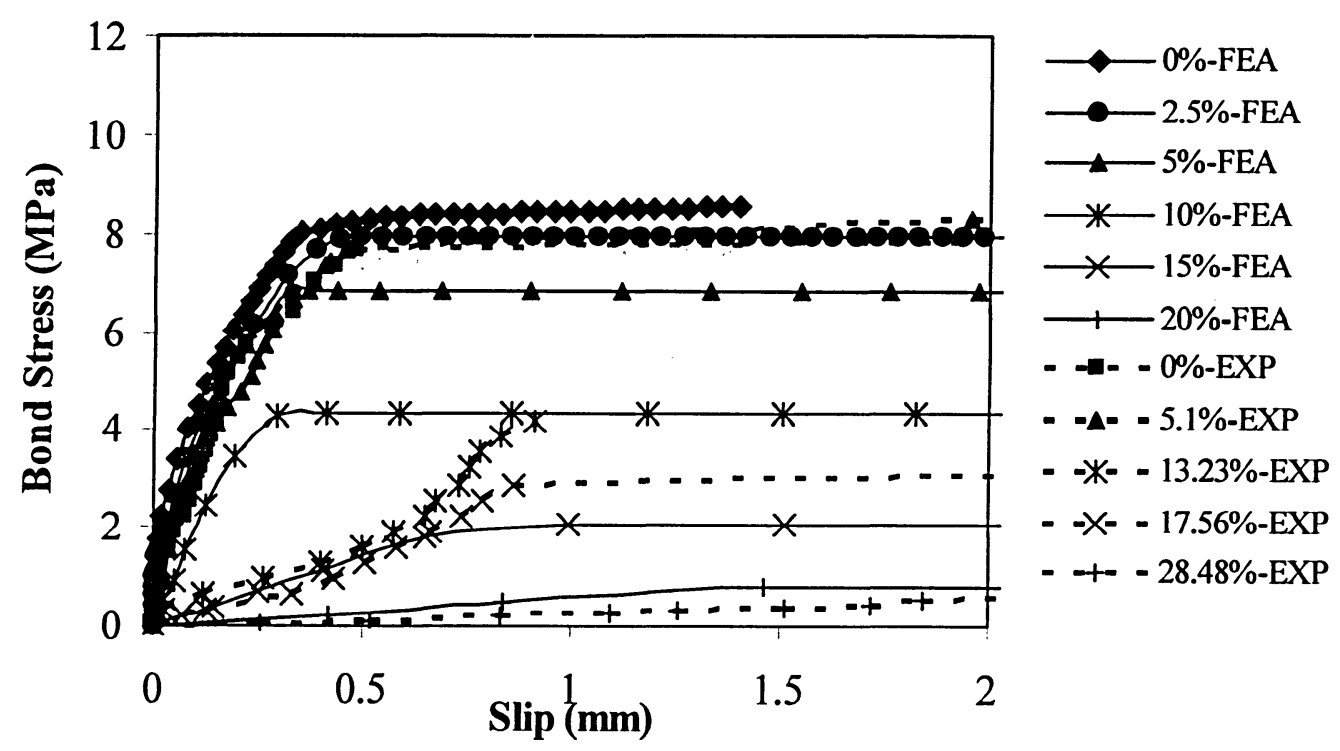

Figure 5.18: Variation of average bond stress with slip at different level of corrosion for $50 \mathrm{~mm}$ cover thickness for $50 \mathrm{MPa}$ concrete mixture

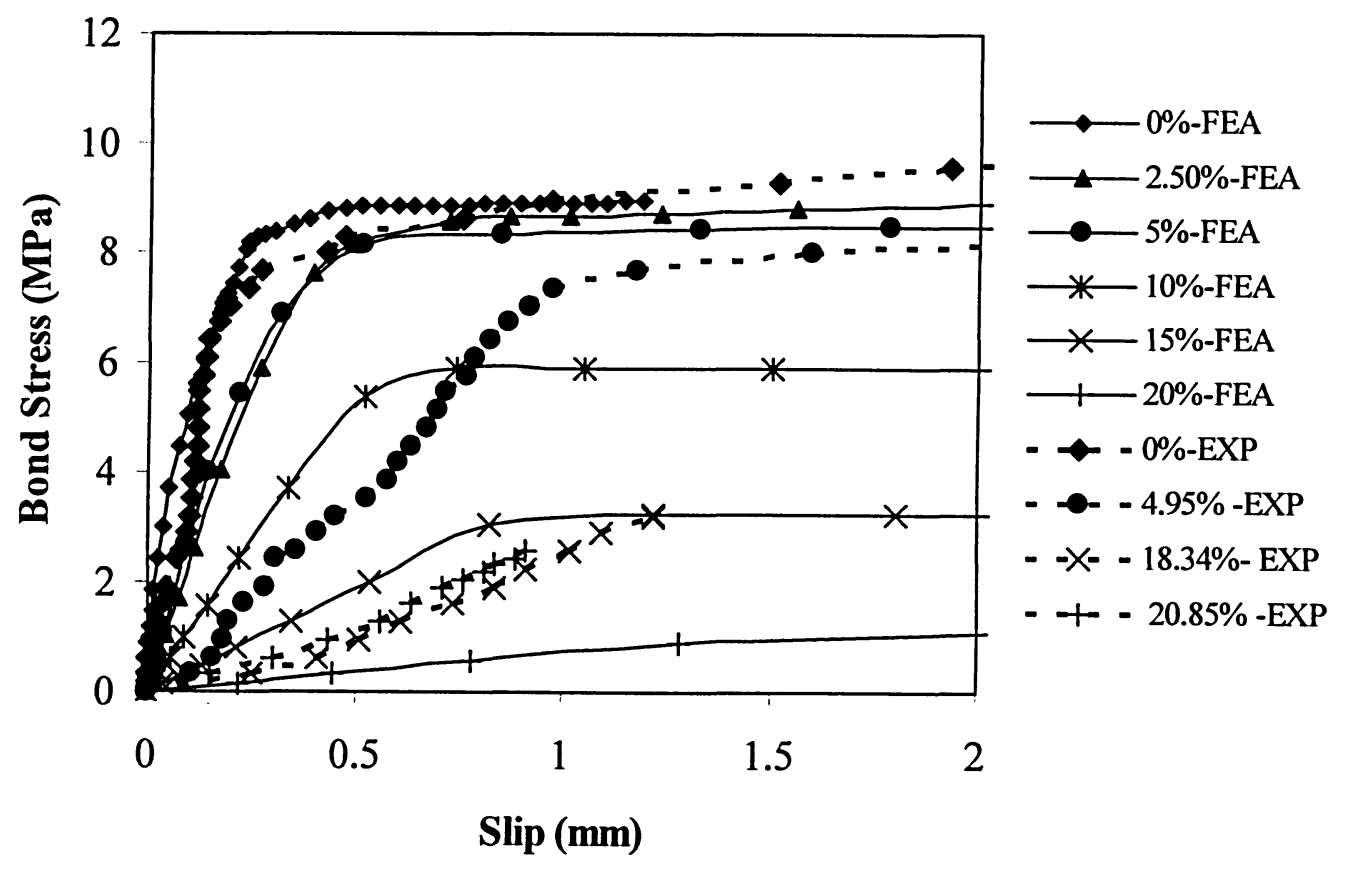

Figure 5.19: Variation of average bond stress with slip at different level of corrosion for $75 \mathrm{~mm}$ cover thickness for $50 \mathrm{MPa}$ concrete 


\subsubsection{Effect of Corrosion on Bond Strength}

The effect of corrosion in terms of mass loss on bond strength is shown in Figure 5.20 through Figure 5.23 where the mass loss is the percentage of loss of weight of the bar. Figure 5.20 and Figure 5.21 show the bond strength at different levels of corrosion for both FE analysis and experimental results. Figure 5.22 and Figure 5.23 show how bond strength decreases with the mass loss.

It is clear from Figure 5.22 and 5.23 that both the experimental and FE analysis results show that the rate of bond capacity loss in case of $25 \mathrm{~mm}$ cover is the highest. The loss of bond capacity is almost linear with mass loss. In FE analysis, for $50 \mathrm{~mm}$ thick concrete cover specimens with $60 \mathrm{MPa}$ concrete mixtures, at $2.5 \%$ mass loss, the loss of bond strength is $4.8 \%$ where at $5 \%$ mass loss the loss of bond strength is $20 \%$ and at $10 \%$ mass loss the loss of bond strength is about $50 \%$. Therefore the rate of loss of bond capacity is higher at higher level of corrosion. Good agreement was noted between the experimental and the finite element analysis results.

Figures 5.22 and 5.23 show that for both $\mathrm{FE}$ analysis and experimental results, up to 5\% mass loss, the bond capacity loss is moderate, at 10 to $15 \%$ mass loss, significant amount of bond capacity is lost and at about $20 \%$ mass almost all bond capacity is lost.

From the Table 5.3 and 5.4 it is clear that both in the FE analysis and experimental results $50 \%$ bond capacity is lost at $5 \%$ mass loss for $25 \mathrm{~mm}$ thick cover, at $10 \%$ mass loss for $50 \mathrm{~mm}$ thick cover and at $15 \%$ mass loss for $75 \mathrm{~mm}$ thick cover. Tables 5.3 and 5.4 show good agreements between the results of $\mathrm{FE}$ analysis and those from the experimental works. 


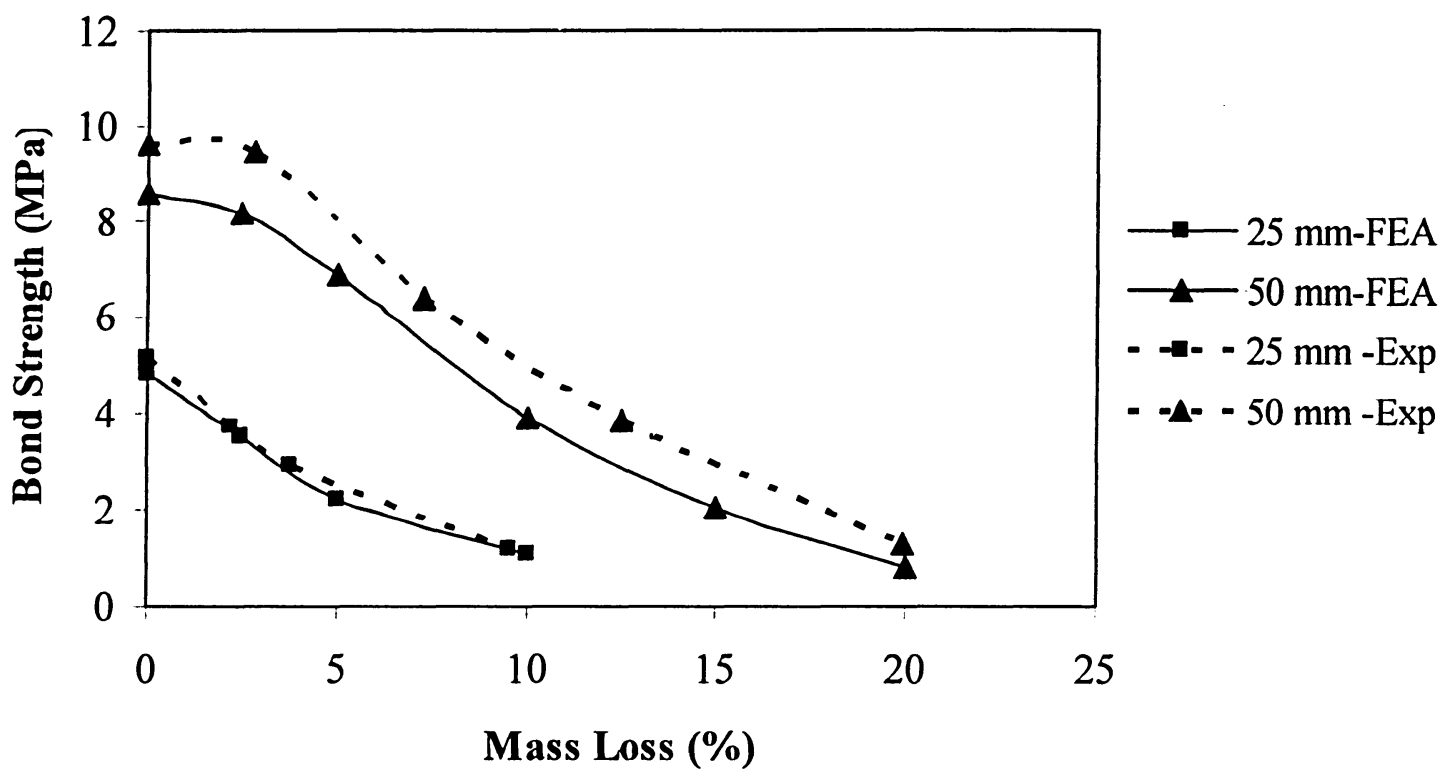

Figure 5.20: Effect of corrosion on bond strength for different cover thicknesses for 60 MPa concrete

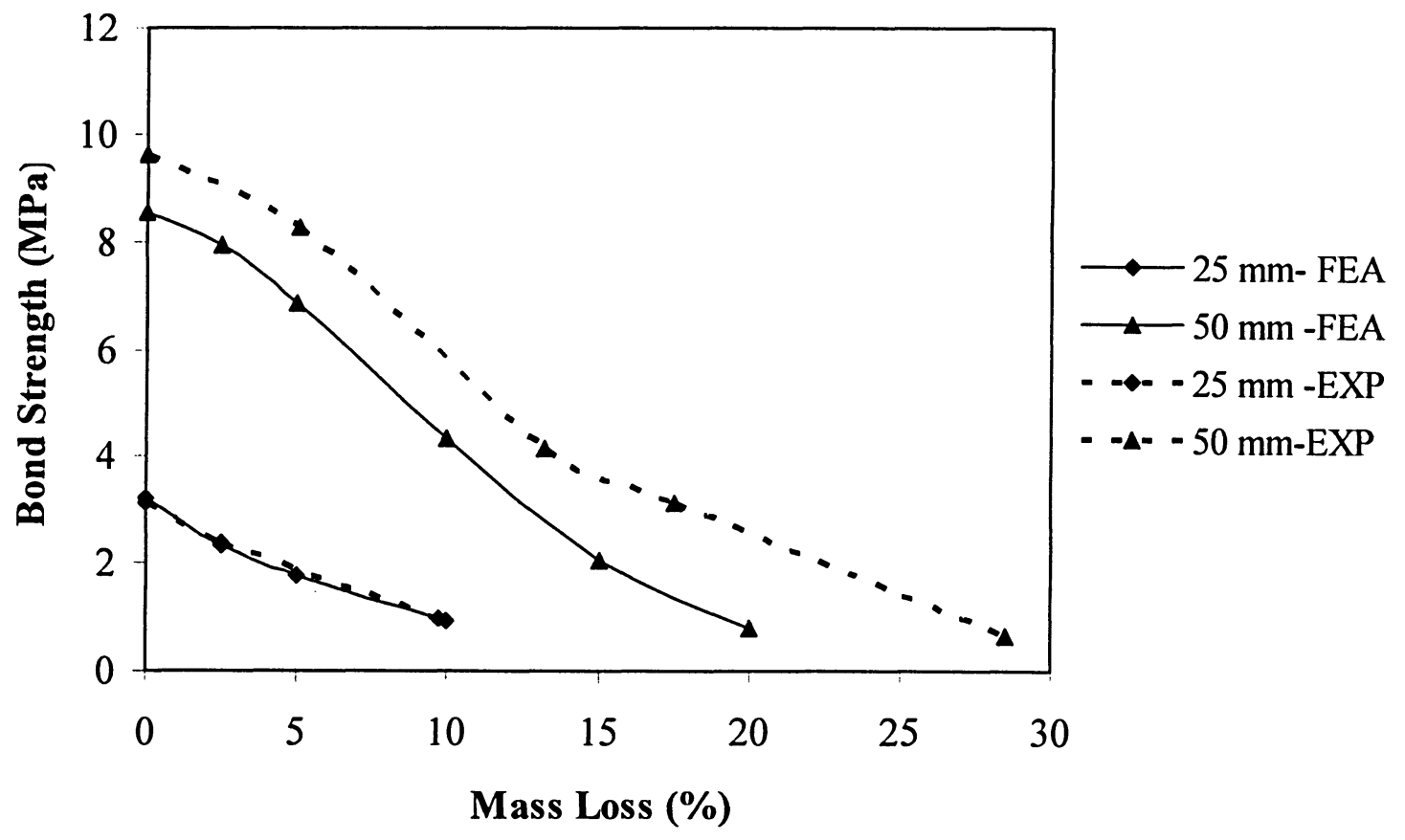

Figure 5.21: Effect of corrosion on bond strength for different cover thicknesses for 50 MPa concrete 


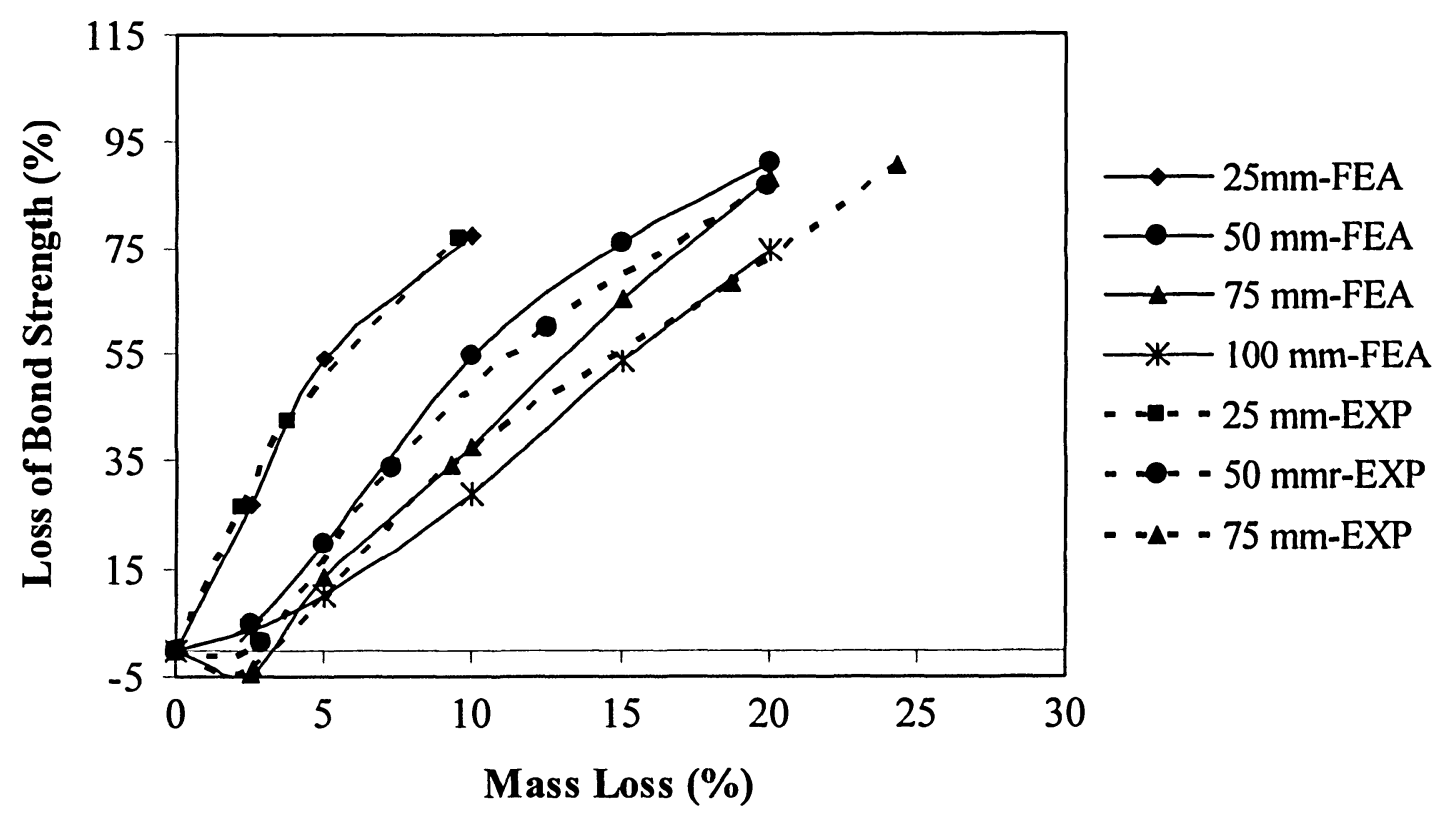

Figure 5.22: Loss of average bond strength at different level of corrosion for $60 \mathrm{MPa}$ concrete mixture

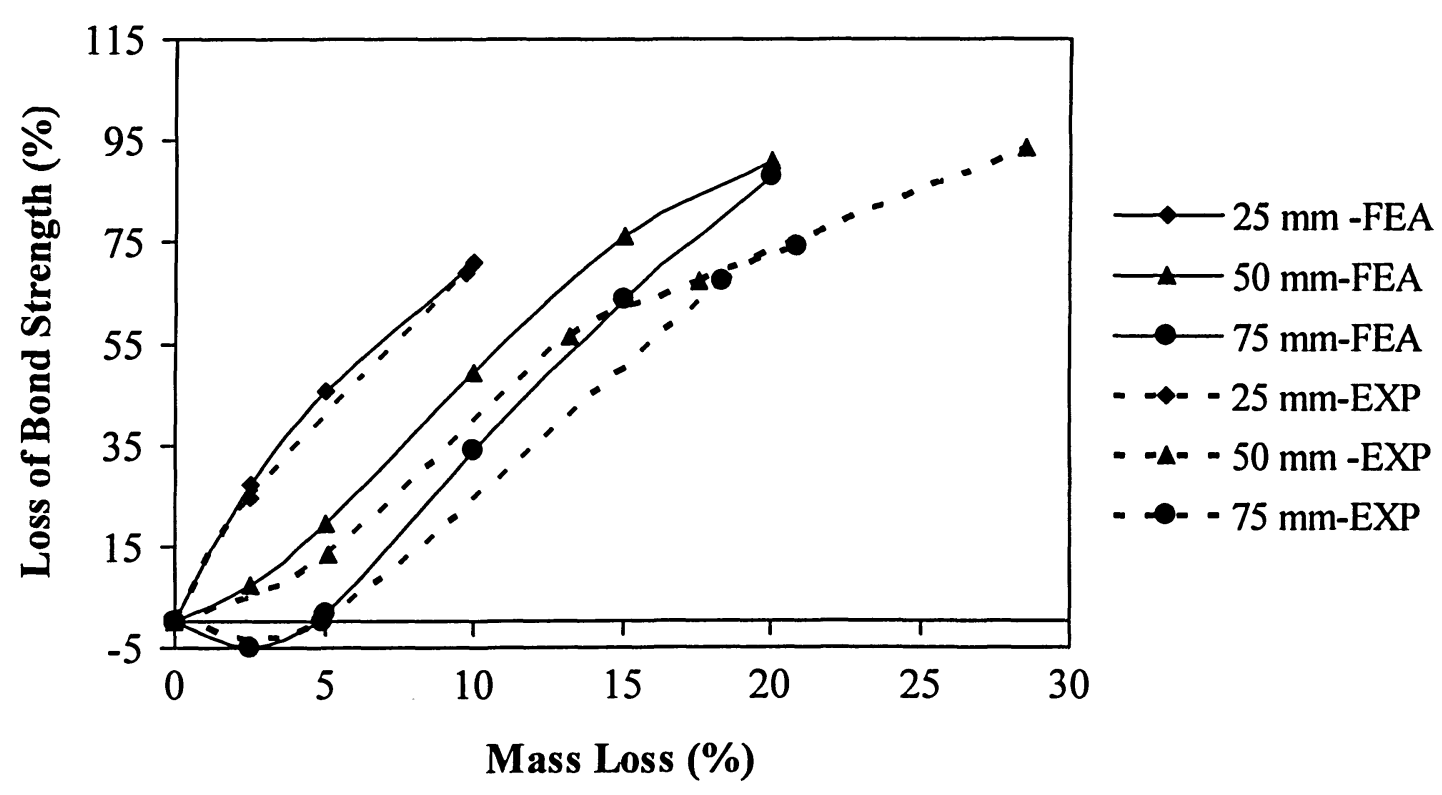

Figure 5.23: Loss of average bond strength at different level of corrosion for $50 \mathrm{MPa}$ concrete mixture 
Table 5.3: Data for loss of average bond strength (\%) at different levels of corrosion for both finite element analysis and experimental results for $60 \mathrm{MPa}$ concrete

\begin{tabular}{|c|c|c|c|c|}
\hline \multirow{2}{*}{ Cover } & \multicolumn{2}{|c|}{ Finite Element Analysis } & \multicolumn{2}{|c|}{ Experimental Results } \\
\hline & $\%$ mass loss & $\begin{array}{l}\% \text { loss of bond } \\
\text { strength (FEA) }\end{array}$ & \%mass loss & $\begin{array}{l}\text { \% loss of bond } \\
\text { strength (EXP) }\end{array}$ \\
\hline \multirow{3}{*}{$25 \mathrm{~mm}$} & 2.5 & 26.83 & 2.2 & 26.58 \\
\hline & 5 & 54.03 & 3.78 & 42.43 \\
\hline & 10 & 77.32 & 9.55 & 76.97 \\
\hline \multirow{5}{*}{$50 \mathrm{~mm}$} & 2.5 & 4.78 & 2.85 & 1.5 \\
\hline & 5 & 19.78 & 7.26 & 33.66 \\
\hline & 10 & 54.44 & - & - \\
\hline & 15 & 75.81 & 12.5 & 60 \\
\hline & 20 & 90.75 & 19.94 & 86.68 \\
\hline \multirow{5}{*}{$75 \mathrm{~mm}$} & 2.5 & -4.48 & 2.65 & -3.52 \\
\hline & 5 & 10.57 & - & - \\
\hline & 10 & 37.67 & 9.23 & 34.06593 \\
\hline & 15 & 65.3 & 18.7 & 67.85714 \\
\hline & 20 & 87.94 & 24.3 & 90.22 \\
\hline
\end{tabular}


Table 5.4: Data for loss of average bond strength (\%) at different levels of corrosion for both finite element analysis and experimental results for $50 \mathrm{MPa}$ concrete

\begin{tabular}{|c|c|c|c|c|}
\hline \multirow{2}{*}{ Cover } & \multicolumn{2}{|c|}{ Finite Element Analysis } & \multicolumn{2}{|c|}{ Experimental Results } \\
\hline & $\%$ mass loss & $\begin{array}{l}\% \text { loss of bond } \\
\text { strength (FEA) }\end{array}$ & \%mass loss & $\begin{array}{l}\% \text { loss of bond } \\
\text { strength (EXP) }\end{array}$ \\
\hline \multirow{3}{*}{$25 \mathrm{~mm}$} & 2.5 & 27.26 & 2.53 & 24.5 \\
\hline & 5 & 45.64 & - & - \\
\hline & 10 & 70.84 & 9.74 & 68.98 \\
\hline \multirow{5}{*}{$50 \mathrm{~mm}$} & 2.5 & 7.16 & - & - \\
\hline & 5 & 19.74 & 5.1 & 13.7 \\
\hline & 10 & 49.34 & 13.23 & 56.67 \\
\hline & 15 & 76 & 17.56 & 67.33 \\
\hline & 20 & 91 & 28.48 & 93.33 \\
\hline \multirow{5}{*}{$75 \mathrm{~mm}$} & 2.5 & -4.87 & - & - \\
\hline & 5 & 1.66 & - & - \\
\hline & 10 & 34.1 & - & - \\
\hline & 15 & 64 & 18.34 & 67.41 \\
\hline & 20 & 87.6 & 20.85 & 73.74 \\
\hline
\end{tabular}




\subsubsection{Effect of Concrete Cover Thickness on the Bond strength at the Corroded Steel-Concrete Interface}

The concrete cover thickness is an important parameter on the effect of corrosion. When the rebar is corroded, the increased volume of corrosion product produces the bursting force which causes cracking of concrete. The resistance of bursting force depends on cover thickness of concrete. Therefore the concrete cover thickness and bar diameter ratio $\left(c / d_{b}\right)$ is considered as a significant parameter.

Figures 5.24 to 5.27 show the effect of concrete cover on the loss of bond capacity at $5 \%$ and $10 \%$ mass loss. The variation of the loss of bond capacity with concrete cover thickness is almost linear. In FE analysis, for $60 \mathrm{MPa}$ concrete at $5 \%$ mass loss, the loss of bond capacity are $54 \%, 19 \%$ and $13 \%$ for $25 \mathrm{~mm}, 50 \mathrm{~mm}$ and $75 \mathrm{~mm}$ concrete cover thicknesses, respectively.

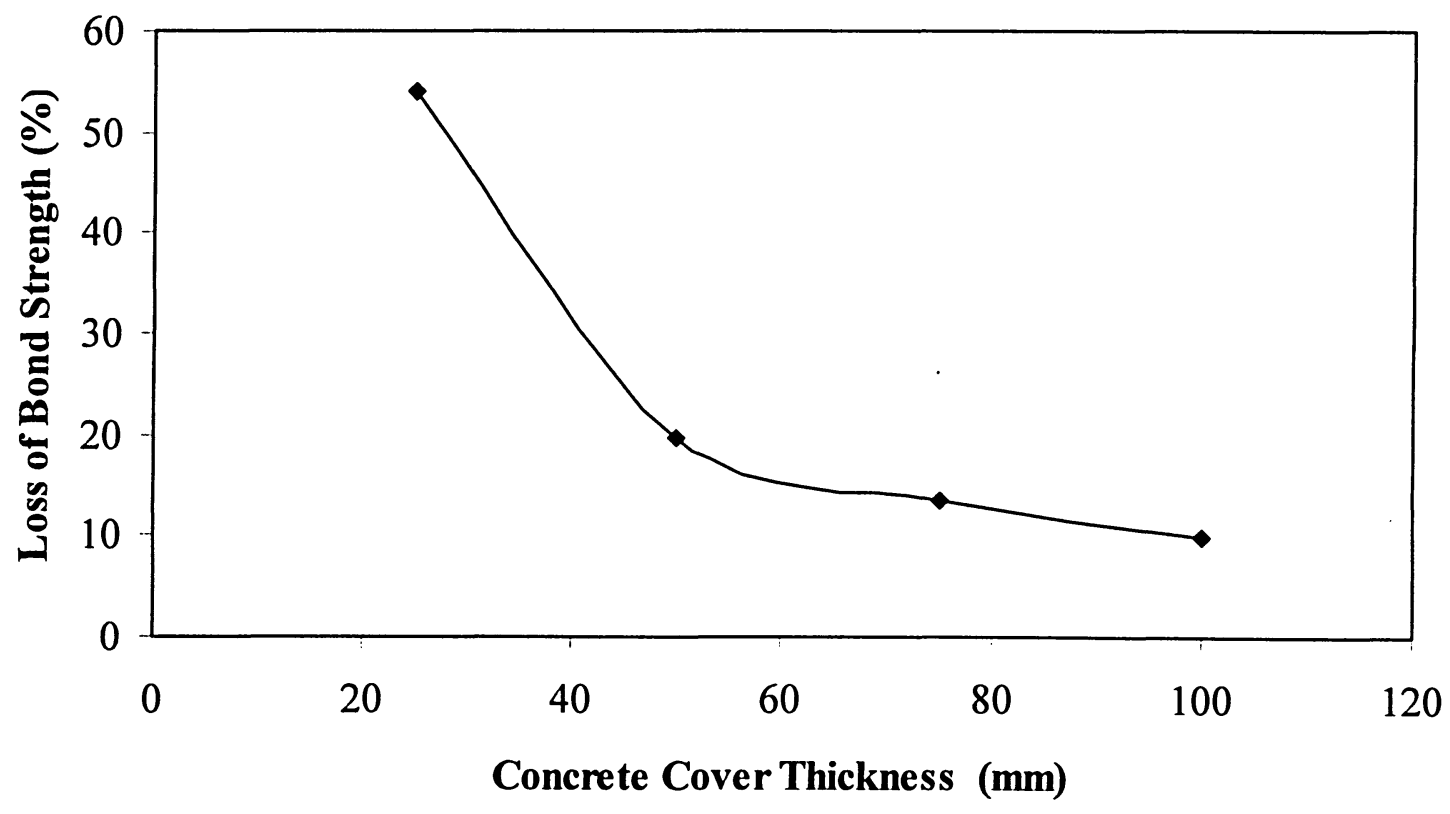

Figure 5.24: Loss of average bond strength for different cover thicknesses at $5 \%$ mass loss for $60 \mathrm{MPa}$ concrete mixture 


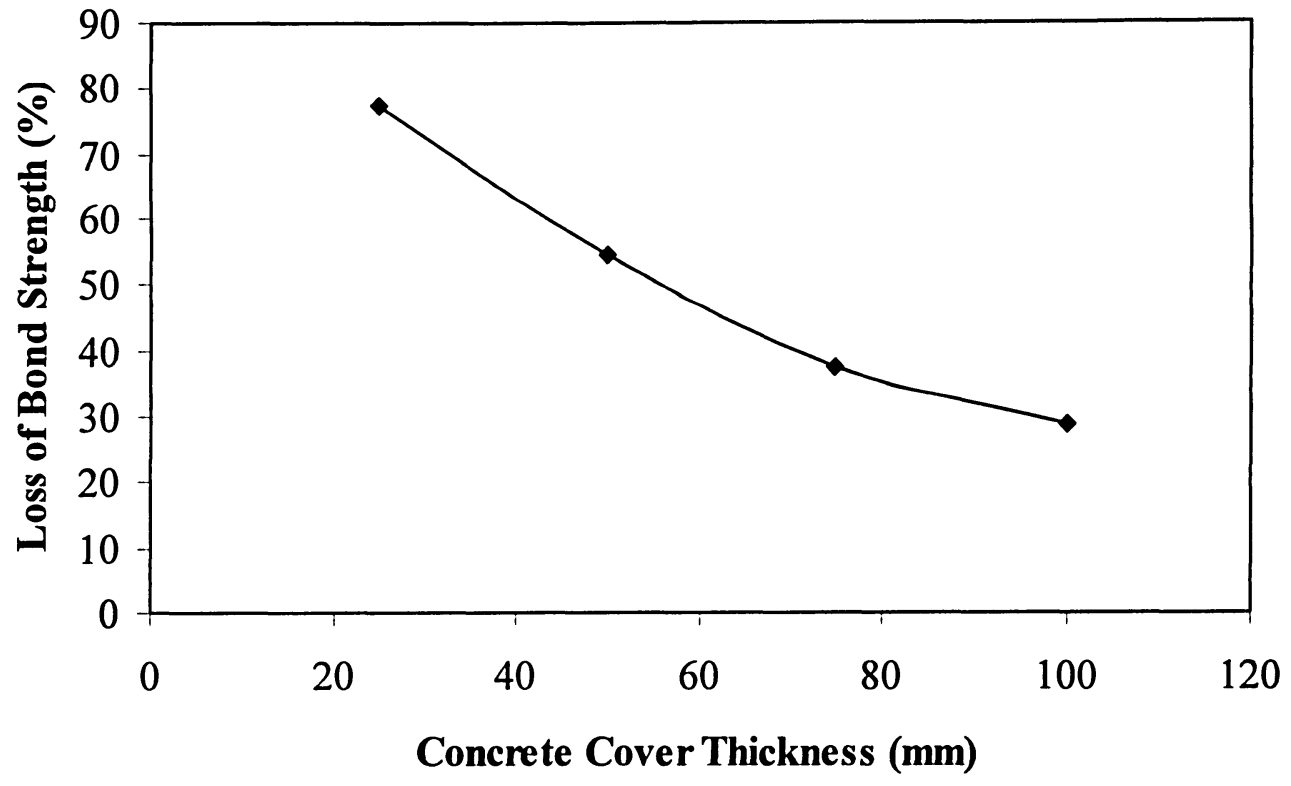

Figure 5.25: Loss of average bond strength for different cover thicknesses at $10 \%$ mass loss for $60 \mathrm{MPa}$ concrete mixture

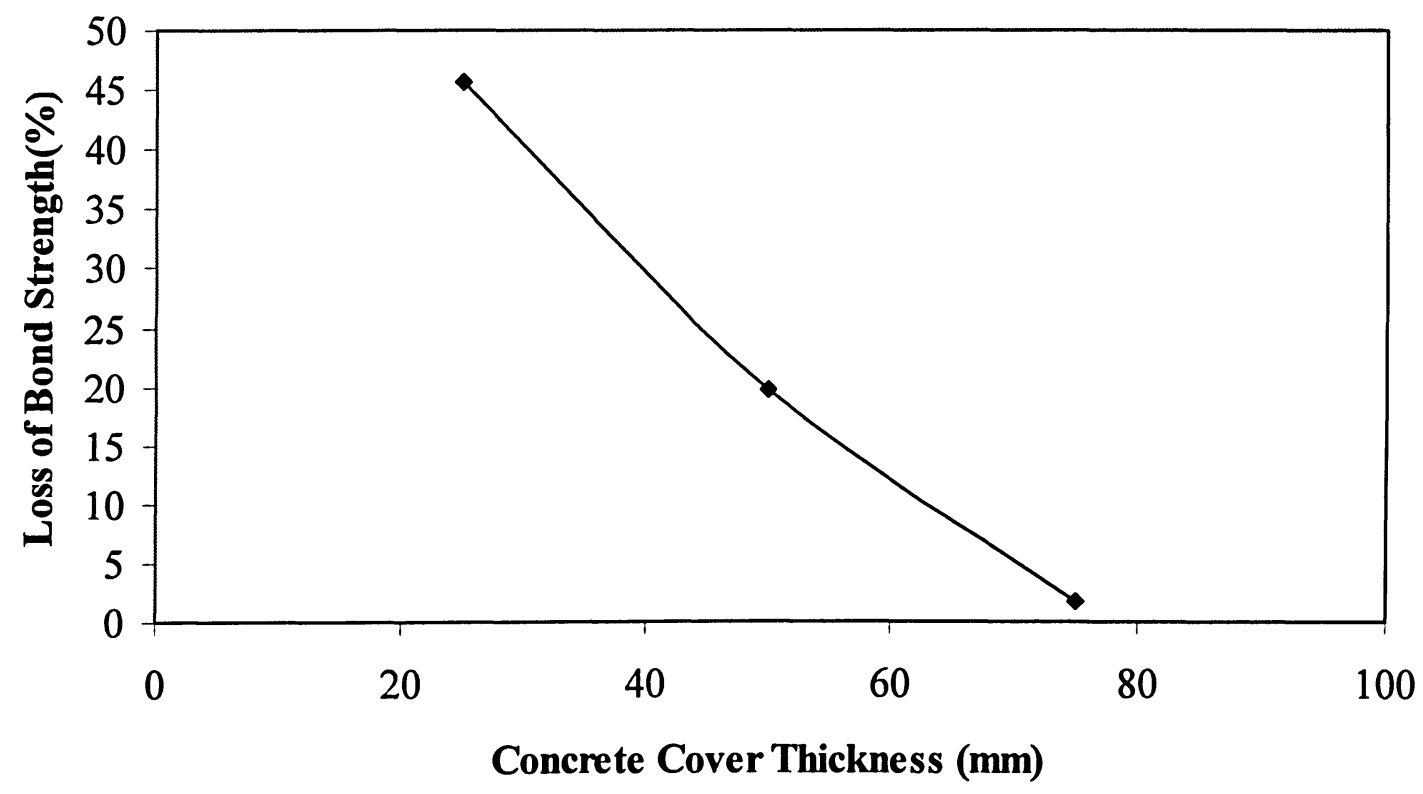

Figure 5.26: Loss of average bond strength for different cover thicknesses at $5 \%$ mass loss for $50 \mathrm{MPa}$ concrete mixture 


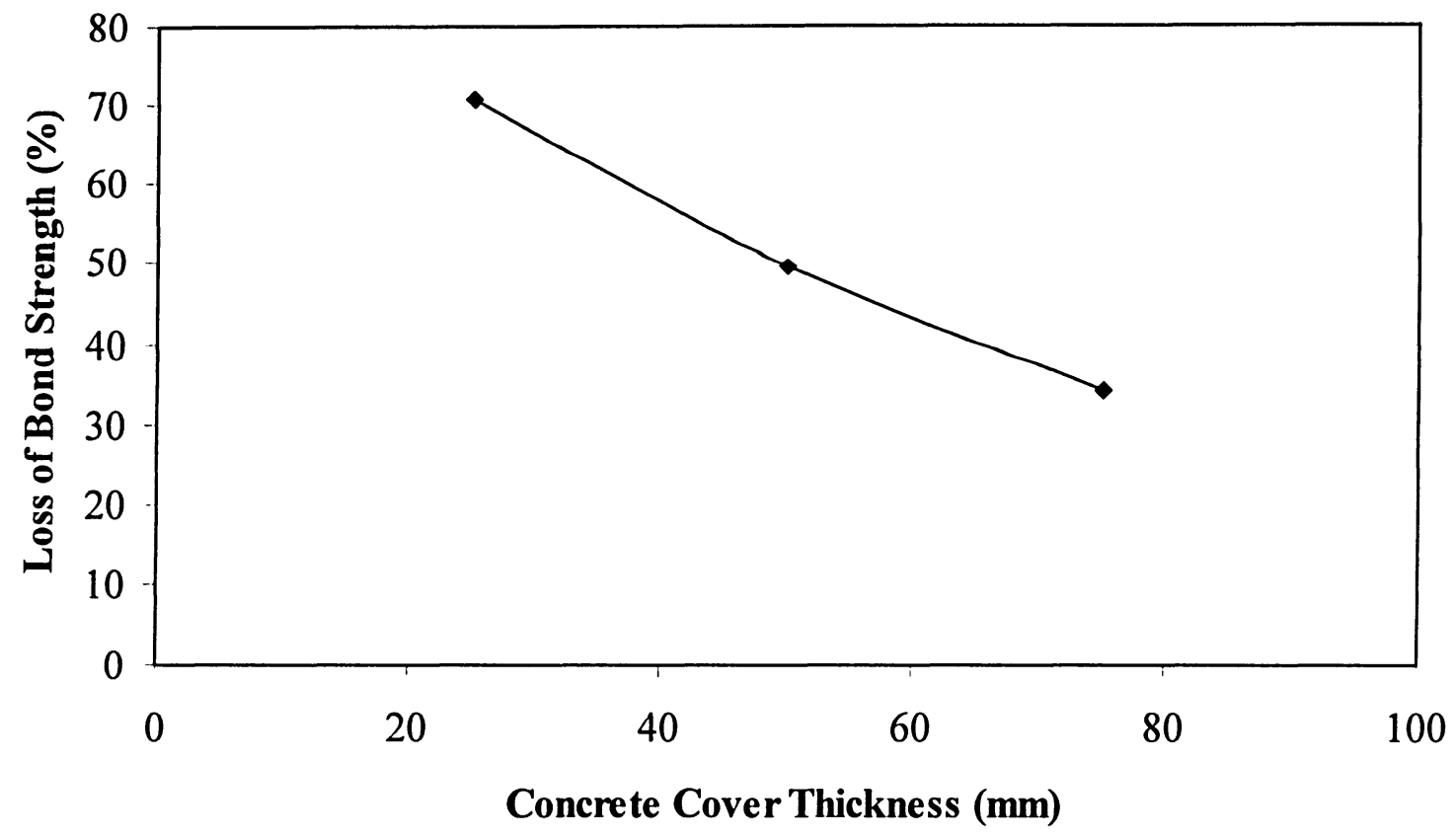

Figure 5.27: Loss of average bond strength for different cover thicknesses at $10 \%$ mass loss for $50 \mathrm{MPa}$ concrete mixture

5.2.4 Effect of Compressive Strength of Concrete on the Bond strength at the Corroded Steel-Concrete Interface

The effect of compressive strength on the loss of bond strength due to corrosion is shown in Figure 5.28 to 5.31. In the case of $25 \mathrm{~mm}$ concrete cover thickness, $60 \mathrm{MPa}$ concrete demonstrates better performance as compared to the specimens with $50 \mathrm{MPa}$ concrete with the same concrete cover. It should be noted that the effect of corrosion is almost same for concrete covers $50 \mathrm{~mm}$ and $75 \mathrm{~mm}$ thick. 


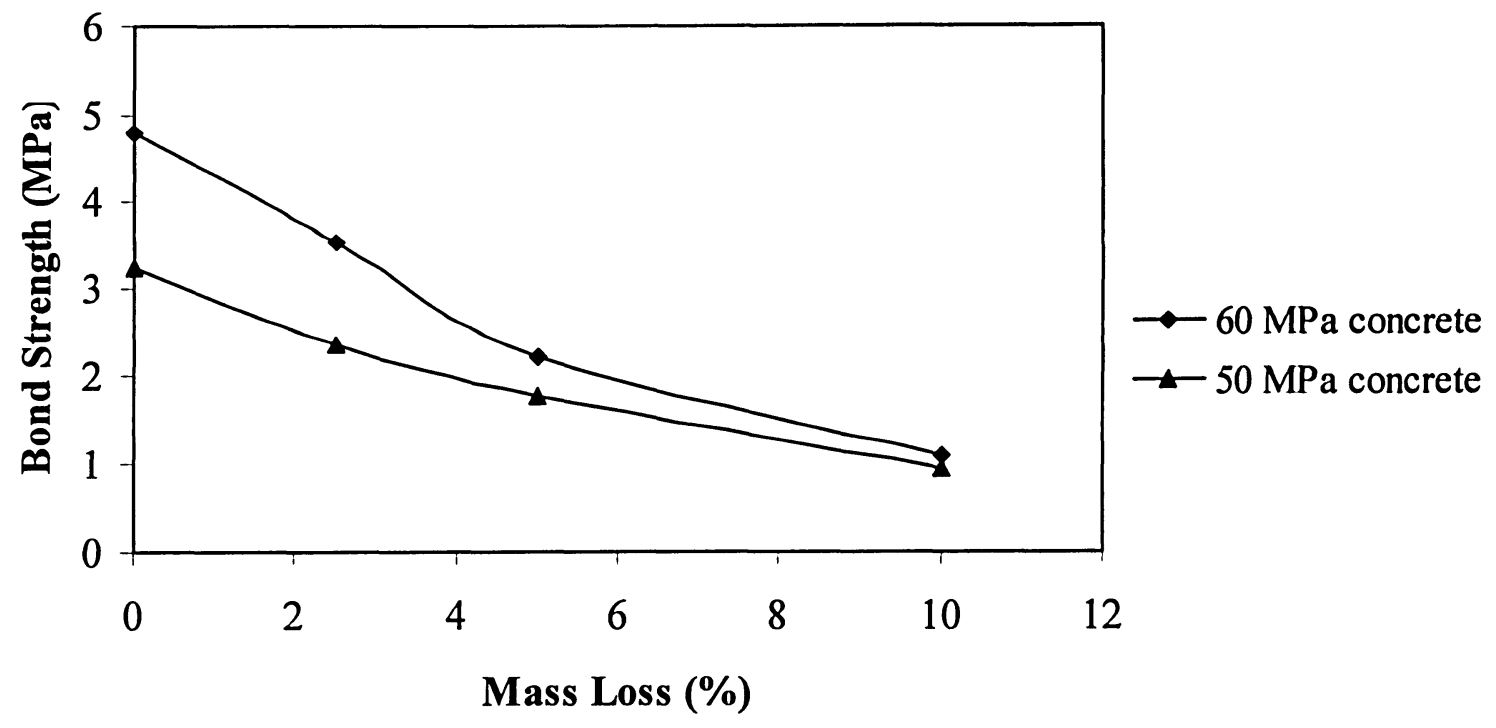

Figure 5.28: Effect of corrosion on average bond strength for $25 \mathrm{~mm}$ concrete cover thickness for different concrete mixtures

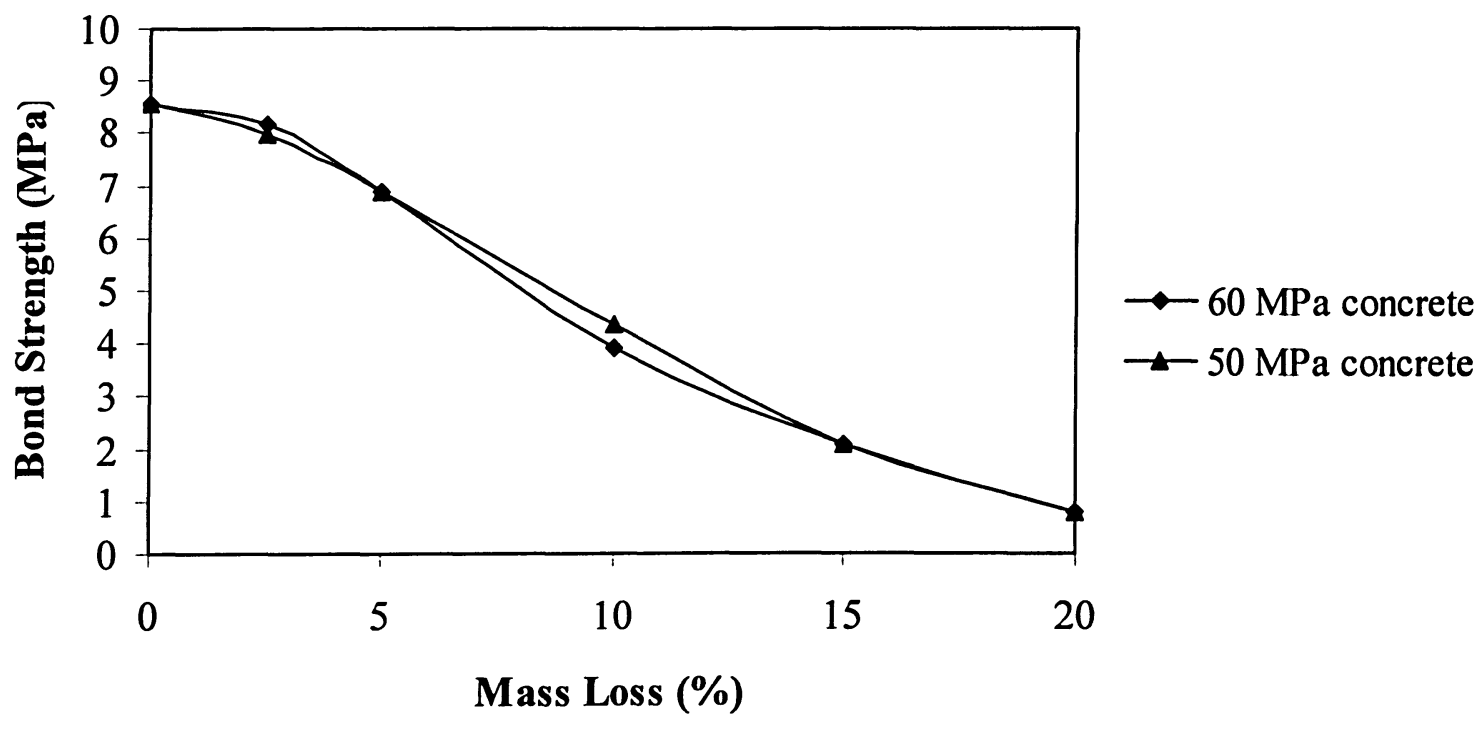

Figure 5.29: Effect of corrosion on average bond strength for $50 \mathrm{~mm}$ concrete cover thickness for different concrete mixtures 


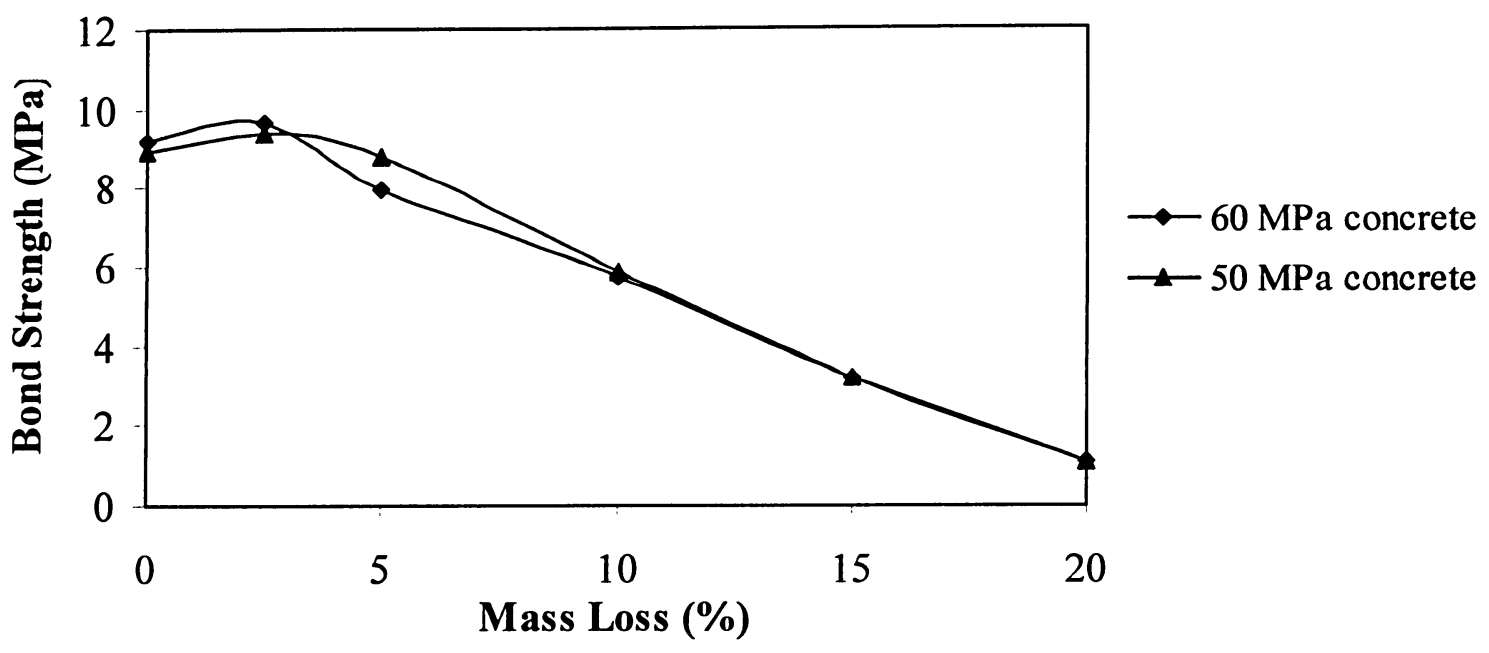

Figure 5.30: Effect of corrosion on average bond strength for $75 \mathrm{~mm}$ concrete cover thickness for different concrete mixtures

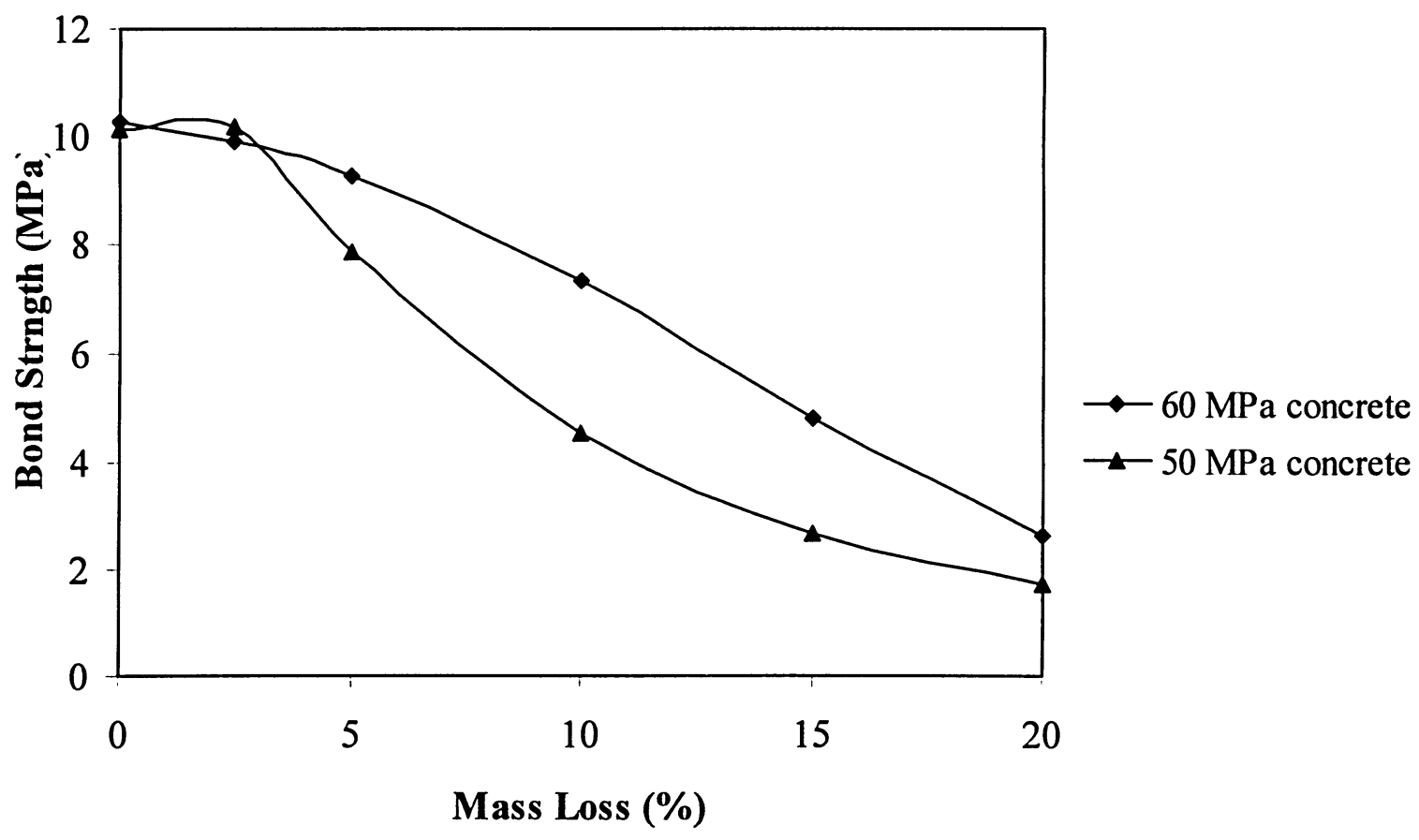

Figure 5.31: Effect of corrosion on average bond strength for $100 \mathrm{~mm}$ concrete cover thickness for different concrete mixtures 


\subsection{Validation of the Model}

The model developed to determine the bond stress at uncorroded and corroded steelconcrete interface is validated by analyzing some pullout tests. The pullout tests performed by Cabrera and Ghoddoussis (1992) and Al-Sulaimani et al. (1990) were analyzed with the model, and the FE and experimental results are compared.

\subsubsection{Cabrera and Ghoddoussis' (1992) Pullout Test}

The bond model is validated by using the results of Cabrera and Ghoddoussiss' (1992) pullout tests which were performed on $150 \mathrm{~mm}$ cubes with $12 \mathrm{~mm}$ diameter reinforcing bar centrally embedded in the cube to find the effect of corrosion on the bond strength at the steel-concrete interface. A short embedded length, that is 4 times the bar diameter of the reinforcing steel is chosen to ensure the splitting failure or the failure by yielding of the reinforcing steel. The average 28 day compressive strength of concrete mixture was $56 \mathrm{MPa}$. Figure 6.1 shows the variation of bond stress with slip for both the experimental and $\mathrm{FE}$ analysis results at different level of corrosion. Figures 5.31 and 5.32 show that the bond strength decreases with corrosion in both experiment and FE analysis. The results of finite element analysis show very good agreement with the experimental results as shown in Figures 5.32 to 5.34 . 


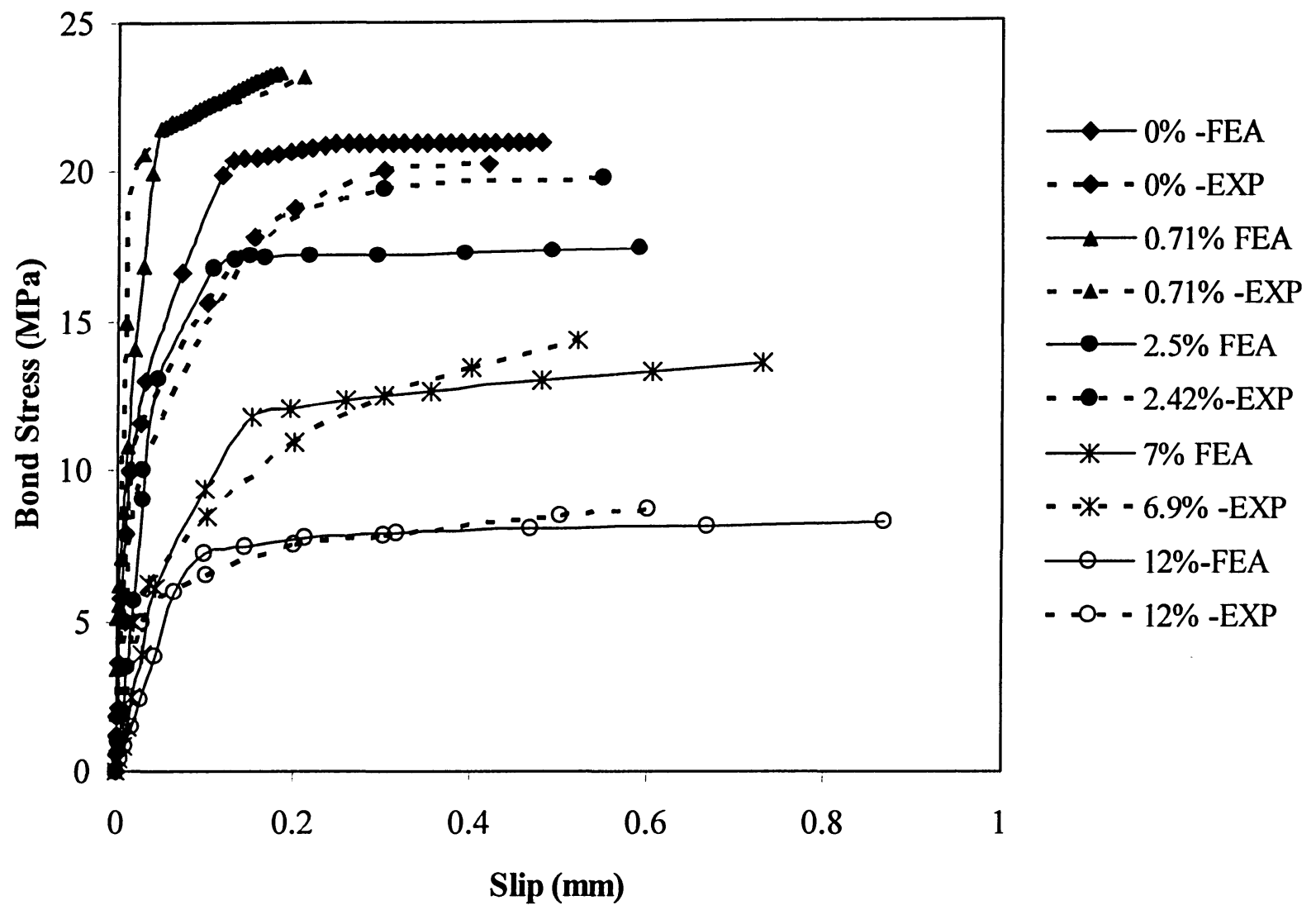

Figure 5.32: Variation of average bond stress with slip at different level of corrosion

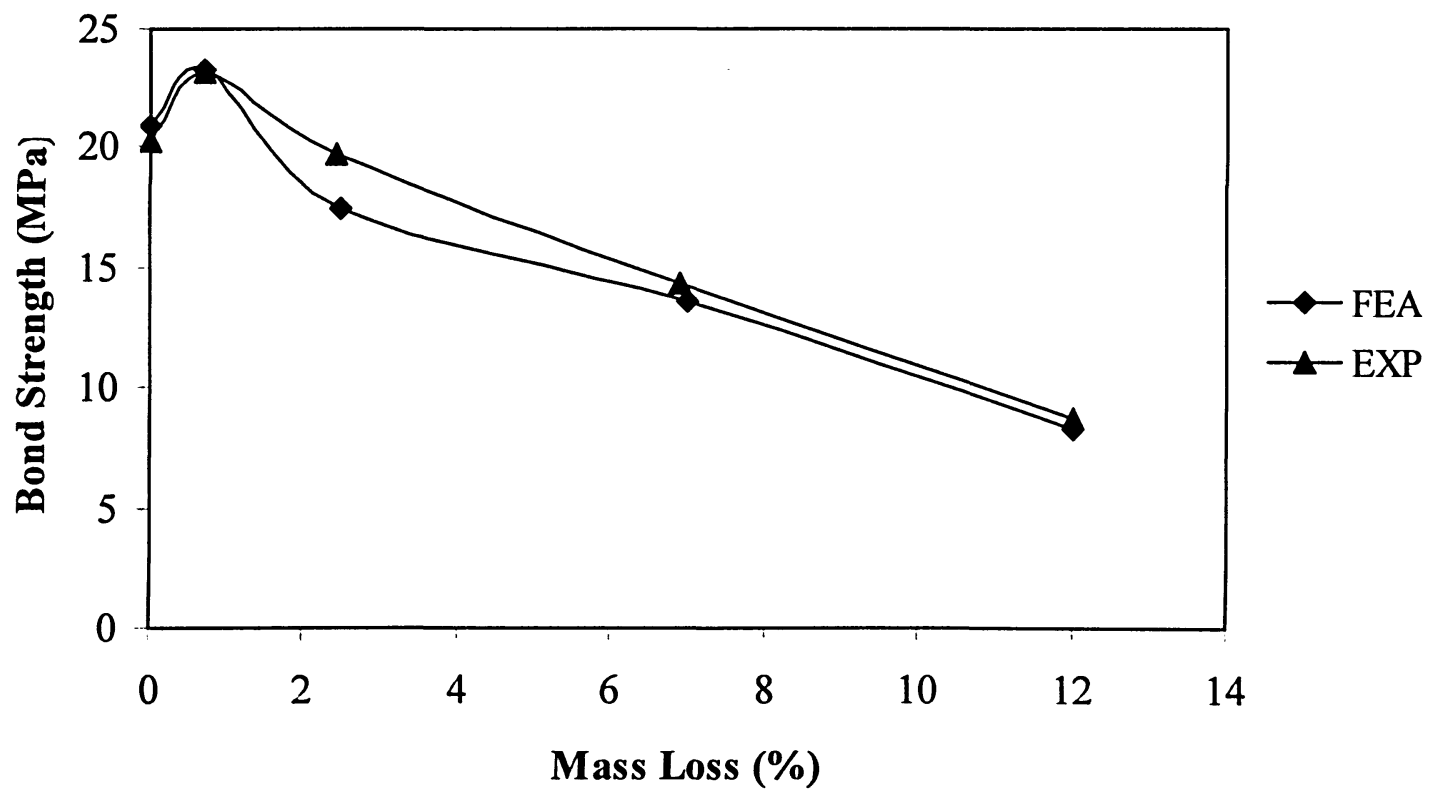

Figure 5.33: Average bond strength at different level of corrosion 


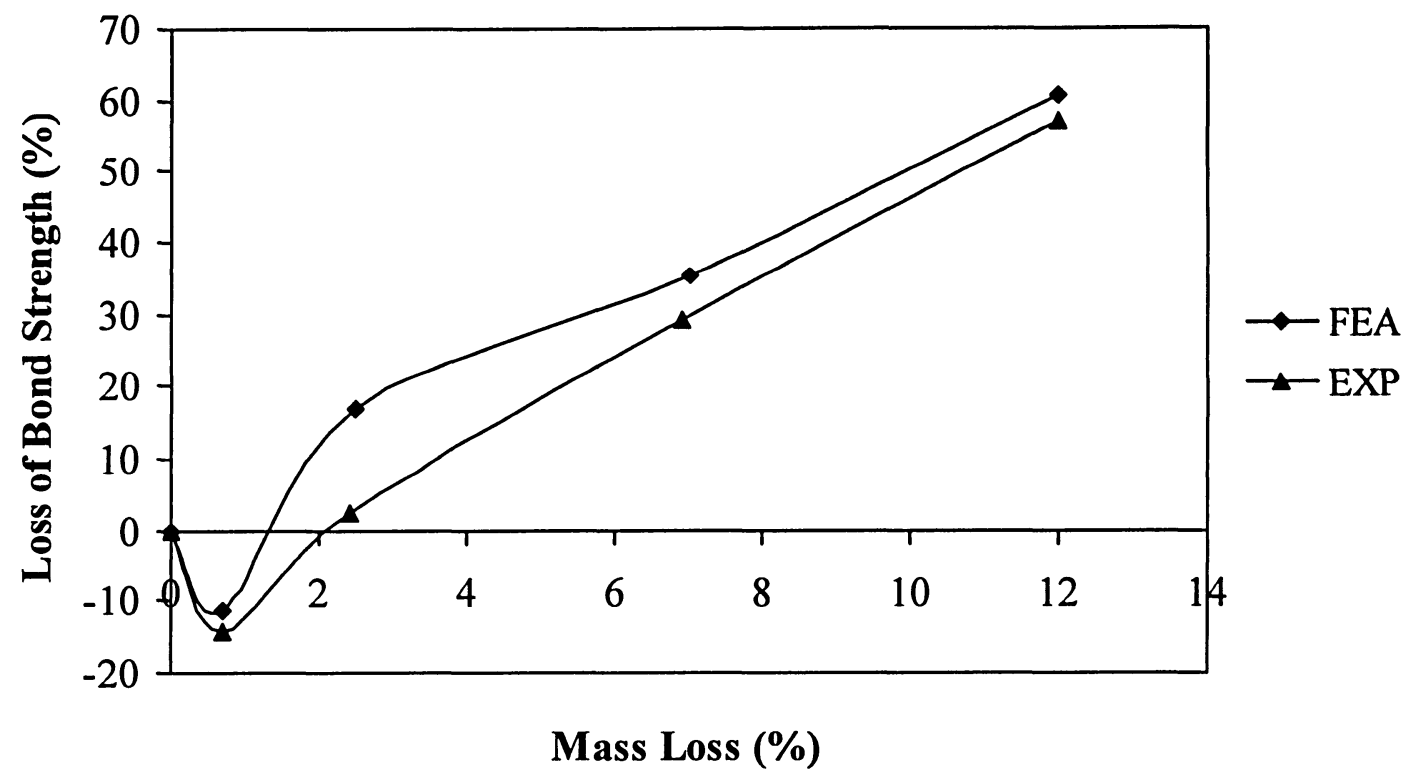

Figure 5.34: Loss of average bond strength at different level of corrosion

\subsubsection{Pullout Tests of Al-Sulaimani et al. (1990)}

The bond model is used to analyze the results of pullout tests conducted by Al-Sulaimani et $a l$. (1990). The pullout tests were conducted on $150 \mathrm{~mm}$ cubic concrete specimens with $10 \mathrm{~mm}$ diameter reinforcing bar surrounded centrally. The ratio of embedded length and bar diameter $\left(L / d_{b}\right)$ is 4 , and the average compressive strength of concrete is $30 \mathrm{MPa}$. Figures 5.35 to 5.37 show how the corrosion affects the average bond stress at the steelconcrete interface in both FE and experimental analysis. The FE analysis results compare well with experimental results. 


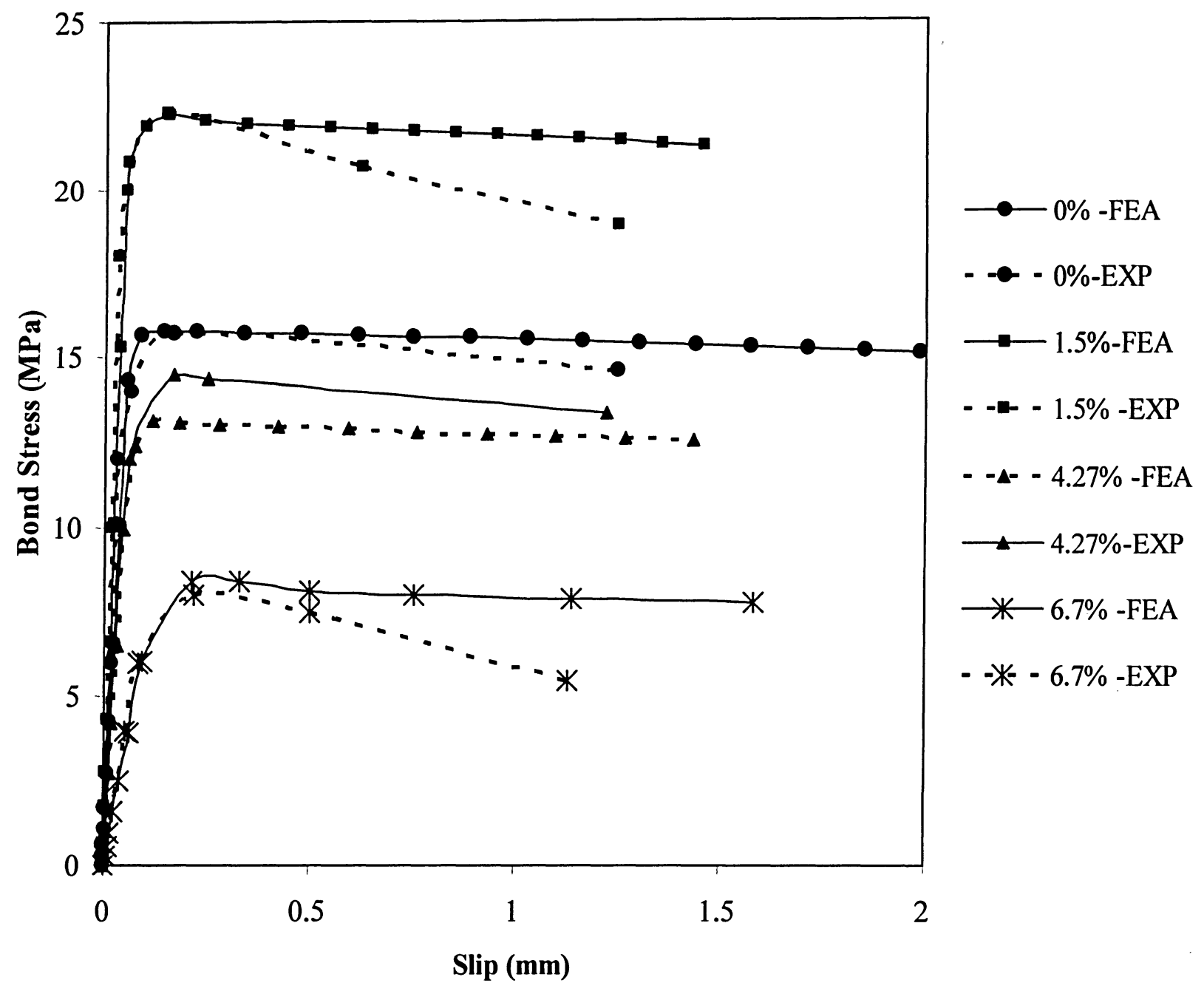

Figure 5.35: Variation of average bond stress with slip at different level of corrosion 


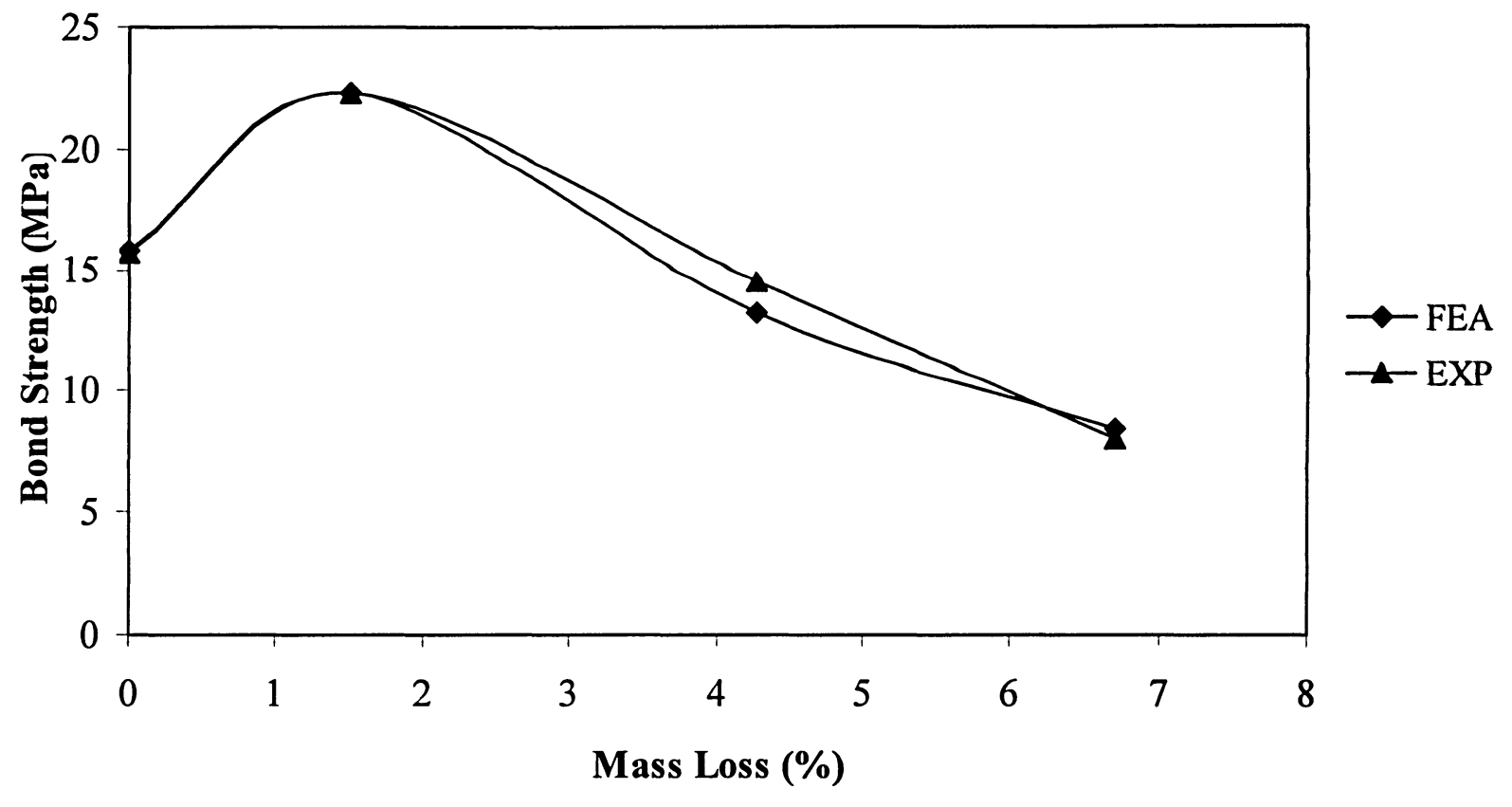

Figure 5.36: Average bond strength at different level of corrosion

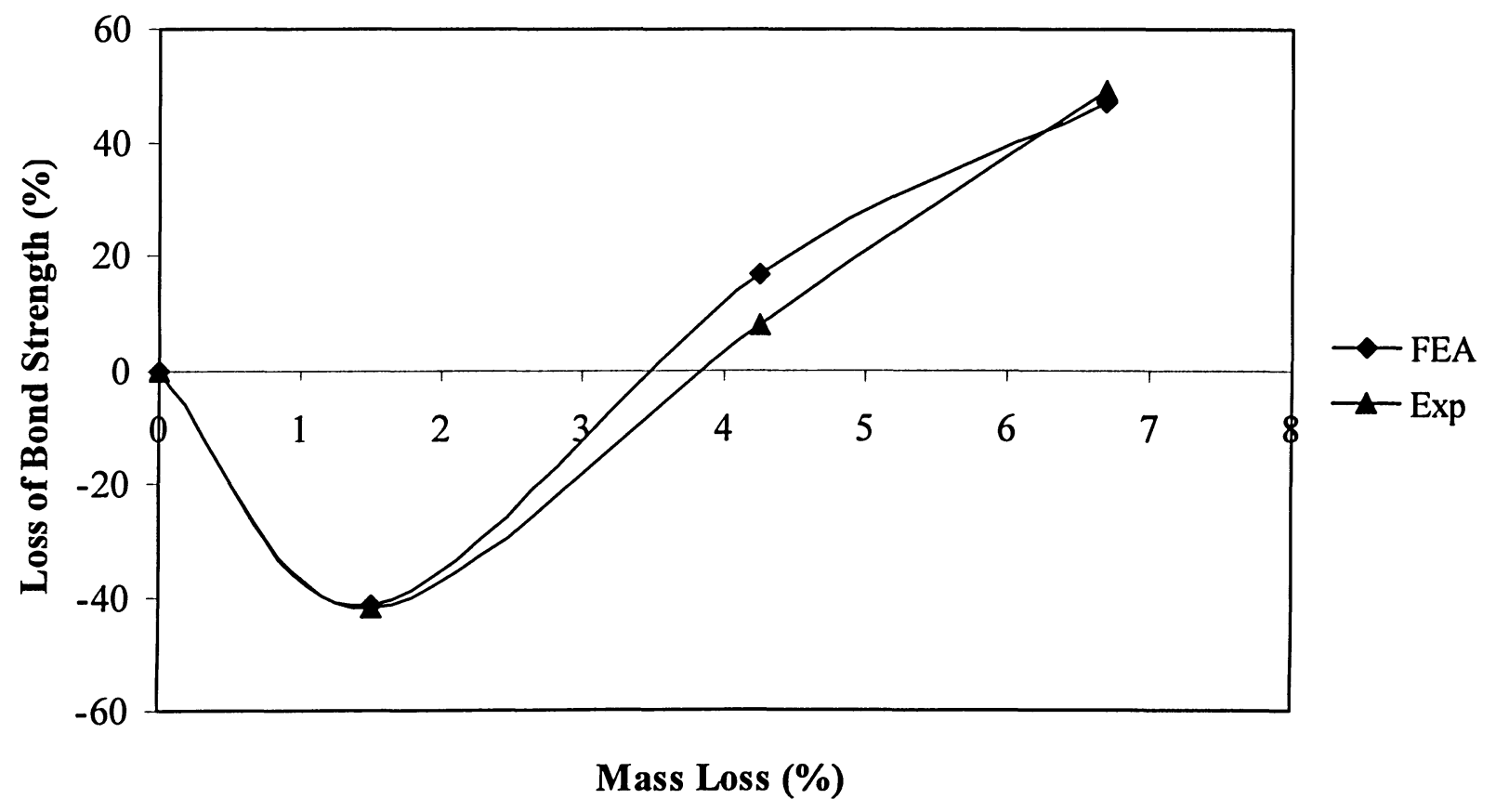

Figure 5.37: Loss of average bond strength at different level of corrosion 


\subsection{Summary}

The bond model developed in Chapter 4 is calibrated by analyzing the pull-out test performed by Amleh (2000). The results obtained from the experiment and the FE analysis, are compared by plotting the bond stress-slip curve for specimens with corroded and uncorroded reinforcing steel, the bond strength at different level of corrosion etc. The FE model shows very good agreement with the experimental results.

The model is also validated by analyzing some pullout tests of Cabrera and Ghoddoussis (1992) and Al-Sulaimani et al. (1990) and the FE analysis and experimental results are compared. A good agreement was noted between the results of the experiment and the FE analysis; this shows a good validation of the model. 


\section{Chapter 6}

\section{Conclusions and Future Recommendations}

\subsection{Conclusions}

A model of bond stress at the steel-concrete interface for both uncorroded and corroded reinforcing steel is developed. The nonlinear finite element software "ABAQUS" is used to develop the model. The mechanical behaviour of contact interface between the steel and the concrete is developed by modeling the contact pressure and the friction.

The bond between steel and concrete is the critical feature of reinforced concrete structures. It enables the use of concrete, which has low-tension, as a structural material. For developing the model of bond stress, it is very important to define the mechanical behaviour at the steel-concrete interface. Therefore, the model defines the contact pressure which acts normal to the steel concrete interface and the friction acting parallel to the contact surfaces.

When the reinforcing steel is corroded, the expanded volume of corrosion product increases the hoop and radial stresses which cause longitudinal cracks on the concrete. With the increase of corrosion, these cracks propagate and the width of the cracks increases. Therefore, the holding capacity of concrete is decreased which reduces the contact pressure at the steel concrete interface. Moreover, due to deterioration of the ribs, the rib height decreases significantly which affects the interlocking capacity of the steel and the concrete and the horizontal component of the bearing force of the ribs also decreases. Therefore, the deterioration of the ribs and the reduction of the effective crosssectional area of the steel bar cause the significant reduction of the contact pressure. 
The flaky corroded layer acts as a lubricant which reduces the friction at the steelconcrete interface. The reduction of contact pressure and friction at different level of corrosion is modeled. The equations describing the contact pressure and friction at different levels of corrosion are developed. Thus the bond stress at the steel-concrete interface is computed.

The pullout tests performed by Amleh $(: 000)$ are used to calibrate the model. Then the results of finite element $(\mathrm{FE})$ analysis il e compared with the experimental results of Amleh which show good agreement. Boii. in FE analysis and experimental results, the loss of bond capacity is almost linear with mass loss of rebar. FE analysis and experimental results show that, up to $5 \%$ mass loss, the bond capacity loss is moderate, at 10 to $15 \%$ mass loss, significant amount of bond capacity is lost and at about $20 \%$ mass almost all bond capacity is lost.

The model is validated by finite element analysis of the pullout tests, performed by Cabrera and Ghoddoussis (1992) and Al-Sulaimani et al. (1990). The FE results are compared with the experimental results and a good agreement is noted.

\subsection{Future Research Work}

The future researches can emphasize on the followings:

1. Modeling the effect of corrosion on bond strength of flexural members such as beams.

2. Bridges are mostly deteriorated due to corrosion (the prestressing tendons. Therefore, modeling the bond stress of corroded prestressilig tendons in prestressed concrete structure is very important.

3. In the current study, the effect of corrosion is modeled by modeling the contact pressure and friction at steel-concrete interface, and modeling the effect of corrosion on 
contact pressure and friction. But the effect of corrosion on crack width is not included. A study should be undertaken to model the crack width at different level of corrosion.

4. As the information is still inadequate on the mechanical behaviour of the corrosive products, it is very difficult to model this phenomenon. As presented by Peter-Lazar and Gerard (2000), there might be possibilities for the rust to fill up the pores of the concrete close to the reinforcing steel, before starting to apply stresses on the structures. It means that the porosity of the concrete is very important on the bond behavoiur. Further efforts can be made on experimental and analytical studies to investigate such bond behaviour.

5. An extensive study is needed to determine the residual bond strength which is very important to determine the remaining service life of deteriorated concrete structures due to corrosion. 


\section{References}

ABAQUS/Standard User's Manual (2002), Volume 2, Version 6.3, Hibbitt, Karlsson and Sorensen, Inc.

ABAQUS/Standard User's Manual (2002), Volume 3, Version 6.3, Hibbitt, Karlsson and Sorensen, Inc.

ACI Committee 408 (1966), "Bond Stress-The State of the Art," Journal of the American Concrete Institute, Vol. 63, No. 11, pp. 1161-1188.

Ahmed, S., Bhattacharjee, B., and Wason, R, (1997), "Experimental Service Life Prediction of Rebar-Corroded Reinforced Concrete Structure" ACI Materials Journal, Vol. 94, No. 4, pp. 311-316.

Al-Sulaimani, G. J., Kaleemullah, M., Basunbul, I. A., and Rasheeduzzafar, (1990), "Influence of Corrosion and Cracking on Bond Behaviour and Strength of Reinforced Concrete Members," ACI Structural Journal, Vol. 87, No. 2, pp. 220-231.

Amleh, L., (2000), "Bond Deterioration of Reinforcing Steel in Concrete due to Corrosion," Ph.D Thesis, McGill University, Canada, pp.1-377.

Amleh, L., and Mirza, S. (1999), "Corrosion Influence on Bond Between Steel and Concrete" ACI Structural Journal, Vol. 96, No. 3, pp. 415-423.

ASTM A615-90 (1992), "Specifications for deformed and plain Billet-Steel Bars for Concrete Reinforcement," 1992 Book of ASTM Standards, Section 1 - Iron and Steel Products, Volume 01.04 Steel-Structural, Reinfircing Pressure Vessel, Railway, pp. 389392. 
Auyeung, Y., Balaguru, P. and Chung, L., (2000), "Bond Behaviour of Corroded Reinforcement Bars," ACI Material Journal, Vol. 97, No. 2, pp. 214-220.

Cabrera, J. G., and Ghoddousi, P., (1992), "The effect of Reinforcement Corrosion on the Strength of the Steel/Concrete Bond" International Conference - Bond in Concrete - from Research to Practise Proceedings, pp. 11-24.

Cabrera, J. G., (1996), "Deterioration of Concrete Due to Reinforcement Corrosion," Cement and Concrete Composites, Vol. 18, Issue 1, pp. 47-59.

Cairns, J., and Du, Y., (2002), "Residual Bond Capacity of Corroded Plain Surface Reinforcement" International Conference - Bond in Concrete from Research to Standards, Budapest, pp. 129-136.

Cairns, J., and Abdullah, R. B., (1996), "Bond Strength of Black and Epoxy-Coated Reinforcement-A Theoretical Approach," ACI Materials Journal, Vol. 93, No. 4, pp. 362-369.

Capozucca, R.,(1995), "Damage to Reinforced Concrete Due to Reinforcement Corrosion," Construction and Building Materials, Vol. 9, No.5, pp.295-303.

CEB-FIP, (2000), Bond of Reinforcement in Concrete: State-of Art Report/Prepares by Task Group Bond Models (former CEB task Group 2.5), Lausanne, and Switzerland: International Federation for Structural Concrete.

CEB-MC90 (1990),"CEB-FIP Model Code 1990, Thomas Telford Services Ltd., London, England.

Choi, C.O., and Lee, S.W., (2002), "Interfacial Bond Analysis of Deformed Bars to Concrete" ACI Structural Journal, Vol. 99, No. 6, pp. 750-756. 
Ciampi, V., Elingehausen, R., Bertero, V., Popov, P., (1981), “Analytical Model for Deformed Bar Bond under Generalized Excitations" Trans. IABSE Colloquium on Advanced Mechanics of Reinforced Concrete, Delft, Netherlands.

Collins, M.P., and Mitchell, D. (1990), "Prestressed Concrete Structures," Prentice-Hall, Englewood Cliffs, N.J.

Coronelli, D., (2002), "Corrosion Cracking and Bond Strength Modeling for Corroded Bars in Reinforced Concrete" ACI Structural Journal, Vol. 99, No. 3, pp. 267-276.

Dagher, H. J., and Kulendran, S., (1992), "Finite Element Modeling of Corrosion Damage in Concrete Structures" ACI Structural Journal, Vol. 89, No. 6, pp. 699-708.

Darwin, D., and Graham, E., (1993), "Effect of Deformation Height and Spacing on Bond Strength of Reinforcing Bars," ACI Structural Journal, Vol. 90, No. 6, pp. 646657.

Eligehausen, R., Popov, E. P., and Bertero, V. V., (1983), "Local Bond Stress-Slip Relationships of Deformed Bars Under Generalized Excitations," Report No. UCB/EERC 83-23, University of Calgary, Berkley, USA.

Gambarova, P. and Karakoc, C. (1982), "Shear-Confinement Interaction at the Bar-toConcrete Interface" International Conference - Bond in Concrete, Paisley, Scotland, pp. 82-96.

Giuriani, E. (1981), "Experimental Investigation on the Bond-Slip Law of Deformed Bars in Concrete", Iabse Colloquium Delft 81 on Advanced Mechanics of Reinforced Concrete, Final Report, pp. 121-142

Goto, Y. (1971), "Cracks Formed in Concrete around Deformed Tension Bars," ACI Journal, Vol. 68, No. 4, pp 244-251. 
Hamad, B., (1995), "Bond Strength Improvement of Reinforcing Bars with Specially Designed Rib Geometries," ACI structural Journal, Vol. 92, No. 1, pp. 3-13.

Idda, K., (1999), "Verbundverhalten von Betonrippendtählen bei Querzug", Schriftenreihe des Instituts für Massivbau und Baustoffechnologie, Universität kerlsruhe, Heft 34 .

Idun, E., and Darwin, D., (1999), "Bond of Epoxy-Coated Reinforcement: Coefficient of Friction and Rib Face Angle,” ACI structural Journal, Vol. 96, No. 4, pp. 609-611.

Leung, K.Y.C., (2001), "Modeling of Concrete Cracking Induced by Steel Expansion," Journal of Materials in Civil Engineering Vol.13, No.3, pp. 169-175.

Li, C.Q., (2002), "Initiation of Chloride-Induced Reinforcement Corrosion in Concrete Structural Members-Prediction" ACI Structural Journal, Vol. 99, No. 2, pp. 133-143.

Lundgren, K., (2002), "Modeling the Effect of Corrosion on Bond in Reinforced Concrete," Magazine of Concrete Research, Vol. 54, No. 3, pp. 165-173.

Lundgren, K., and Gylltoft, K., (2000), "A model for the Bond between Concrete and Reinforcement," Magazine of Concrete Research, Vol. 52, No. 1, pp. 53-63.

Lutz, L.A., and Gergely, P. (1967)," Mechanics of Bond and Slip of Deformed Bars in Concrete," ACI Journal Proceedings, Vol. 64, No. 11, pp. 711-721.

Martin, H. (1982)," Bond Performance of Ribbed Bars (Pull-Out-Tests) - Influence Of Concrete Composition and Consistency" International Conference - Bond in Concrete, Paisley, Scotland, pp. 289-299.

Marti, P. (1999), "How to treat shear in structural concrete" ACI Structural Journal Vol. 96, No. 3, pp. 408-414. 
Maslehuddin, M., Allam, M. I., Al-Sulaimani, Al-Mana, A. (1990), "Effect of Rusting of Reinforcing Steel on Its Mechanical Properties and Bond with Concrete," ACI Materials Journal, Vol. 87, No. 5, pp. 496-502.

Mirza, S. M., anad Houde, J., (1978), "Study of Bond Stress-Slip Relationships in Reinforced Concrete," ACI Journal, Vol.76, No. 1, pp. 47-71.

Molina, F., Alonso, C. and Andrade, C., (1993), "Cover Cracking as a Function of Bar Corrosion: Part 2-Numerical Model," RILEM Materials and Structures, Vol. 26, pp. 532548.

Nowak, A. S., and Cho, T., (2002), "Reliability Models for Bond Resistance and Corrosion in Concrete Bridges," International Conference - Bond in Concrete from Research to Standards, Budapest, pp. 137-144.

Orangun, C. O., Jirsa, J. O., and Breen, J. E., (1977), "A Re-evaluation of Test Data on Development length and Splices," ACI Journal, vol 77, No 3, pp. 114-122

Park, R., and Paulay, T. (1975), "Reinforced Concrete Structures," John Wiley \& Sons, Inc. N.Y.

Peter-Lazer, I. and Gerard, B.(2000), "Mechanical Behaviour of Corrosion Products Formed at the Steel-Concrete Interface. Testing and Modeling. In Proceedings EM2000, Fourteenth Engineering Mechanics Conference, ASCE, Austin, Texas, USA.

Popovics, S., (1970), "A Review of Stress-Strain Relationships for Concrete," $A C I$ Journal, Vol. 67, No. 3, pp. 243-248. 
Rasheeduzzafar, Ali, M., Al-Sulaimani, (1993), "Degradation of Bond between reinforcing Steel and Concrete Due to Cathodic Protection Current," ACI Materials Journal, Vol. 90, No. 1, pp. 8-13.

Rehm, G. (1968), "The Basic Principles of the Bond between Steel and Concrete," Translation No. 134, Cement and Concrete Association, London, pp 66.

Rehm, G. (1957), "The Fundamental law of Bond," Proceedings, Symposium on Bond and Crack Formation in Reinforced Concrete, Stockholm, RILEM, Paris, Pub. Tekniska Hogskolans Rotaprinttrychkeri, Stockholm.

Russo, G. and Pauletta, M. (2002), "Bond Solution for a RC Element with Concrete in Tension," International Conference - Bond in Concrete from Research to Standards, Budapest, pp. 316-323.

Russo, G., and Romano, F. (1990), "Bond Response in a Push-in/Pull-out Test When the Rebar and the Concrete are Loaded at Opposite ends", Scuola di specializzazione in construzioni in c.a.-Fratelli pesenti, Studi e ricerche n 12, Politecnico di Milano, Italy, pp.19-44.

Shima, H., (2002), "Local Bond Stress-Slip Relationship of Corroded Steel Bars Embedded in Concrete," International Conference - Bond in Concrete from Research to Standards, Budapest, pp. 153-158.

Stanish, K., Hooton, R.D., Pantazopoulou, S.J., (1999), "Corrosion Effects on Bond Strength in Reinforced Concrete," ACI Structural Journal, Vol. 96, No. 6, pp. 915-921

Tassios, T. P., "Properties of Bond between Concrete and Steel under Load Cycles Idealizing Seismic Actions,” AICAP-CEB Symposium, Rome, May 1979, pp. 97-122 
Tepfers, R.A., (1979), "Cracking of Concrete Cover along Anchored Deformed Reinforcing Bars," Magazine of Concrete Research, Vol. 31, No. 106, pp. 3-12.

Tepfers, R. (1973), "A theory of Bond Applied to Overlapped Tensile Reinforcement Splices for Deformed Bars," Division of Concrete Structures, Chalmers University of Technology, Goteborg, Sweden, Publication 73:2, 328p.

Tepfers, R. and Olsson, P.-' ., (1992) "Ring Test for Evaluation of Bond Properties of Reinforcing Bars “Bond in Concrete Proceedings (CEB), Riga, pp. 1-89

Thorenfeldt, E., Tomaszewicz, and Jesen, J.J., (1987), "Mechanical Properties of HighStrength Concrete and Application in Design," Proceedings of the Symposium-Utilization of High Strength Concrete, Stavanger, Norway, pp. 149-159

Yoon, S., Wang, K., Weiss, W.J., and Shah, P.S., (2000), "Interaction between Loading, Corrosion, and Serviceability of Reinforced Concrete," ACI Materials Journal, Vol. 97, No. 6, pp. 637-644. 